\title{
Annual Aboveground Biomass Growth in Temperate Forests of Eastern North America
}

Alex W. Dye

Follow this and additional works at: https://researchrepository.wvu.edu/etd

\section{Recommended Citation}

Dye, Alex W., "Annual Aboveground Biomass Growth in Temperate Forests of Eastern North America" (2018). Graduate Theses, Dissertations, and Problem Reports. 5522.

https://researchrepository.wvu.edu/etd/5522

This Dissertation is protected by copyright and/or related rights. It has been brought to you by the The Research Repository @ WVU with permission from the rights-holder(s). You are free to use this Dissertation in any way that is permitted by the copyright and related rights legislation that applies to your use. For other uses you must obtain permission from the rights-holder(s) directly, unless additional rights are indicated by a Creative Commons license in the record and/ or on the work itself. This Dissertation has been accepted for inclusion in WVU Graduate Theses, Dissertations, and Problem Reports collection by an authorized administrator of The Research Repository @ WVU.

For more information, please contact researchrepository@mail.wvu.edu. 


\title{
Annual aboveground biomass growth in temperate forests of eastern North America
}

\author{
Alex W. Dye \\ Dissertation submitted \\ to the Eberly College of Arts and Sciences \\ at West Virginia University \\ in partial fulfillment of the requirements for the degree of \\ Doctor of Philosophy in \\ Geography
}

\author{
Amy Hessl, Ph.D., Chair \\ Jamison Conley, Ph.D. \\ Eungul Lee, Ph.D. \\ Jason McLachlan, Ph.D. \\ Nicholas Skowronski, Ph.D. \\ Department of Geology and Geography \\ Morgantown, West Virginia \\ 2018
}

Keywords: dendroecology, biomass, net primary productivity, temperate forests Copyright 2018 Alex William Dye 


\begin{abstract}
Annual aboveground biomass growth in temperate forests of eastern North America Alex Dye
\end{abstract}

The below dissertation is organized into three individual standalone manuscripts supporting the overarching theme of reconstructing annual aboveground biomass growth in temperate forests of eastern North America using dendrochronological applications. Each manuscript is organized with the intent of submission to a peer-reviewed journal. The first manuscript validated the technique I use throughout my dissertation by comparing tree-ring derived estimates of annual aboveground productivity with estimates from co-located or nearby permanent remeasurement plots at Howland, Maine, Harvard Forest, Massachusetts, and Fernow, West Virginia. The second manuscript investigated the size-related distribution of biomass growth at 16 eastern U.S. forest sites and compared results with United States Forest Service inventory plot data. The goal of this manuscript was to determine where, structurally, biomass was allocated in forests and whether these quantities changed over time and between forests. The third manuscript was inspired by the results of my second chapter. Here, I investigated whether the degree of asymmetry, or the slope of the linear regression between tree diameter and growth, is a useful indicator of total forest productivity. Previous studies linking asymmetry and productivity have been inconclusive, and this chapter evaluates consistency or lack of consistency across the same 16-site eastern U.S. forest network. 


\section{Acknowledgements}

There are many people who deserve my heartfelt thanks: my advisor Amy Hessl for her encouragement, shared knowledge, and confidence in my abilities; Kristen, Shawn, John, and others in the Montane Forest Dynamics Lab for sharing the joys and terrors of dendrochronology; Jason and the PalEON PIs for their advice and support; Ross Alexander, Dan Bishop, and Neil Pederson for assistance interpreting our datasets; Kerry Woods for interpreting Upper Midwest natural history; Andria, Connor, Kellie, Ann, Malcolm, John, Ross, Christie, and the members of PalEON for conversation, advice, and good times; Julie, Dan, Ruth, Jonathon, Lynsey, Morgan, and Emily for field and lab help; Owen Dwyer and Tim Brothers of IUPUI Geography for starting me on this path 10 years ago; Steve Kite for easing me through the teaching process; Eungul Lee and Jamison Conley for being steady voices of reason through numerous manuscript edits; Nick Skowronski for his insightful outside-of-academia perspectives on my work.

Funding for this work was generously contributed by: National Science Foundation PalEON MacroSystems Biology grant 1241930; Huron Mountain Wildlife Foundation; the Eberly College of Arts and Sciences; and the Department of Energy Global Climate Modeling program SC0016011 for development of data contributed by Ross Alexander, Dave Moore, and the University of Arizona team. Sampling permissions were graciously granted by Howland Research Forest, Huron Mountain Club, and the Hiawatha National Forest. 


\section{Table of Contents}

Abstract.................................................................................................................... ii

Acknowledgements.................................................................................................... iii

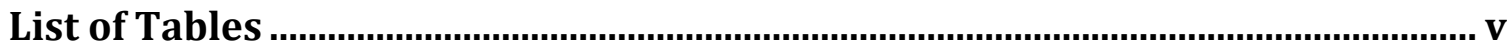

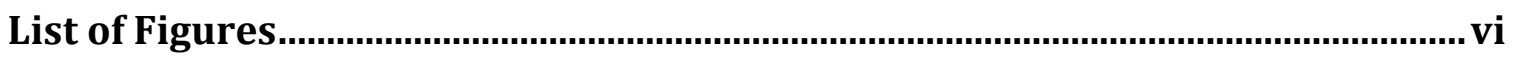

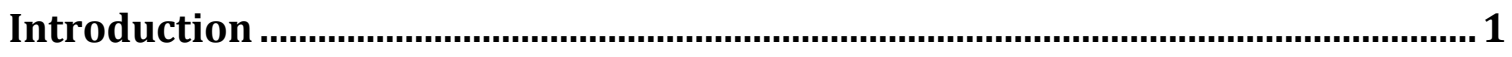

Chapter 1: Comparing tree-ring and permanent plot estimates of aboveground net primary productivity in three eastern U.S. forests ............................................ 8

Chapter 2: Structural distribution of forest productivity in eastern U.S.

temperate forests .............................................................................................. 37

Chapter 3: Size-growth asymmetry is not consistently related to basal area growth across an eastern U.S. temperate forest network ...................................69

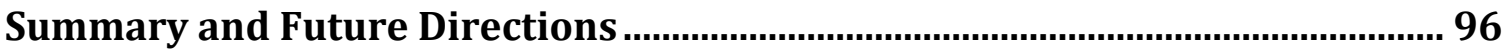




\section{List of Tables}

\section{Chapter One}

Table 1. Study sites...................................................24

Table 2. Mann-Whitney-Wilcoxon test summary..............................24

Table A1. Species-specific allometric equations..............................29

Chapter Two

Table 1. Site descriptions...............................................5 53

Table 2. Statistical test summary......................................54

Table C1. Summary of BAI size quartile proportions........................66

Chapter Three

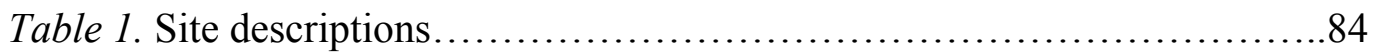

Table 2. Asymmetry and productivity summary............................ 85 


\section{List of Figures}

Introduction

Figure 1. Study sites..................................................... 5

Figure 2. Sampling designs...........................................6

Figure 3. Example reconstructed diameter and biomass increment.............. 7

Chapter One

Figure 1. Map of study sites...........................................25

Figure 2. Tree-ring and permanent plot aNPP time series....................26

Figure 3. aNPP scatterplot with SE for each remeasurement interval............27

Figure 4. aNPP boxplots for tree rings and permanent plots...................27

Figure 5. Density plot of resampled permanent plot aNPP ....................28

Figure B1. Permanent plot aNPP including trees $<10 \mathrm{~cm} \mathrm{DBH....................} 31$

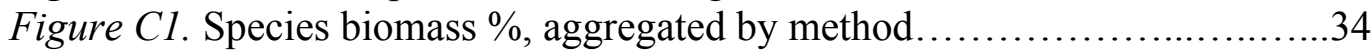

Figure $C 2$. Species biomass \%, aggregated by tree-ring plot................... 34

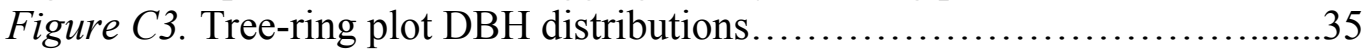

Figure C4. Permanent plot DBH distributions............................ 35

Figure D1. "Fading record" in tree-ring aNPP .......................... 36

Chapter Two

Figure 1. Map of sampled sites and FIA states............................55

Figure 2. Mean $\mathrm{DBH}_{\mathrm{BAI}}$ and mean $\mathrm{DBH}_{\mathrm{FREQ}}$ over time with 2011 histograms...56

Figure 3. Distribution of mean $\mathrm{DBH}_{\mathrm{BAI}}$ for tree-ring and FIA data..............60

Figure 4. Productivity to size quartile boxplots............................61

Figure A1. Canopy position by size quartile..............................62

Figure B1. Proportional BAI to size quartiles over time......................63

Figure $C 1$. Within-site variability of proportional BAI....................6 67

Figure $C 2$. Trend in proportional BAI to size quartile, 1970-2011............68

Figure C3. Trend in between-site variability in proportional BAI, 1970-2011..68

Chapter Three

Figure 1. Asymmetric, symmetric, and inverse asymmetric examples.........86

Figure 2. Productivity vs. asymmetry over full study period....................87

Figure 3. Productivity vs. asymmetry time series, $1970-2011 \ldots \ldots \ldots \ldots \ldots \ldots . . \ldots 88$

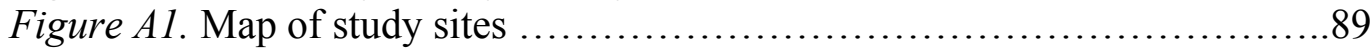

Figure B1. Annual between-site correlations.................................90 90

Figure B2. 2-year interval between-site correlations..........................91

Figure B3. 5-year interval between-site correlations...................... 92

Figure B4. 10-year interval between-site correlations.......................93

Figure B5. 20-year interval between-site correlations........................93

Figure $C 1$. Productivity vs. asymmetry time series, 2-year interval.............94

Figure $C 2$. Productivity vs. asymmetry time series, 5 -year interval............95 
Overview of scientific objectives

\section{Introduction}

The following dissertation consists of three interrelated chapters supporting the overall theme of my dissertation, "Annual aboveground biomass growth in temperate forests of eastern North America." Each chapter is designed as a standalone article to be submitted for publication. Over the course of intensively investigating my proposed research topics, my chapters deviated slightly from my original objectives but still adequately support my primary research theme. In my first chapter, I evaulate the validity of using tree rings to reconstruct annual aboveground forest productivity. I do this by comparing dendrochronological estimates of productivity with co-located or nearby permanent remeasurement plot estimates at Howland Forest in Maine, Harvard Forest in Massachusetts, and Fernow Experimental Forest in West Virginia. By resampling subsets of the permanent plot data that were of equivalent spatial coverage as the tree-ring datasets, I developed a range of reasonable productivity estimates given a specific sample size. At each site and over time, tree-ring estimates always fell within the $95 \%$ confidence interval of these ranges. This manuscript was published in the journal Ecosphere in September 2016.

In my second chapter, I move to a more local scale to study the size-related biomass dynamics in forests. Here, I quantify the distribution of new annual basal area increment to individual trees according to tree diameter in order to provide long-term, annually resolved information to managers and ecosystem modelers regarding where newly acquired biomass is produced. I found that between 19702011 , typically $30-60 \%$ of new aboveground biomass is allocated to the biggest $25 \%$ of trees in a site. For all but 2 sites, the proportion of biomass allocated to the biggest trees at a site has been increasing since 1970, while the proportion allocated to smaller trees has been decreasing. Analyzing remeasurement data from the Forest Inventory and Analysis for the entire eastern U.S. also reveals disproportionate production of the biggest trees, although proportions vary from the tree-ring data.

In my third chapter, I investigated size-related biomass dynamics further by looking for consistency or lack of consistency in the relationship between productivity and the degree of asymmetry, or the slope of the linear relationship between tree diameter and growth. Many researchers have assumed that total forest productivity will increase when asymmetry is higher, although the literature provides inconsistent evidence supporting this expectation. In my work, I find no consistent relationship between asymmetry and productivity, neither within sites nor between sites. This inconsistency continues to persist even after dividing data into common ecological remeasurement intervals (i.e. 2-year, 5-year, 10-year, 20year, and 41-year).

\section{Overview of dataset}

In my dissertation, I have incorporated multiple datasets that have been created both by myself and graciously shared by others. Most of these datasets were 
constructed in support of the Paleo-Ecological Observatory Network (PalEON) research project. Planning meetings prior to sampling excursions ensured all data and collection followed standard protocols (Figure 1). Data developed by myself included sites at Howland Forest in central Maine and both Huron Mountain Club sites in northern Michigan (Rush Lake and West). Neil Pederson and Daniel Bishop of Harvard Forest contributed data from the following sites: Gill Brook, Goose Egg State Forest, Rooster Hill, Palmaghatt, Harvard Forest (Lyford and EMS), and Pisgah State Park (Harvard Tract and North Round Pond). Ross Alexander of the University of Arizona provided data from the following sites: Morgan Monroe, Missouri Ozark, UMBS, Ohio Oak Openings, and Duke Hardwood. Additionally, I used a dataset from Fernow Experimental Forest developed by Sarah Davis and Amy Hessl at West Virginia University in the mid-2000s (Davis et al. 2009). In collaboration with each of these research teams, I have taken on the task of integrating each of these rich datasets throughout this dissertation.

\section{Overview of tree rings and productivity}

Dendrochronology is a relatively new addition to the suite of tools used by forest ecologists to investigate the carbon cycle. In the last decade, numerous researchers have begun studying the efficacy of tree rings as recorders of aboveground net primary productivity (Davis et al. 2009, Babst et al. 2014a, Nehrbass-Ahles et al. 2014). Tree-ring biomass reconstructions are being integrated with other metrics of ecosystem carbon cycling, including permanent remeasurement plots (Klesse et al. 2016, Dye et al. 2016, Evans et al. 2017), eddy covariance (Rocha et al. 2006, Babst et al. 2014b, Teets et al. 2017), remote sensing (Bunn et al. 2013), and validation of ecosystem models (Rollinson et al. 2016, Montane et al. 2017). Because tree rings are annually resolved, multi-decadal records of forest growth that can be developed from a single sampling effort, they are invaluable assetts to studies of forest biomass dynamics.

Here, I briefly overview the process of using tree rings to reconstruct productivity. This general workflow results in the aboveground net primary productivity estimates (Chapter 1 ) and basal area increment (Chapters 2 and 3 ) that I use as estimates of forest productivity in my dissertation. First, past tree diameters are reconstructed by subtracting annual ring widths from the diameter measured when sampling (Figure 2a). Second, the reconstructed diameters are transformed into an areal measurement of standing biomass, such as basal area (e.g. $\left.\mathrm{cm}^{2}\right)$ or aboveground carbon content (e.g. Mg C) using species specific allometric equations. Third, first-differencing the annual standing basal area or carbon content values provides an estimate of annual basal area increment or aboveground carbon sequestration, respectively, for each tree (Figure $2 b$ ). When a mapped-plot sampling design is employed, productivity from all trees can be summed to develop a per unit area estimate of aboveground forest productivity (e.g. $\mathrm{Mg} \mathrm{C} / \mathrm{m}^{2} /$ year). 


\section{Works Cited}

Babst, F., et al. 2013. Above-ground woody carbon sequestration measured from tree rings is coherent with net ecosystem productivity at five eddy-covariance sites. New Phytologist 201 (4): 1289-1303.

Babst, F., O. Bouriaud, M.R. Alexander, V. Trouet, and D. Frank. 2013. Toward consistent measurements of carbon accumulation: A multi-site assessment of biomass and basal area increment across Europe. Dendrochronologia 32 (2): 153161.

Bunn, A.G., M.K. Hughes, A.V. Kirdyanov, M. Losleben, V.V. Shishov, L.T. Berner, A. Oltchev, and E.A. Vaganov. 2013. Comparing forest measurements from tree rings and a space-based index of vegetation activity in Siberia. Environmental Research Letters 8: 035034.

Davis, S.C., A.E. Hessl, C.J. Scott, M.B. Adams, and R.B. Thomas. 2009. Forest carbon sequestration changes in response to timber harvest. Forest Ecology and Management 258 (9): 2101-9.

Dye, A., A. Barker-Plotkin, D. Bishop, N. Pederson, B. Poulter, and A. Hessl. 2016. Comparing tree-ring and permanent plot estimates of aboveground net primary production in three Eastern U.S. forests. Ecosphere 7(9): e01454.

Evans, M.E.K., D.A. Falk, A. Arizpe, T.L. Swetnam, F. Babst, and K.E. Holsinger 2017. Fusing tree-ring and forest inventory data to infer influences on tree growth. Ecosphere doi: 10.1002/ecs2.1889.

Klesse, S., S. Etzold, and D. Frank. 2016. Integrating tree-ring and inventory-based measurements of aboveground biomass growth: research opportunities and carbon cycle consequences from a large snow breakage event in the Swiss Alps. European Journal of Forest Research doi: 10.1007/s10342-015-0936-5.

Montane, F., et al. 2017. Evaluating the effect of alternative carbon allocation schemes in a land surface model on carbon fluxes, pools and turnover in temperate forests. Geoscientific Model Development 10: 3499-3517.

Nehrbass-Ahles, C., F. Babst, S. Klesse, M. Notzli, O. Bouriaud, R. Neukom, M. Dobbertin, and D. Frank. 2014. The influence of sampling design on tree-ringbased quantification of forest growth. Global Change Biology 20 (9): 2867.

Rocha, A.V., M.L. Goulden, A.L. Dunn, and S.C. Wofsy. 2006. On linking interannual tree ring variability with observations of whole forest $\mathrm{CO}_{2}$ flux. Global Change Biology 12: 1378-1389. 
Rollinson, C., et al. 2017. Emergent climate and $\mathrm{CO}_{2}$ sensitivities of net primary productivity in ecosystem models do not agree with empirical data in temperate forests of eastern North America. Global Change Biology doi: 10.1111/gcb.13626.

Teets, A., S. Fraver, D.Y. Hollinger, A.R. Weiskittel, R.S. Seymour, and A.D. Richardson In press. Linking annual tree growth with eddy-flux measures of net ecosystem productivity across twenty years of observation in a mixed conifer forest. Agricultural and Forest Meteorology 


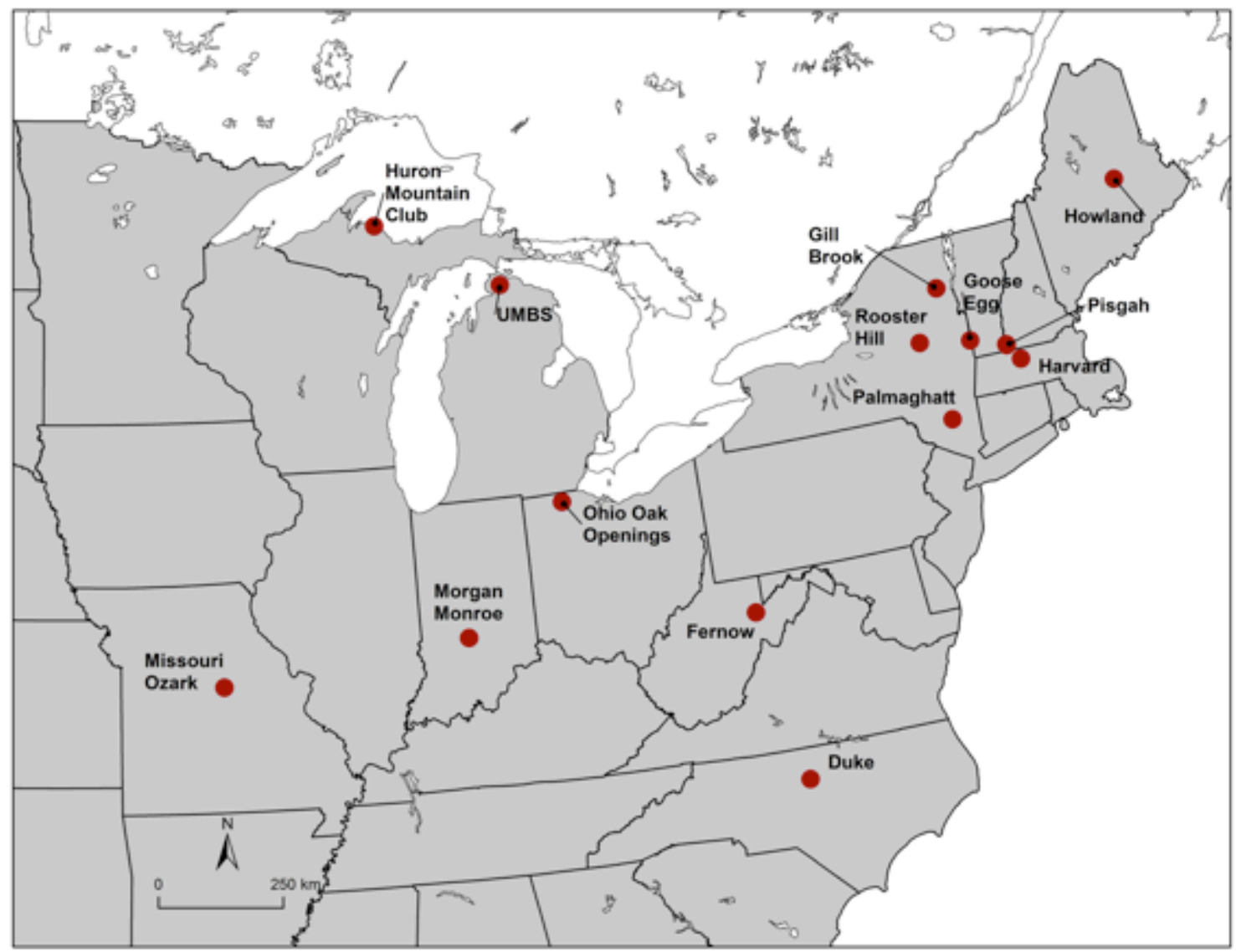

Figure 1. Map of all sampled dendrochronological sites used in this dissertation. The labelled point for "Huron Mountain Club" contains both Huron Mt. Club-West and Huron Mt. Club-Rush Lake sites; "Harvard" contains both Harvard Forest-Lyford and Harvard Forest-EMS; "Pisgah" contains both Pisgah State Park-North Round Pond and Pisgah State Park-Harvard Tract. Fernow was not used in Chapters 2 and 3 because the sampling design was inconsistent with other sites and the tree-ring record ends in 2002. 
a)

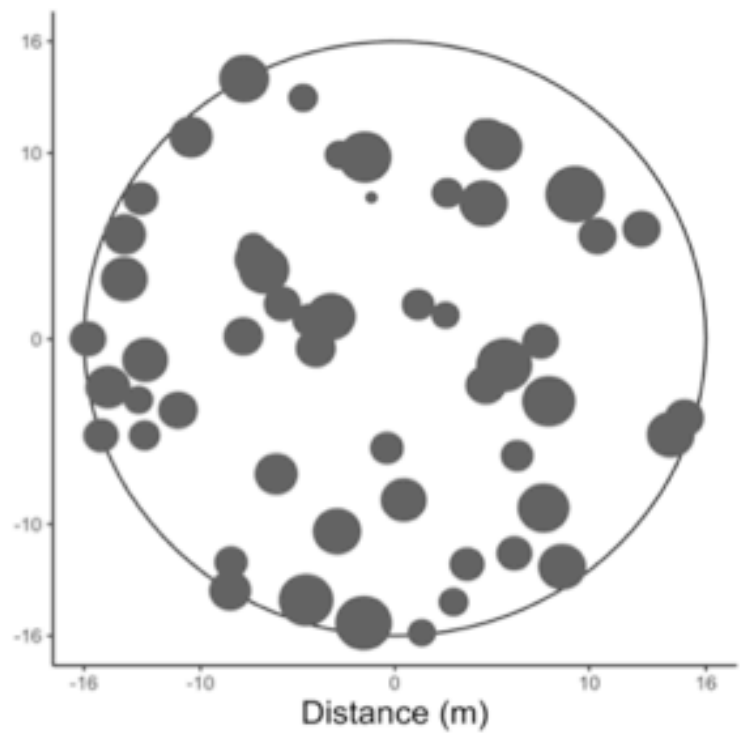

b)

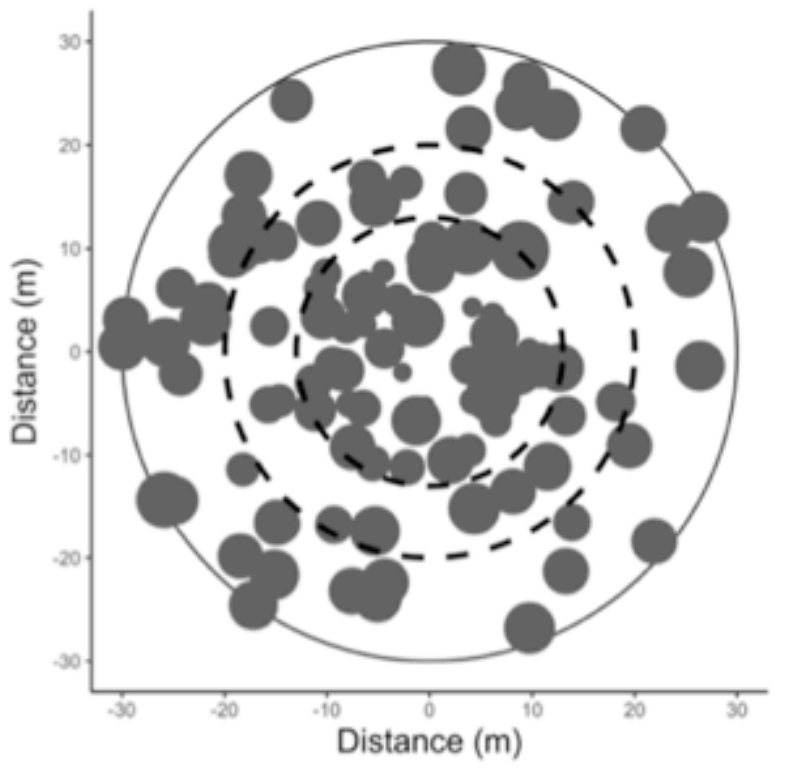

c)

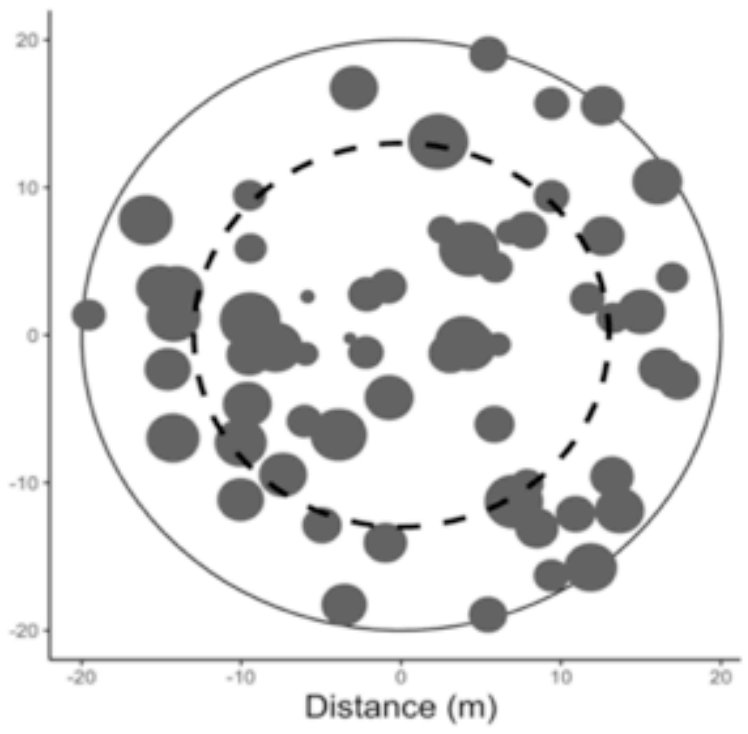

Figure 2. Selected examples of the three primary sampling designs use for collection of tree rings. All are a variation of a mapped-plot sampling design, shown to be an effective method when reconstructing productivity using tree rings. Specific designs are: (a) Fixed-diameter plots (Huron Mt. Club-Rush Lake and Huron Mt. Club-West). All trees $>10 \mathrm{~cm}$ $\mathrm{DBH}$ within a 16-m radius of plot center were cored. Example shown: Huron Mountain Club-West Plot 3; (b) Triple-nested "old-growth" plots (Gill Brook, Goose Egg, Palmaghatt, Pisgah State Park-North Round Pond, and Rooster Hill). All trees $>10 \mathrm{~cm} \mathrm{DBH}$ within a $13-\mathrm{m}$ radius, $>20 \mathrm{~cm} \mathrm{DBH}$ within a $20-\mathrm{m}$ radius, and $>30 \mathrm{~cm} \mathrm{DBH}$ within a 30-m radius. Example shown: Goose Egg plot 3; and (c) Doublenested "second-growth" plots (Duke, Howland, Harvard Forest-Lyford, Harvard Forest-EMS, Pisgah State Park-Harvard Tract, Ohio Oak Openings, Morgan Monroe, Missouri Ozark, UMBS). All trees $>10 \mathrm{~cm} \mathrm{DBH}$ within a $13-\mathrm{m}$ radius, all trees $>20 \mathrm{~cm}$ DBH within a $20-\mathrm{m}$ radius. Example shown: Harvard Forest-Lyford plot 1. 
a) Diameter growth for tree $\mathrm{HMC} 1023$ (hemlock)

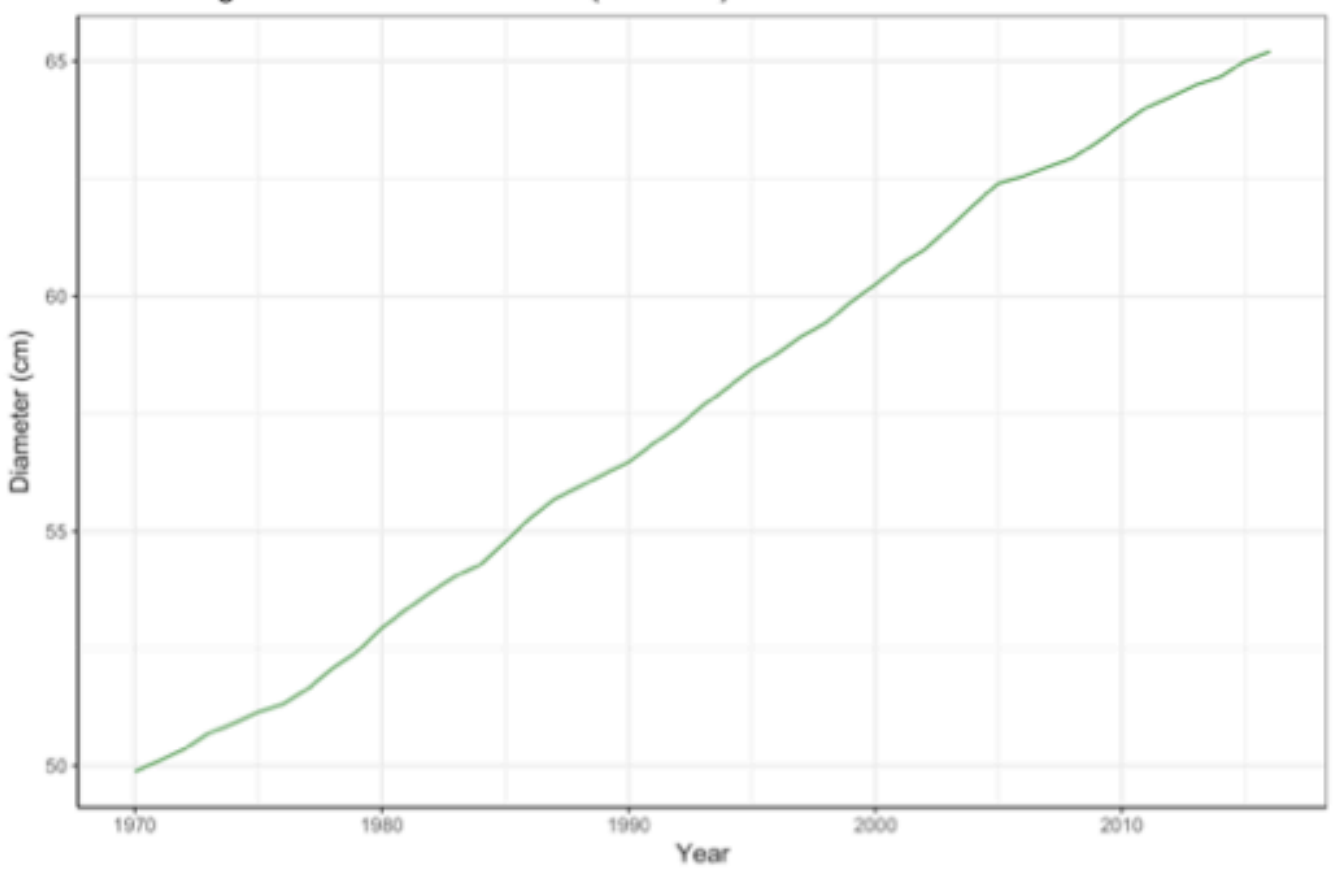

b) Annual biomass increment for tree HMC1023 (hemlock)

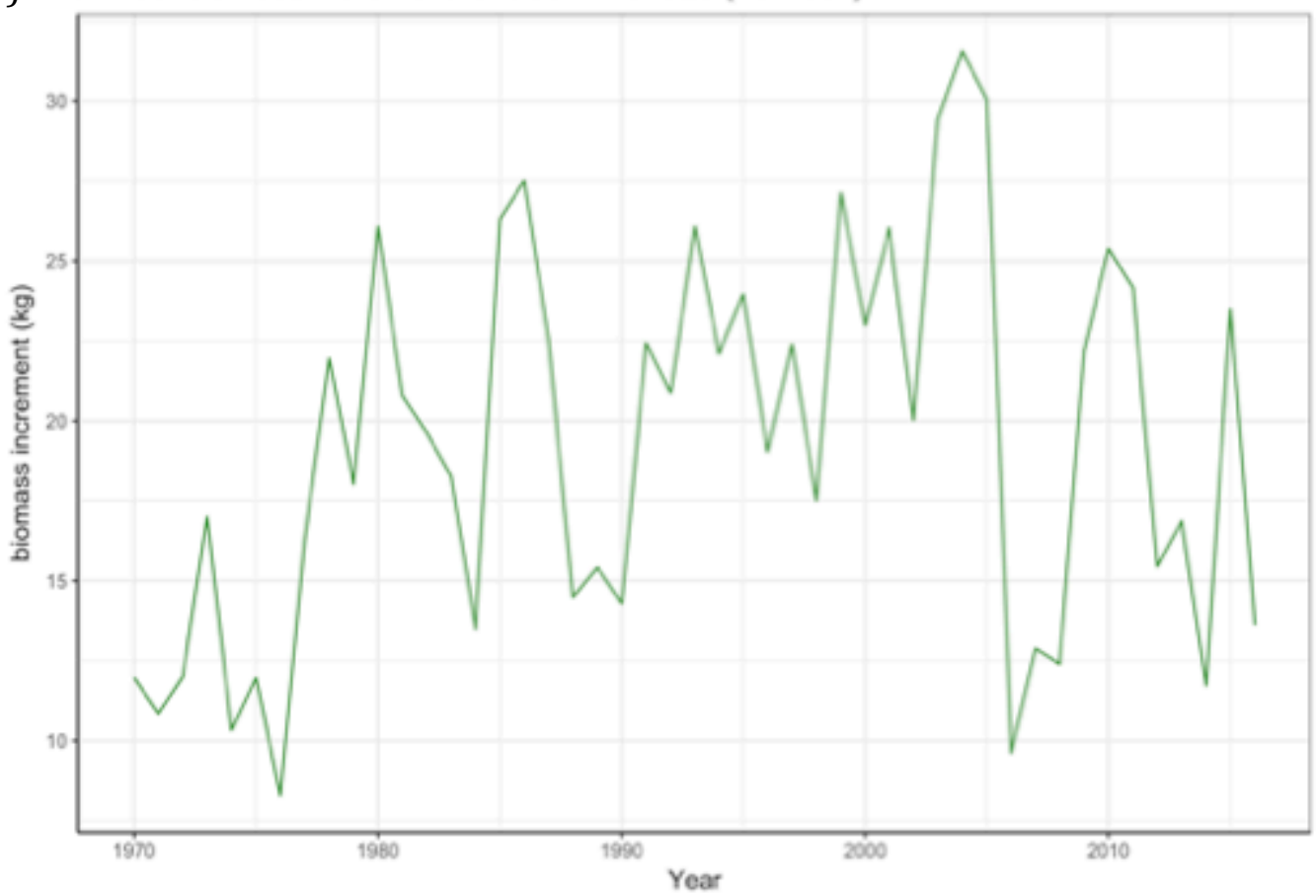

Figure 3. Example graph of (a) reconstructed diameters and (b) the related aboveground biomass increment $(\mathrm{kg})$ for an example eastern hemlock (Tsuga canadensis) tree HMC1023 at Huron Mt. Club-West. 
Chapter 1: Comparing tree-ring and permanent plot estimates of aboveground net primary productivity in three eastern U.S. forests

Alex Dye $^{\dagger}$, Audrey Barker-Plotkin ${ }^{\ddagger}$, Daniel Bishop ${ }^{\ddagger}$, Amy Hessl ${ }^{\dagger}$, Neil Pederson ${ }^{\ddagger}$, and Benjamin Poulter ${ }^{\S}$

$\dagger$ Department of Geology and Geography, West Virginia University, Morgantown, WV 26505

${ }^{\ddagger}$ Harvard Forest, Harvard University, Petersham, MA 01366

$\S$ Department of Ecology, Montana State University, Bozeman, MT 59717

published September, 2016:

Dye, A., A. Barker Plotkin, D. Bishop, N. Pederson, B. Poulter, and A. Hessl. (2016). Comparing tree-ring and permanent plot estimates of aboveground net primary productivity in three Eastern U.S. forests. Ecosphere 7: e01454. 


\begin{abstract}
Globally, forests account for a large portion of sequestered carbon, much of which is stored as wood in trees. Measurements of the rate of carbon accumulation in the aboveground plant material, or aboveground net primary productivity (aNPP), quantify annual to decadal variations in forest carbon sequestration. Permanent remeasurement plots are often used to estimate stand-level aNPP but are usually not annually resolved and take many years to establish a long dataset. Tree rings are a unique and relatively infrequently used source for measuring aNPP, and benefit from fine spatial (individual trees) and temporal (annual) resolution. Because of this precision, tree rings are a complementary addition to permanent plots and the suite of tools used to study forest productivity.

For a lowland evergreen (Howland, Maine), mixed deciduous (Harvard Forest, Massachussets), and mixed mesophytic (Fernow, West Virginia) forest in the eastern United States, we demonstrate that annual estimates of aNPP developed from tree rings approximate estimates derived from permanent remeasurement plots, even when plots are not directly co-located. Permanent plots at the sites cover an area of 2-3 ha, and we use this as a benchmark indicative of the forest stand. We simulate random draws of subsets of permanent plot data to describe the distribution of possible aNPP estimates given a sampling area size equivalent to the tree-ring plots. Though mean tree-ring aNPP underestimates permanent plot aNPP slightly at the Maine site and overestimates at the Massachusetts and West Virginia sites, it is still within the distribution of random draws of equal-sized sampling area at all sites.

To investigate how well tree-ring aNPP can be upscaled to the forest stand, we conducted a second random draw of permanent plot subsets simulating a two-fold increase in sampling area. ANPP estimates from this distribution were not significantly different from our current samplign area, though variance decreases as sampling area approaches stand area. Additionally, we develop the benefits and concerns associated with using tree rings to reconstruct annual aNPP, and call for the application of tree rings in carbon cycle studies across a broader range of species diversity, productivity, and disturbance histories.
\end{abstract}

\title{
Keywords
}

biomass; carbon cycle; dendrochronology; Eastern United States; net primary productivity; permanent plots 


\section{INTRODUCTION}

Forests account for a large portion (up to 80\%) of total sequestered live terrestrial biomass, and are essential to understanding the global carbon cycle (Dixon et al. 1994, Pan et al. 2011). Temperate forests in the Northern Hemisphere, especially those in eastern North America, comprise some of the largest and most active global carbon sinks (Pacala et al. 2001, Goodale et al. 2002). However, the large, dynamic inter-annual variability in the terrestrial carbon sink are poorly understood and demand better quantification. Interannual changes in forest productivity are quantified using a variety of methods, including biometric (manual measurement of tree growth), eddy covariance meaurements of the influx and outflux of $\mathrm{CO}_{2}$ (Barford et al. 2001, Baldocchi 2003, Hollinger et al. 2004), and remote sensing (Running et al. 2004, Ollinger et al. 2007). Attempts at incorporating these data into ecosystem models to estimate productivity over longer time scales have achieved varying results (Friedlingstein et al. 2010, Jones et al. 2013), and a more detailed understanding of forest productivity is needed to improve forecasts of carbon dynamics under climate change.

Net primary productivity (NPP) is defined as the biomass increment of woody and herbaceous plants in terrestrial ecosystems and is the difference between total photosynthetic uptake, or gross primary productivity, and losses from autotrophic respiration (Chapin et al. 2006). Total NPP in forests can be quantified by summing the carbon allocated to all components of the plant including sapwood in stems, branches, fine roots, and live foliage. Measurement of each of these carbon fluxes requires different techniques (see Clark et al. 2001 for a comprehensive review). Aboveground production (aNPP) is important in forests because of the long-term storage capacity of carbon gained by wood (preventing carbon release to the atmosphere) and commercial interest in forest woody carbon stocks (Harmon 1990, Fahey et al. 2009).

Biometric methods, such as permanent plots and tree rings, quantify incremental tree growth over time to estimate aNPP. These methods can develop aNPP records over relatively long time scales, and robust techniques and applications have been described for permanent remeasurement plots (Siccama et al. 2007, Schuster et al. 2008, Xu et al. 2012, Fahey et al. 2013, Eisen and Barker-Plotkin 2015) and for tree rings (Graumlich et al. 1989, Davis et al. 2009, Xu et al. 2012, Babst et al. 2014). The biomass of individual trees can be calculated with species-specific allometric equations relating stem diameter to aboveground dry weight of wood and aNPP calculated as the change in biomass over a time interval (where carbon content is typically $50 \%$ of biomass). The main attraction of using tree rings or permanent plots to measure biomass increment is the ability to track aNPP of individual trees, advantageous for the study of aNPP variability at a local scale.

In permanent plots, all trees above a certain diameter threshold are remeasured periodically and aNPP defined as the change in biomass between measurements. Permanent plots provide an excellent record of productivity over time because they track growth and mortality of individual trees. No other method is capable of precisely quantifying biomass lost to mortality. However, permanent plots require decades of intensive labor to obtain meaningful results and rarely capture the annual dynamics of aNPP. Error in permanent plot studies can stem from discrepencies in measurements between field workers, differences in the season measurements were taken, non-growth 
related expansion or contraction of bark, and human error measuring tree diameters (McRoberts et al. 1994, Holdaway et al. 2014).

Tree rings have been shown to serve as reliable indicators of biomass increment (Bouriaud et al. 2005) and are recognized as a valid source for estimating aNPP (Clark et al. 2001, Kloeppel et al. 2007), but they have only rarely been used as a measure of biomass accumulation (Babst et al. 2014, Hember et al. 2015). Tree rings have the potential to preserve decadal to centennial scale variability in aNPP, but their use needs to be demonstrated across a range of sites with different species composition, rates of productivity, and disturbance histories.

Tree rings minimize many challenges in quantifying productivity by providing very fine temporal (annual) and spatial (the individual tree) resolution with only a single sampling effort. However, disadvantages of tree rings include a loss of information on trees that died previously and could not be sampled (Foster et al. 2014) and allometric uncertainties in scaling ring width to total biomass increment (Dietze et al. 2008, Alexander et al. 2015). In addition, tree-ring collections developed for specific studies involving climate reconstructions, stand dynamics, stream flow, or disturbance history, for example, rarely include a complete census of trees in a fixed-area plot, which is critical for developing stand-level productivity estimates on a per area unit scale (Babst et al. 2013, Nehrbass-Ahles et al. 2014).

Both tree-ring and permanent plot estimates of aNPP aim to develop estimates that describe the whole stand in addition to individual trees or sampling plots because this vastly expands our inferential capabilities. However, upscaling aNPP from the plot-level can be problematic, especially in forests with considerable species and structural heterogeneity (Weins 1989). Growth rates and allocation percentages of carbon to aboveground plant components can vary by species and tree size, and failure to include a representative selection of the species and structural diversity present in a forest has potential to bias estimates of stand-level aNPP.

Permanent plots are an established standard method for estimating aNPP and can be further improved with the annual resolution that tree rings provide. With advances in measuring carbon dynamics, increasing attention is being given to comparing different sampling techniques. Comparisons of meteorological gross primary productivity and net ecosystem exchange measured by eddy covariance with tree rings (Rocha et al. 2006, Babst et al. 2014) and permanent plots (e.g. Curtis et al. 2002, Ehman et al. 2002) have been attempted with variable results. With the past success and future potential of the eddy covariance technique and global coverage of remote sensing, comparisons such as these are an important avenue for continued research, especially across a wide range of forest types. However, extensive comparisons of tree-ring and permanent plot estimates of aboveground productivity are generally lacking in the literature, and a more complete set of studies across varied forest types combining these two methods is needed to ask the fine scale ecological questions that can only be addressed using these biometric approaches. Biondi 1999 analyzed tree-ring chronologies in the Western United States with growth rates of trees in U.S. Forest Service inventory plots, but did not explore biomass increment. A recent study in Europe used a combination of tree-ring and permanent plot basal area increment to study climate response over the length of forest measurement intervals, but did not perform an explicit comparison or quantify aNPP (Rohner et al. 2016), and Klesse, Etzold, and Frank 2016 conducted one of the first and 
only integrations of tree ring and permanent plot measurement for the express purpose of improving estimates of aboveground biomass increment in a Swiss pine/larch dry valley forest.

In this study, we compare field estimates of aboveground aNPP derived from tree rings with estimates from co-located permanent plots for a temperate coniferous, mixed deciduous, and mixed mesophytic forest in the eastern United States. By analyzing treering aNPP in concert with another well-established biometric method, we develop a basis for how much confidence we can place in tree-ring estimates and the types of inferences they allow us to make. We evaluate different configurations of our dataset to investigate how area sampled, allometric equations used, and variability in species and structural diversity influence the comparison and assess to what extent we can scale up aNPP from a small collection of plots. We use these analyses to inform future sampling campaigns and call attention to the benefits of including both tree rings and permanent plots in carbon sequestration research.

\section{METHODS}

Study Areas

We included three sites representing differing forest types of the eastern United States in this analysis (Figure 1). Howland Research Forest is a lowland coniferous forest in central Maine dominated by eastern hemlock (Tsuga canadensis L.) and red spruce (Picea rubens Sarg.) with subdominates red maple (Acer rubrum L.), eastern white pine (Pinus strobus L.), northern white cedar (Thuja occidentalis L.), balsam fir (Abies balsamea L.), and yellow birch (Betula allegheniensis Britton). Harvard Forest is a mixed deciduous forest in central Massachussets dominated by red oak (Quercus rubra L.) and red maple, with subdominates American beech (Fagus grandifolia Ehrh), eastern hemlock, eastern white pine, and yellow birch. Fernow Experimental Forest is a mixed mesophytic forest located in the Allegheny Mountains of West Virginia composed predominately of red oak, chestnut oak (Quercus montana Willd.), scarlet oak (Quercus coccinea Menchh.), American beech, red maple, sugar maple (Acer saccharum Marsh.), black cherry (Prunus serotina Ehrh.), and American basswood (Tilia americana L.). We chose these sites for proximity of tree-ring data and ongoing permanent plots, and each differ in species composition, forest age, productivity, and data availibility (Table 1).

\section{Tree-ring aNPP estimates}

At Howland and Harvard Forest, we established nested circular plots with a $20 \mathrm{~m}$ radius, coring all trees $\geq 10 \mathrm{~cm}$ diameter at breast height $(\mathrm{DBH})$ within a $13 \mathrm{~m}$ radius and all trees $\geq 20 \mathrm{~cm} \mathrm{DBH}$ between $13 \mathrm{~m}$ and $20 \mathrm{~m}$. The dominant trees in a forest may account for up to $95 \%$ of total aboveground biomass (Kloeppel et al. 2007), but are rare, requiring a larger sample area. This design ensures adequate sampling of larger trees when time and resources limit the feasibility of sampling all trees in multiple $20 \mathrm{~m}$ radius plots. To account for growth differences caused by tree asymmetry, we collected two cores from each tree. We sampled three plots at Howland. At the Harvard Forest, we deliberately placed three tree-ring plots within the permanent plot study area (the "Lyford plots"). Because of concerns about long-term monitoring, we were unable to place plots inside the permanent plot boundaries at other sites. Ideally, the aNPP estimates are meant to be indicative of the entire forest, not just the plot, and this locational offset allows us to 
assess this assumption. Additionally, two tree-ring plots (the "EMS plots") were established outside the Harvard Forest permanent plot study area near the EMS eddy covariance tower. Tree cores at Fernow were collected in 2002 for a study comparing forest productivity with management strategy (Davis et al. 2009). Two cores were removed from all trees $\geq 10 \mathrm{~cm}$ DBH in six 10 m radius plots.

We dried, mounted, and sanded cores according to standard dendrochronological procedure (Stokes and Smiley 1968). To ensure annual dating, we visually crossdated ring widths using the skeleton plotting method. We measured all rings to $0.001 \mathrm{~mm}$ accuracy using a measuring stand and binocular microscope and statistically confirmed crossdating using COFECHA (Holmes 1983). We averaged ring widths from all cores per tree and scaled measurements from radius to diameter.

We used regional, species-specific allometric equations to calculate aboveground biomass increment of each living tree (Appendix A). Because developing site-specific equations is beyond the scope of this paper, we selected equations from published studies that most closely matched the relevant diameter range, forest type, and species. We used equations either of the form $M=a \times D^{b}$ or $\ln (M)=a+b \times \ln (D)$, where $\mathrm{M}$ is total aboveground dry weight of the tree (stem, branches, foliage) in $\mathrm{kg}$, D is stem diameter in $\mathrm{cm}$, and $\mathrm{a}$ and $\mathrm{b}$ are species-specific coefficients. To calculate annual biomass increment of each tree, we subtracted previous ring increments from the current diameter and reapplied allometric equations on the reconstructed diameter (Davis et al. 2009). We define aboveground net primary productivity (aNPP) as the total sum of annual biomass increment of all trees in a plot. We assume carbon content to be $50 \%$ of dry weight, per standard conventions (Fahey et al. 2005). For the nested plots (Howland and Harvard), a plot total was defined as the per hectare sum of the inner plot (all trees $\geq 10 \mathrm{~cm}$ and $<$ $20 \mathrm{~cm}$ ) and the outer nest (all trees $\geq 20$ ). A site average was defined as the average of all plots, and inter-plot variability represented as the range of estimates of the three plots. All calculations and data management were performed in R (R Core Development Team 2008).

\section{Permanent plot productivity estimates}

At Howland, a 3 ha permanent plot (with 48 subplots, each $625 \mathrm{~m}^{2}$ ) was established in 1989, and all trees $>4 \mathrm{~cm}$ DBH were measured in 1998, 2002, and 2010 (J.Lee, pers.comm.). The Lyford permanent plot at Harvard Forest was established by Walter Lyford for long-term forest study in 1969. Covering a 2.88 ha area, the single, large plot was subdivided into 32 blocks, each $930 \mathrm{~m}^{2}$. Measurements of all trees $>5 \mathrm{~cm}$ DBH were taken in 1975, 1991, 2001, and 2011 (HF Data Archive HF032, Eisen and Barker Plotkin 2015). Unlike at Howland and Harvard, the Fernow permanent plots are not spatially contiguous. Ten permanent plots, each 0.5 acres, were established in the WS4 section of Fernow in 1979. Measurements were conducted on all trees $>5 \mathrm{~cm} \mathrm{DBH}$ in 1983, 1989, 1994, 1999, and 2009 (F. Wood, pers comm.).

Because the minimum diameter requirement for sampling varied between the three forests ( $4 \mathrm{~cm}$ at Howland, $5 \mathrm{~cm}$ at Lyford, and $5 \mathrm{~cm}$ at Fernow), we subsetted all permanent plot datasets to include only trees that were at least $10 \mathrm{~cm} \mathrm{DBH}$ at any time during the census period to provide consistency with the tree-ring data. Measurements of trees that grew into this size class from one census to the next were also included to account for ingrowth. Trees that died in between time steps were attributed zero growth 
for all subsequent intervals. For context, we also provide the full permanent plot datasets without subsetting to a minimum diameter (Appendix B).

For instances when individual trees were missing a measurement entry for a given year (measurement error), an interpolated value was calculated using the previous and subsequent measurement for that tree. Missing values occurring in the final census, preventing interpolation, were replaced with the average absolute increment for other trees of the same species.

We calculated aboveground biomass as the biomass of living trees present at each census year and aNPP as the difference in aboveground biomass of surviving trees between census points divided by the number of intervening years (Clark et al. 2001) and applied the same allometric equations used for tree-ring aNPP calculations.

\section{Statistical comparisons}

Total area sampled varied between permanent plots and tree-ring plots. We compared tree-ring aNPP estimates with permanent plot estimates from approximately equal-sized sampling areas to show biases associated with sample size and display the extent that our tree-ring sampling area is representative of an equivalent sampling area from the permanent plots. Total area sampled for tree rings was $3768 \mathrm{~m}^{2}$ at Howland and the Harvard Lyford plots and $1884 \mathrm{~m}^{2}$ at Fernow. Six census subplots $\left(3750 \mathrm{~m}^{2}\right)$ at Howland, four census subplots $\left(3721 \mathrm{~m}^{2}\right)$ at Harvard, and one census sub plot $\left(2023 \mathrm{~m}^{2}\right)$ at Fernow approximately equal the total area cored at their respective sites. From the Howland and Harvard permanent plot data, we drew 10000 random samples of 6 and 4 plots, respectively, and recalculated aNPP to construct a distribution of possible estimates given a specific sampling size. The small number of subplots at Fernow did not allow for sufficient random sampling, and aNPP variability was described as the distribution of the ten individual subplots.

We evaluated differences between the tree-ring and permanent plot estimates with a Mann-Whitney-Wilcoxon (MWW) test, using the wilcox.test function in R. MWW is a nonparametric test that tests the null hypothesis that both tree-ring and permanent plot aNPP estimates come from the same distribution. We used a nonparametric test because it is difficult to assume normality with so few data points. Additionally, MWW provides a location parameter that quantifies the extent one distribution over- or underestimates another distribution. We use the location parameter to examine consistent biases between tree rings and permanent plots.

\section{Uncertainty}

We assessed uncertainty derived from two sources: allometric equations and upscaling. While we carefully selected allometric equations we considered most applicable to each study site for our aNPP calculations used in our primary analyses, these are not the only equations available. We compiled all potentially applicable allometric equations for all species at each site that could conceivably be used. We defined "potentially applicable" as equations developed for trees in the eastern/northeastern United States for an upper DBH limit of at least $25 \mathrm{~cm}$. We recalculated 1000 iterations of aNPP using the same methods described above, each time applying a new random set of equations drawn from this pool. From these recalculations, 
we developed a range of aNPP estimates that may result depending on the equations the researcher chooses to use.

To investigate the extent increasing the size of tree-ring sampling plots could reduce variability (or, how well the data can be scaled up), we conducted a second round of Monte Carlo sampling from the Howland and the Harvard permanent plots assuming the size of each tree-ring plot was increased to a $30 \mathrm{~m}$ radius, more than doubling the hypothetical area to be sampled. This sampling design equates to approximately $13 \mathrm{sub}$ plots from the Howland permanent plot and 9 sub plots from the Harvard permanent plot data. At Fernow, where only 10 permanent plots are available, we repeatedly drew combinations of two plots, approximately doubling the area sampled for tree rings. We conducted another Mann-Whitney-Wilcoxon test to compare these new simulated distributions at each site with our original Monte Carlo draws.

\section{RESULTS}

aNPP reconstructions

To develop estimates of annual aNPP from tree rings, we measured two increment cores per stem for 266 live trees at Howland, 287 trees at Harvard Forest (136 at Lyford plots, 151 at EMS plots), and 132 trees at Fernow. Permanent plots resulted in at least one measurement of over 7000 trees at Howland, 6000 trees at Harvard Forest Lyford plots, and 1500 trees at Fernow. We present a more detailed plot inventory describing biomass distributions by size and species for each of the tree-ring and permanent plots in Appendix C.

Tree-ring and permanent plot annual aNPP estimates for all sites are shown in Figure 2. For all census periods and sites, tree-ring aNPP estimates are within the distribution of possible estimates from 10000 Monte Carlo draws of equal-sized sampling areas (Figure 2, violin plots). There is considerable variability in permanent plot aNPP draws for each time interval, ranging from a low standard deviation of $0.20 \mathrm{Mg} / \mathrm{ha} / \mathrm{year}$ over the 1975-1991 interval at Harvard Forest to a $0.41 \mathrm{Mg} / \mathrm{ha} / \mathrm{year}$ standard deviation over the 2002-2010 interval at Howland. Overall, variability in the Monte Carlo distributions is lowest for all intervals at the Harvard Forest permanent plots.

The range of individual tree-ring plot estimates for each year (Figure 2, green ribbons) is minimal at Howland (maximum range of $0.39 \mathrm{Mg} \mathrm{C} / \mathrm{ha}$ in 2006), Lyford (maximum range $0.79 \mathrm{Mg} \mathrm{C} / \mathrm{ha}$ in 1971), and EMS (maximum range $0.53 \mathrm{Mg} \mathrm{C} / \mathrm{ha}$ in 2010), but is wide at Fernow (maximum range of $5.4 \mathrm{Mg} \mathrm{C} / \mathrm{ha}$ in 2001). While aNPP averaged across all tree-ring and permanent plots are commensurate, the tree-ring plot range at Fernow is large (Figure 2c), and an analysis focused on only one of these plots could produce aNPP estimates anywhere from 1 to over $6 \mathrm{Mg} \mathrm{C} /$ ha in a given year. Interannual variability in aNPP (assessed as the range of mean annual values over the study period) is greater for the permanent plot estimates than for tree rings at all sites (Figure 3). At Harvard Forest, where tree-ring plots were installed within (Lyford plots) and separate (EMS plots) from the permanent plots, both annual tree-ring aNPP series correlate significantly over the period 1969-2012 (Pearson's $r=0.74$, p-value $<0.001$ ).

Results from the MWW test show significance at the $<0.05$ level for Harvard (both Lyford and EMS) and Fernow (Table 2). Significant p-values indicate tree-ring and permanent plot aNPP estimates are not likely drawn from the same distribution. Results at Howland are not significant, suggesting the tree-ring and permanent plot aNPP 
populations are equivalent. The test is also not significant when all sites are grouped together. Location parameters from the MWW test show that tree-ring aNPP is underestimating permanent plot aNPP at Howland and Fernow and overestimating at Harvard (Table 2, Figure 4). Tree rings slightly overestimate permanent plots when all sites are grouped together.

\section{Uncertainty}

MWW tests between the random permanent plot draws of equal area to the treering plots and random draws simulating a hypothetical larger tree-ring sampling area are not significant for Howland ( $p$-value $=0.05)$, Harvard $(p$-value $=0.18)$, or Fernow $(0.65)$, indicating that there is not a statistically significant difference in aNPP estimates when the sampling area is increased in this manner. However, increasing the area sampled tightens the variability around the mean (Figure 5). Standard deviation decreases from 0.21 to 0.15 at Howland, 0.30 to 0.19 at Harvard, and 1.08 to 0.61 at Fernow.

Changing the set of species-specific allometric equations applied to aNPP calculations has little effect on the interannual variation in aNPP (this is controlled by tree growth), but can considerably influence magnitude of aNPP (Figure 6). Depending on the set of equations applied, tree-ring aNPP estimates at Howland vary by as much as $0.25 \mathrm{MgC} /$ ha/year (Figure 6a), $0.60 \mathrm{MgC} /$ ha/year at the Harvard Lyford plots (Figure 6b), $0.55 \mathrm{MgC} / \mathrm{ha} /$ year at the Harvard EMS plots (Figure $6 \mathrm{c}$ ), and $5.10 \mathrm{MgC} / \mathrm{ha} /$ year at Fernow. The aNPP calculated by the set of equations we applied for our primary analyses (Figure 6, green lines) are high relative to the other combinations at Howland, and low at Harvard Lyford, Harvard EMS, and Fernow.

\section{DISCUSSION}

In our analysis of three eastern U.S. forests, we have shown that tree-ring aNPP estimates are within the distribution of permanent plot subsets equal to the tree-ring area sampled (Figure 2). Because of this agreement, we claim that both tree-ring and permanent plots are producing estimates that are within a reasonable proximity. While we show that tree-ring aNPP estimates at all sites is within the range of permanent plot estimates if equal-sized sampling areas are considered, tree-ring aNPP tends to overestimate permanent plot aNPP at Harvard and Fernow and underestimate at Howland when the mean of all 10000 resamples of the permanent plot dataset is considered (Figure 4). Because the permanent plots at our sites cover 2-3 ha of forest, we consider these aNPP estimates to be generally representative of the stand, with our tree-ring aNPP overestimating stand-level aNPP at Harvard and Fernow and underestimating at Howland.

To absolutely resolve the issue of a mismatch in sampling area between both methods would require tree-ring aNPP reconstructions from every tree within the permanent plots or every tree within an equivalent sized area, which is not a dataset we have developed at this time. When co-located permanent plot data is available, however, an approach similar to our equal-area resample can help contextualize tree-ring aNPP estimates from a particular sampling area. The ability to contextualize tree-ring aNPP estimates with permanent plots is becoming increasingly more possible, as sites that have prioritized co-location of long-term ecological datasets, including those in this study, are 
developing longer and longer growth records from permanent plots (e.g. Woods 2007, Anderson-Texeira et al. 2015).

However, many attempts at using dendrochronology to retroactively calculate aNPP are beset with numerous biases inherent in the sampling design (Bowman et al. 2013, Nehrbass-Ahles et al. 2014). Some common problems include the "modern sampling bias", in which only trees alive at the time of sampling are analyzed (Cherubini et al. 1998, Briffa and Melvin 2011), the "slow-grower bias", which assumes older trees have slower growing rings (Bigler and Veblen 2009, Brienen et al. 2012), the "big-tree selection bias", in which only the largest, most dominant trees are sampled, common in dendrochronology (Brienen et al. 2012), the "pre-death suppression bias", in which a growth decrease is observed due to the inclusion of old, slow-growing trees in the analysis (Wyckoff and Clark 2002, Pederson 1998), and the "fading record bias", in which an apparent decrease in growth in seen back in time due to trees that are not included because they died before the time of sampling (Foster et al. 2014).

Because permanent remeasurement plots track growth as it occurs, these data are less affected by these biases. Recognizing the presence of these biases in tree-ring aNPP reconstructions, we attempted to control for them in the following ways: i) We sampled all trees over a specified dbh threshold within our delineated plots. This minimizes biases associated with only including the oldest, most dominant trees in a stand, and follow a "fixed-plot" design, shown to be the most effective sampling method for obtaining aNPP estimates (Babst et al. 2013). However, we are still missing growth information on trees that died during the study period. ii) We have only included aNPP estimates from the previous 30-40 years. Many of these biases increase in magnitude further into the past, but our aNPP reconstructions are not obviouly affected over this short time period. However, when increasing the study extent to $>60$ years before present, the aNPP estimates plummet unrealistically (Appendix D). iii) By calculating aNPP as an areal mass sum $(\mathrm{Mg} \mathrm{C} / \mathrm{ha})$, we obtain a plot-level aNPP measure, minimizing abnormal contributions of individual trees to growth in every year.

Two other problems are associated with using tree growth specifically to reconstruct aNPP: using species-specific allometric equations to translate diameter growth to aboveground carbon gain and the ability to upscale plot-based estimates to make inferences at the stand or ecosystem scale. Site-specific allometric equations are rarely available, and researchers must use their judgement to select a set of equations published for other sites. There is no sampling standard for creating these equations, and local differences in tree growth may also exist. For this study, we carefully selected the best equations to use based on criteria of geographic proximity to study sites and the size distribution and number of trees from which the equations were developed. However, randomly chosen selections of equations drawn from the entire set of potentially applicable published equations generates a large range of aNPP magnitudes (Figure 6). While many of the equations from this set would likely not be applied to a particular site (e.g. most researchers would not apply the equation developed by Young 1984 for red maple in Maine to red maples in West Virginia), Figure 6 shows the wide range in aNPP that results when equations are not carefully chosen. Despite efforts to apply the best equations given our criteria, it is still impossible to absolutely validate their accuracy without having explicit allometric information from each site. Constraining the uncertainties surrounding allometric equations is an urgent area of research that is 
actively being addressed (Dietze et al. 2006, Nickless et al. 2011, Alexander et al. 2015). Problems surrounding allometric equations effect both tree-ring and permanent plot aNPP calculations equally.

Understanding the extent that plot-based aNPP estimates can be upscaled to the stand or ecosystem scale is another area of inquiry, complicated by landscape-level changes in vegetation composition, age, and structure. We addressed the upscaling problem in our data by comparing distributions of permanent plot aNPP estimates calculated from two different areal extents, one equal to the area sampled in our tree-ring plots, and one simulating an approximately two-fold increase in tree-ringsampling area (Figure 5). These two distributions were not significantly different for any of our three sites, indicating that increasing the sampling area does not provide estimates that are significantly better. But, the spread of potential aNPP estimates does decrease, which would continue to occur until a sampling area equivalent to the permanent plots is achieved, and we can expect the tree-ring aNPP estimates to move closer to the permanent plot (stand-level) aNPP estimates as we increase our sampling area.

Further upscaling beyond the stand is problematic due to potential larger-scale variations that cannot be addressed using our localized datasets (Fahey et al. 2015). Fully addressing the problem of upscaling past the stand level will likely involve integrating multiple data sources developed at various scales, including remote sensing, eddy covariance, and modelling in addition to tree rings and permanent plots. Our present comparison of tree-ring and permanent plot aNPP adds to a growing body of literature working toward this goal (e.g. Rocha et al. 2006, Bunn et al. 2013, Babst et al. 2014, Girardin et al. 2014, Klesse et al. 2016, Rohner et al. 2016). Additionally, aNPP upscaling estimates for forests of high heterogeneity may be even more difficult because a particular sampling plot will not necessarily include all representative species or habitat types (e.g. ridges, valleys, riparian areas). Both our tree-ring and permanent plot aNPP estimates at Fernow, which has high species diversity and contrasting topography, have a considerably wide range between individual sampling plots (Figure 2). This range is less pronounced at both Howland and Harvard, which have more homogeneity in species and topography. We discuss this in more detail along with a biomass plot inventory in Appendix C.

\section{CONCLUSIONS}

Permanent plots are the ecological standard for tracking productivity of forest stands over time and are an ideal dataset for contxtualizing aNPP estimates developed from tree-ring plots. Comparisons such as our study are a necessary step towards developing more complete, multi-method datasets. Since many of the strengths and weaknesses of each method are complementary, combining data sets can improve detail and applicability of long-term measurements. As permanent plot data becomes available over more years at more sites, we encourage continued research combining co-located tree-ring records to further develop what we have presented here for three Eastern United States forest sites. Combining these two data sources provides opportunities for modeling of spatial, temporal, and ecological dynamics of annual aNPP at a variety of scales. Additionally, we promote the continued use of tree rings to estimate aNPP for forests that differ in species composition, age, rates of productivity, and disturbance histories. As we have outlined in our paper, using tree rings to reconstruct aNPP comes with numerous 
challenges. But, the detailed temporal and spatial resolution of these data make surmounting these challenges worthwhile. Tree rings are still a relatively rarely used method for estimating aNPP, and broadening the diversity of sites where they have been applied will further develop the advantages and limitations of using tree rings in carbon cycle research.

\section{Works Cited}

Alexander, M.R., C.R. Rollinson, F. Babst, M. Litvak, D.J.P. Moore, and V. Trouet. 2015. Quantifying uncertainties in tree-ring estimates of biomass at the Valles Caldera, NM. Ecological Society of America Annual Meeting, Baltimore, MD.

Anderson-Texeira, K.J., et al. 2015. CTFS-ForestGEO: a worldwide network monitoring forests in an era of global change. Global Change Biology 21: 528-549.

Babst, F., M.R. Alexander, P. Szejner, O. Bouriaud, S. Klesse, J.Roden, P. Cias, B. Poulter, D. Frank, D.J.P. Moore, and V. Trouet. 2014. A tree-ring perspective on the terrestrial carbon cycle. Oecologia 176 (2): 307-22.

Babst, F., et al. 2013. Above-ground woody carbon sequestration measured from tree rings is coherent with net ecosystem productivity at five eddy-covariance sites. New Phytologist 201 (4): 1289-1303.

Babst, F., O. Bouriaud, M.R. Alexander, V. Trouet, and D. Frank. 2013. Toward consistent measurements of carbon accumulation: A multi-site assessment of biomass and basal area increment across Europe. Dendrochronologia 32 (2): 153161.

Baldocchi, D. 2003. Assessing the eddy covariance technique for evaluating carbon dioxide exchange rates of ecosystems: past, present and future. Global Change Biology 9 (4): 479-92.

Barford, et al. 2001. Factors controlling long and short term sequestration of atmospheric $\mathrm{CO}_{2}$ in a mid-latitude forest. Science 294: 1688-1690.

Bigler, C. and T.T. Veblen. 2009. Increased early growth rates decrease longevities of conifers in subalpine forests. Oikos 118: 1130-1138.

Biondi, F. 1999. Tree-ring chronologies and repeated timber inventories as forest monitoring tools. Ecological Applications 9(1): 216-227.

Bouriaud, O., N. Bréda, J.L. Dupouey, and A. Granier. 2005. Is ring width a reliable proxy for stem-biomass increment? A case study in European beech. Canadian Journal of Forest Research 35 (12): 2920-33. 
Bowman, D.M.J.S., R.J.W. Brienen, M. Gloor, O.L. Phillips, and L.D. Prior. 2013. Detecting trends in tree growth: not so simple. Trends in Plant Science 18: 11-17.

Brienen, R.J.W., E. Gloor, and P.A. Zuidema. 2012. Detecting evidence for CO2 fertilization from tree-ring studies: the potential role of sampling biases. Global Biogeochemical Cycles 26: GB1025.

Briffa, K.R. and T.M. Melvin. 2011. A closer look at regional curve standardization of tree-ring records: justification of the need, a warning of some pitfalls, and suggested improvements in its application. In Dendroclimatology. pp. 113-145. Dordrecht: Springer.

Chapin, F.S., et al. 2006. Reconciling carbon-cycle concepts, terminology, and methods. Ecosystems 9 (7): 1041-1050.

Cherubini, P., M. Dobbertin, and J.L. Innes. 1998. Potential sampling bias in long-term forest growth trends reconstructed from tree rings: a case study from the Italian Alps. Forest Ecology and Management 109: 103-118.

Clark, D.A., S. Brown, D.W. Kicklighter, and J.Q. Chambers. 2001. Measuring net primary production in forests: concepts and field methods. Ecological Applications 11 (2): 356.

Curtis, P.S., P.J. Hanson, P. Bolstad, C. Barford, J.C. Randolph, H.P. Schmid, and K.B. Wilson. 2002. Biometric and eddy covariance based methods of annual carbon storage in five eastern North America deciduous forests. Agricultural and Forest Meteorology 113: 3-19.

Davis, S.C., A.E. Hessl, C.J. Scott, M.B. Adams, and R.B. Thomas. 2009. Forest carbon sequestration changes in response to timber harvest. Forest Ecology and Management 258 (9): 2101-9.

Dietze, M.C., M.S. Wolosin, and J.S. Clark. 2008. Capturing diversity and interspecific variability in allometries: a hierarchical approach. Forest Ecology and Management 256: 1939-1948.

Dixon, R.K., A. M. Solomon, S. Brown, R. A. Houghton, M. C. Trexier, and J. Wisniewski. 1994. Carbon pools and flux of global forest ecosystems. Science 263 (5144): 185-90.

Ehman, J.L., H.P. Schmid, C.S.B. Grimmond, J.C. Randolph, P.J. Hanson, C.A. Wayson, and D. Cropley. 2002. An initial intercomparison of micrometeorological and ecological inventory estimates of carbon exchange in a mid-latitude deciduous forest. Global Change Biology 8: 575-589. 
Eisen, K., and A. Barker Plotkin. 2015. Forty years of forest measurements support steadily increasing aboveground biomass in a maturing, Quercus-dominant Northeastern forest. Journal of the Torrey Botanical Society 142 (2): 97-112.

Fahey, T.J., et al. 2005. The biogeochemistry of carbon at Hubbard Brook. Biogeochemistry 75: 109-176.

Fahey, T.J., P.B. Woodbury, J.J. Battles, C.L. Goodale, S.P. Hamburg, S.V. Ollinger, and C.W. Woodall. 2009. Forest carbon storage: ecology, management, and policy. Frontiers in Ecology and the Environment 8: 245-252.

Fahey, T.J., R.E. Sherman, and D.A. Weinstein. 2013. Demography, biomass and productivity of a Northern hardwood forest on the Allegheny Plateau. Journal of the Torrey Botanical Society 140 (1): 52-64.

Fahey, T.J., et al. 2015. The promise and peril of intensive-site-based ecological research: insights from the Hubbard Brook ecosystem study. Ecology 96: 885-901.

Foster, J.R., A.W. D'Amato, and J.B. Bradford. 2014. Looking for age-related growth decline in natural forests: unexpected biomass patterns from tree rings and simulated mortality. Oecologia 175 (1): 363-74.

Friedlingstein, P., et al. 2010. Update on $\mathrm{CO}_{2}$ emissions. Nature Geosciences 3(12): 811812.

Goodale, C.L., et al. 2002. Forest carbon sinks in the Northern hemisphere. Ecological Applications 12 (3): 891-99.

Graumlich, L.J., L.B. Brubaker, and C.C. Grier. 1989. Long-term trends in forest net primary productivity: Cascade Mountains, Washington. Ecology 70 (2): 405-10.

Harmon, M.E., W.K. Ferrell, and J.F. Franklin. 1990. Effects on carbon storage of conversion of old-growth forests to young forests. Science 247: 699-702.

Hember, R.A., W.A. Hurtz, and J.M. Metsaranta. 2015. Ideas and perspectives: use of tree-ring width as an indicator of tree growth. Biogeosciences Discussions 12: 8341-8352.

Holdaway, R.J., S.J. McNeill, N.W.H Mason, and F.E. Carswell. 2014. Propagating uncertainty in plot-based estimates of forest carbon stock and carbon stock change. Ecosystems 17 (4): 627-40.

Hollinger, D.Y., et al. 2004. Spatial and temporal variability in forest-atmosphere $\mathrm{CO}_{2}$ exchange. Global Change Biology 10: 1689-1706. 
Holmes, R.L. 1983. Computer-sssisted quality control in tree-ring dating and measurement. Tree-Ring Bulletin 43 (1): 69-78.

Jones, C., et al. 2013. Twenty-first-century compatible CO2 emissions and airborne fraction simulated by CMIP5 earth system models under four representative concentration pathways. Journal of Climate 26 (13): 4398-4413.

Klesse, S., S. Etzold, and D. Frank. 2016. Integrating tree-ring and inventory-based measurements of aboveground biomass growth: research opportunities and carbon cycle consequences from a large snow breakage event in the Swiss Alps. European Journal of Forest Research doi: 10.1007/s10342-015-0936-5.

Kloeppel, B.D., M.E. Harmon, and T.J. Fahey. 2007. Estimating aboveground net primary productivity in forest-dominated ecosystems. In Principles and Standards for Measuring Primary Production, 268. New York: Oxford.

McRoberts, R.E., J.T. Hahn, G.J. Hefty, and J.R. Van Cleve. 1994. Variation in forest inventory field measurements. Canadian Journal of Forest Research 24 (9): 176670 .

Nehrbass-Ahles, C., F. Babst, S. Klesse, M. Notzli, O. Bouriaud, R. Neukom, M. Dobbertin, and D. Frank. 2014. The influence of sampling design on tree-ringbased quantification of forest growth. Global Change Biology 20 (9): 2867.

Nickless, A., R.J. Scholes, and S. Archibald. 2011. A method for calculating the variance and confidence intervals for tree biomass estimates obtained from allometric equations. South African Journal of Science 107: 1-10.

Ollinger, S.V., R.N. Treuhaft, B.H. Braswell, J.E. Anderson, M.E. Martin, and M. Smith. 2007. The role of remote sensing in the study of terrestrial net primary production. In Principles and Standards for Measuring Primary Production. New York: Oxford.

Pacala, S.W., et al. 2001. Consistent land-and atmosphere-based US carbon sink estimates. Science 292 (5525): 2316-20.

Pan, Y., et al. 2011. A large and persistent carbon sink in the world's forests. Science 333 (6045): 988-93.

Pederson, B.S. 1998. The role of stress in the mortality of midwestern oaks as indicated by growth prior to death. Ecology 79:79-93.

Rocha, A., M.L. Goulden, A.L. Dunn, and S.C. Wofsy. 2006. On linking interannual treering variability with observations of whole forest $\mathrm{CO}_{2}$ flux. Global Change Biology 12: 1378-1389. 
Rohner, B., P. Weber, and E. Thurig. 2016. Bridging tree rings and forest inventory: how climate effects on spruce and beech growth aggregate over time. Forest Ecology and Management 360: 159-169.

R Development Core Team 2008. R: A language and environment for statistical computing. R Foundation for Statistical Computing,Vienna, Austria.

Running, S.W., R.R. Nemani, F. Heinsch, M. Zhao, M. Reeves, and H. Hashimoto. 2004. A continuous satellite-derived measure of global terrestrial primary production. BioScience 54 (6): 547-560.

Schuster, W. S. F., K. L. Griffin, H. Roth, and M. H. Turnbull. 2008. Changes in composition, structure and aboveground biomass over seventy-six years (19302006) in the Black Rock Forest, Hudson Highlands, Southeastern New York State. Tree Physiology 28 (4): 537.

Siccama, T.G., T.J. Fahey, C.E. Johnson, T.W. Sherry, E.G. Denny, E.B. Girdler, G.E. Likens, and P.A. Schwarz. 2007. Population and biomass dynamics of trees in a Northern hardwood forest at Hubbard Brook. Canadian Journal of Forest Research 37 (4): 737-49.

Stokes, M.A., and T.L. Smiley. 1968. An Introduction to Tree-Ring Dating. University of Arizona Press.

Weins, J.A. 1989. Spatial scaling in ecology. Functional Ecology 3 (4): 385-97.

Woods, K.D. 2007. Predictability, contingency, and convergence in late succession: slow systems and complex data-sets. Journal of Vegetation Science 18: 543-554.

Wyckoff, P.H. and J.S. Clark. 2002. The relationship between growth and mortality for seven co-occurring tree species in the southern Appalachian Mountains. Journal of Ecology 90: 604-615.

Xu, C., M.H. Turnbull, D.T. Tissue, J.D. Lewis, R. Carson, W.F. Schuster, D. Whitehead, A.S. Walcroft, J. Li, and K.L. Griffin. 2012. Age-related decline of stand biomass accumulation is primarily due to mortality and not to reduction in NPP associated with individual tree physiology, tree growth or stand structure in a Quercusdominated forest. Journal of Ecology 100 (2): 428-440. 
Table 1: Summary characteristics of the three study sites.

\begin{tabular}{|c|c|c|c|c|}
\hline Site & Forest type & Method & Time scale ${ }^{\dagger}$ & Reference \\
\hline & $\begin{array}{l}\text { Dominants: P.rubens, } \\
\text { T. canadensis }\end{array}$ & Tree rings & $1989-2013$ & this paper \\
\hline Howland & Approx. age: 140 yrs & Permanent plots & 1989,1998, 2009 & $\begin{array}{l}\text { J. Lee, pers } \\
\text { comm }\end{array}$ \\
\hline \multirow{3}{*}{ Harvard } & \multirow{3}{*}{$\begin{array}{l}\text { Dominants: } Q \text {. rubra, } \\
\text { A. rubrum } \\
\text { Approx. age: } 115 \mathrm{yrs}\end{array}$} & Tree rings (Lyford) & $1969-2012$ & this paper \\
\hline & & Tree rings (EMS) & 1969-2012 & this paper \\
\hline & & Permanent plots & $\begin{array}{l}1969,1975,1991, \\
2001,2011\end{array}$ & $\begin{array}{l}\text { HF Data } \\
\text { Archive HF032 }\end{array}$ \\
\hline & $\begin{array}{l}\text { Dominants: } Q . \text { rubra, } \\
\text { Q. montana, }\end{array}$ & Tree rings & $1979-2002$ & $\begin{array}{l}\text { Davis et al. } \\
2006\end{array}$ \\
\hline Fernow & $\begin{array}{l}\text { A.rubrum, } \\
\text { A.saccharum, } \\
\text { P.serotina } \\
\text { Age: } 100 \text { yrs }\end{array}$ & Permanent plots & $\begin{array}{l}1979,1983,1989, \\
1994,1999,2009\end{array}$ & $\begin{array}{l}\text { F.Wood, } \\
\text { pers comm }\end{array}$ \\
\hline
\end{tabular}

'Range of annual data (tree rings) or years when measurements ocurred (permanent plots).

Table 2. Results of the Mann-Whitney-Wilcoxon test of equality of tree-ring and permanent plot aNPP.

\begin{tabular}{lll} 
Site & p-value & $\begin{array}{c}\text { Location parameter } \\
(95 \% \mathrm{CI})^{\dagger}\end{array}$ \\
\hline Howland & 0.51 & $0.15(-0.3,0.18)$ \\
Harvard Lyford & $0.03^{*}$ & $-0.29(-0.51,-0.01)$ \\
Harvard EMS & $0.03^{*}$ & $-0.19(-0.52,-0.06)$ \\
Fernow & $0.03^{*}$ & $0.59(0.12,1.04)$ \\
All & 0.37 & $-0.11(-0.42,0.39)$ \\
\hline
\end{tabular}

${ }^{\dagger}$ Tests were conducted as permanent plots against tree rings, so positive values indicate overestimation by permanent plots and negative values overestimation by tree rings.

*Significant at $<0.05$ level 


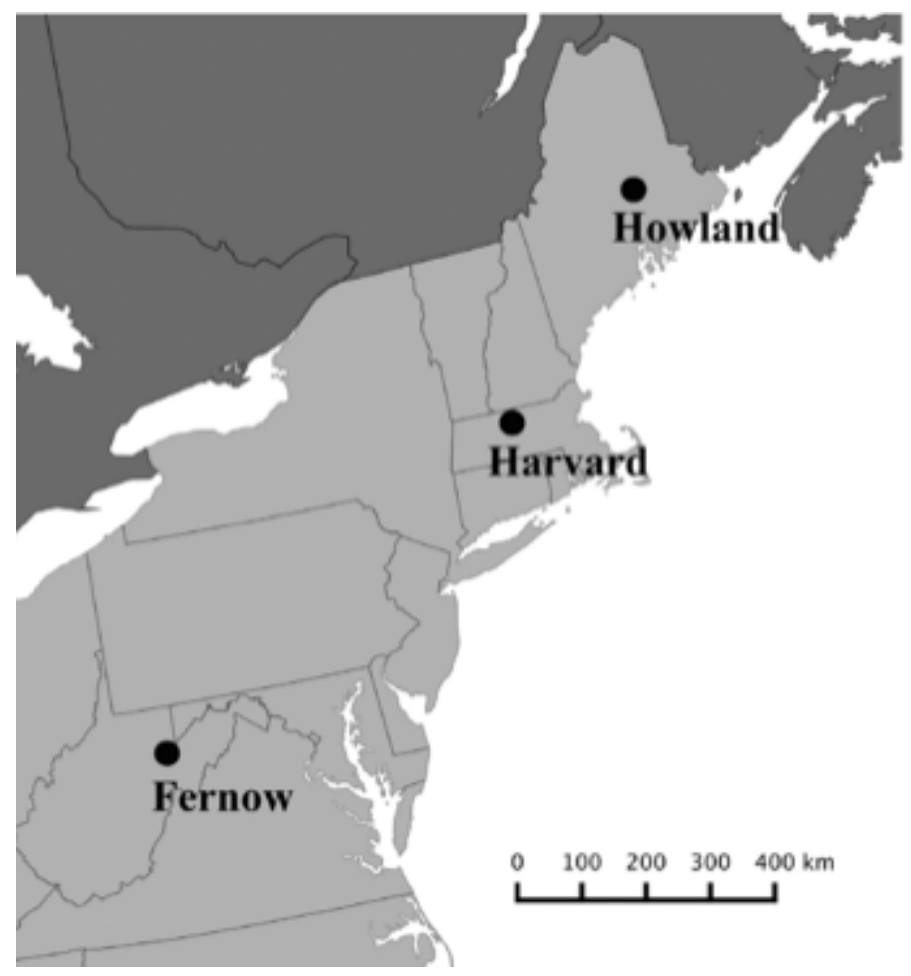

Figure 1. Map of three study sites included in this analysis: Howland Research Forest, Harvard Forest, and Fernow Experimental Forest. 

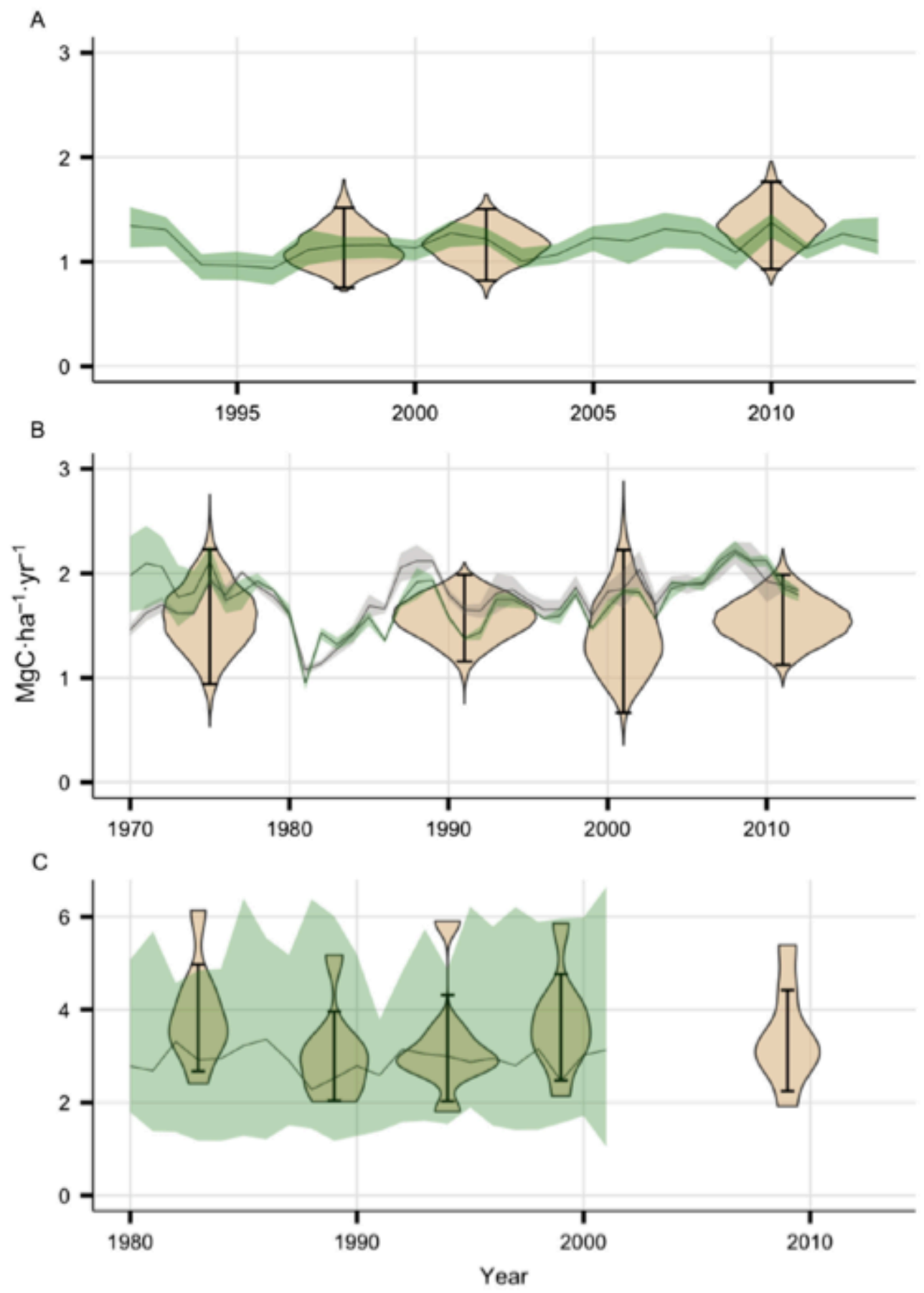

Figure 2. Graphical comparisons of tree-ring aNPP versus permanent plots at A) Howland Research Forest, B) The Harvard Forest, and C) Fernow Experimental Forest. Green ribbons represent the range of aNPP across all tree-ring sampling plots, with the mean marked by the black line. At Harvard, grey ribbons represent the EMS tree-ring plots, and green ribbons the Lyford tree-ring plots. Beige violin plots show the distribution of aNPP estimates from 10000 random subsets of the permanent plot data equal to the area cored. At Fernow, violin plots represent the distribution of aNPP from all 10 sub plots. Error bars denote $95 \%$ confidence intervals for the resampled distributions. 


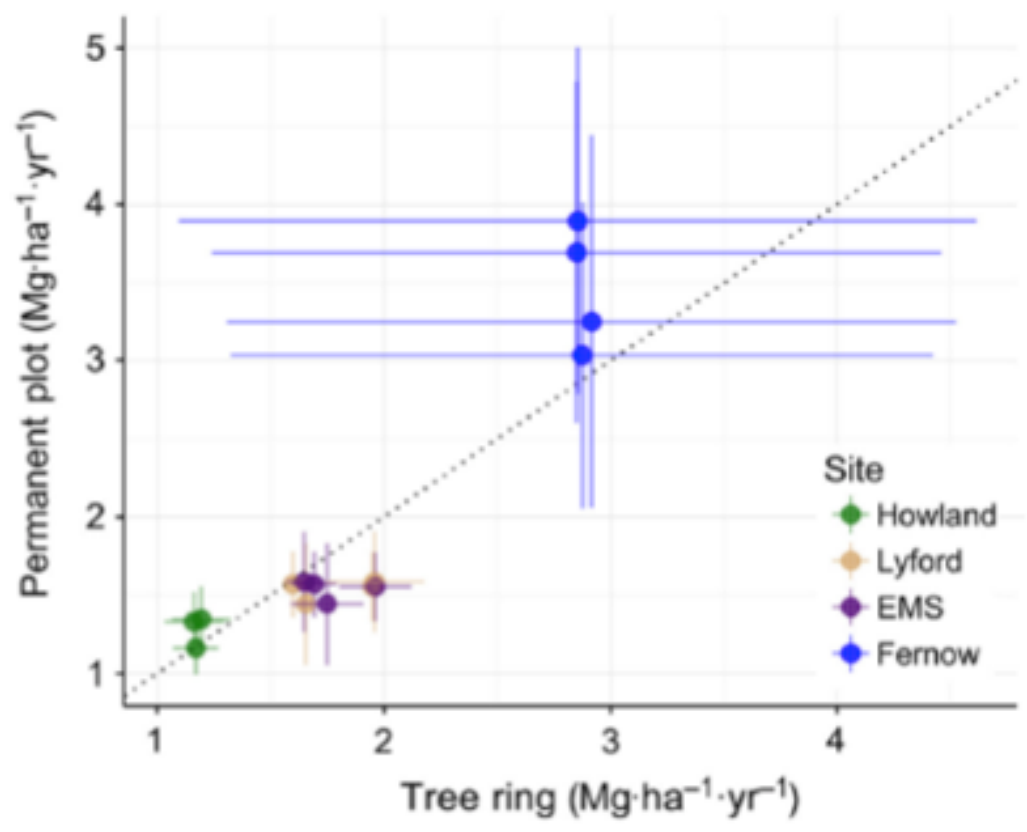

Figure 3. Tree-ring aNPP is plotted against permanent plot aNPP for all remeasurement intervals at the three sites. Error bars are +-1 standard error above the mean for tree rings (horizontal) and permanent plots (vertical). The black dashed line represents the 1-to-1 relationship. Points above this line indicate underestimation by tree rings and points below indicate overestimation by tree rings.

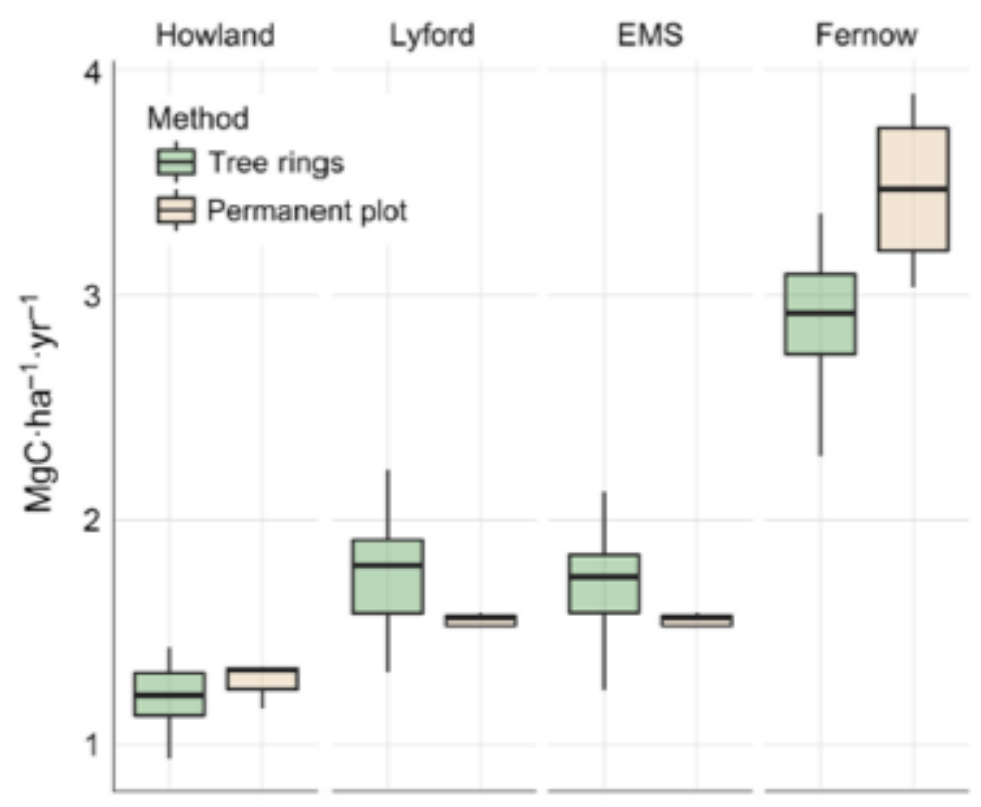

Figure 4. Boxplots showing the distribution of annual tree-ring aNPP estimates across all years overlapping with permanent plots. Biege boxplots show the distribution of aNPP for all permanent plot intervals. Tree rings from the Harvard Lyford and EMS tree-ring plots are both compared with Lyford permanent plots. 


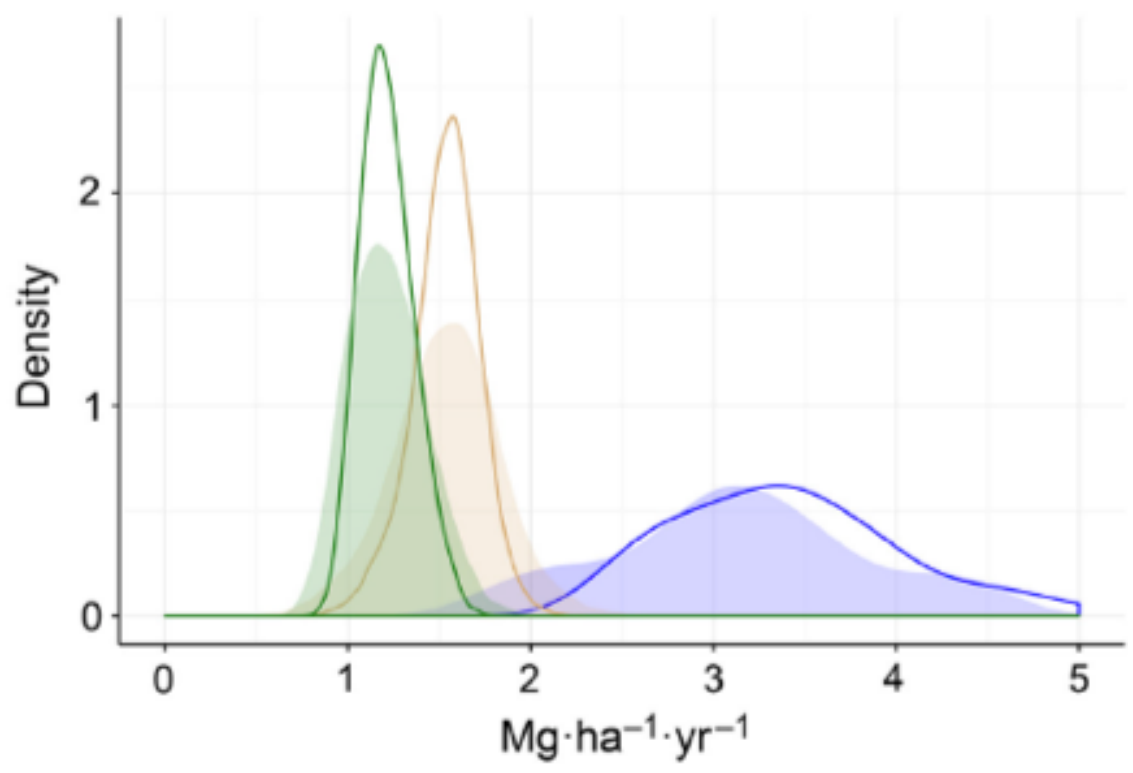

Figure 5. The distribution of aNPP estimates from permanent plots resulting from 10,000 random combinations of subplots equalling the area sampled by tree rings (solid fill) is shown against the distribution of estimates from permanent plot draws simulating a larger sampling area (transparent fill). Green curves are Howland, biege curves Harvard, and blue curves Fernow. 
Appendix A.

Table A1. Species-specific allometric equations used for biomass calculations.

\begin{tabular}{|c|c|c|c|c|c|c|c|c|}
\hline Species & Site & Form & $a$ & b & DBH $(\mathrm{cm})$ & $\mathrm{n}$ & region & source \\
\hline ACRU & Fer & $\mathrm{A}$ & 0.091 & 2.508 & $5-50$ & 27 & WV & 1 \\
\hline ACRU & How,Har & $\mathrm{A}$ & 0.127 & 2.380 & $3-66$ & 62 & ME & 7 \\
\hline ACSA & Fer & A & 0.101 & 2.574 & $5-50$ & 119 & $\overline{\text { WV }}$ & 1 \\
\hline ACSP & Fer & A & 0.204 & 0.252 & $1-20$ & 15 & $\mathrm{NH}$ & 6 \\
\hline ABBA & How & A & 0.088 & 2.402 & $3-51$ & 95 & ME & 7 \\
\hline ASTR & Fer & B & -2.549 & 2.501 & $3-65$ & 15 & $\begin{array}{l}\text { Southern } \\
\text { Appalachians }\end{array}$ & 2 \\
\hline BEAL & How & $\mathrm{A}$ & 0.159 & 2.338 & $3-66$ & 42 & ME & 7 \\
\hline BEAL & Har & $\mathrm{A}$ & 0.168 & 2.415 & $1-55$ & 14 & $\mathrm{NH}$ & 6 \\
\hline BEPA & How & A & 0.061 & 2.663 & $3-51$ & 51 & ME & 7 \\
\hline BELE & Fer & A & 0.063 & 2.661 & $5-50$ & 8 & $\overline{\text { WV }}$ & 1 \\
\hline CACO & Fer & $\mathrm{A}$ & 0.079 & 2.635 & $5-50$ & 14 & WV & 1 \\
\hline CAOV & Fer & $\mathrm{A}$ & 0.079 & 2.635 & $5-50$ & 14 & WV & 1 \\
\hline FAGR & Fer & $\mathrm{A}$ & 0.084 & 2.572 & $5-50$ & 56 & $\overline{\text { WV }}$ & 1 \\
\hline FAGR & Har & $\mathrm{A}$ & 0.196 & 2.392 & $1-60$ & 14 & $\mathrm{NH}$ & 6 \\
\hline FRAM & Fer & $\mathrm{A}$ & 0.106 & 2.480 & $5-50$ & 15 & WV & 1 \\
\hline HAVI & Har & A & 0.038 & 2.900 & $0-4$ & 21 & Canada & 4 \\
\hline JUCI & Fer & B & -2.510 & 2.618 & $3-70$ & 13 & $\begin{array}{l}\text { Southern } \\
\text { Appalachians }\end{array}$ & 2 \\
\hline LITU & Fer & $\mathrm{A}$ & 0.037 & 2.732 & $5-50$ & 12 & WV & 1 \\
\hline MAAC & Fer & B & -2.550 & 2.501 & $3-65$ & 15 & $\begin{array}{l}\text { Southern } \\
\text { Appalachians }\end{array}$ & 2 \\
\hline MAFR & Fer & B & -2.550 & 2.501 & $3-65$ & 15 & $\begin{array}{l}\text { Southern } \\
\text { Appalachians }\end{array}$ & 2 \\
\hline NYSA & Fer & B & -2.212 & 2.413 & $3-64$ & 46 & $\begin{array}{l}\text { Southern } \\
\text { Appalachians }\end{array}$ & 2 \\
\hline OSVI & Fer & B & -1.810 & 2.348 & $3-70$ & 16 & $\begin{array}{l}\text { Southern } \\
\text { Appalachians }\end{array}$ & 2 \\
\hline OXAR & Fer & B & -2.212 & 2.413 & $3-64$ & 46 & $\begin{array}{l}\text { Southern } \\
\text { Appalachians }\end{array}$ & 2 \\
\hline PCRU & How & $\mathrm{A}$ & 0.207 & 2.183 & $1-35$ & 15 & $\mathrm{NH}$ & 6 \\
\hline PIAB & Har & $\mathrm{A}$ & 0.2722 & 2.104 & $12-44$ & 30 & NY & 3 \\
\hline PIST & How,Har & $\mathrm{A}$ & 0.070 & 2.449 & $3-66$ & 35 & ME & 7 \\
\hline PRSE & Fer & $\mathrm{A}$ & 0.072 & 2.617 & $5-50$ & 26 & $\overline{\mathrm{WV}}$ & 1 \\
\hline PRPE & Fer & $\mathrm{A}$ & 0.156 & 2.195 & $3-24$ & 30 & ME & 7 \\
\hline QUAL & Fer & A & 0.058 & 2.689 & $5-50$ & 29 & WV & 1 \\
\hline QUCO & Fer & $\mathrm{A}$ & 0.124 & 2.440 & $5-40$ & 19 & WV & 5 \\
\hline QUMO & Fer & $\mathrm{A}$ & 0.055 & 2.728 & $5-50$ & 13 & WV & 1 \\
\hline QURU & Har,Fer & A & 0.113 & 2.457 & $5-50$ & 24 & WV & 1 \\
\hline QUVE & Fer & $\mathrm{A}$ & 0.095 & 2.503 & $5-40$ & 19 & WV & 5 \\
\hline ROPS & Fer & B & -2.510 & 2.544 & $4-42$ & 2 & $\begin{array}{l}\text { Southern } \\
\text { Appalachians }\end{array}$ & 2 \\
\hline SAAL & Fer & B & -2.212 & 2.413 & $3-64$ & 46 & $\begin{array}{l}\text { Southern } \\
\text { Appalachians }\end{array}$ & 2 \\
\hline THOC & How & A & 0.231 & 1.927 & $3-51$ & 39 & ME & 7 \\
\hline TIAM & Fer & A & 0.062 & 2.533 & $5-50$ & 13 & WV & 1 \\
\hline TSCA & Fer & A & 0.062 & 2.450 & $5-50$ & 21 & WV & 1 \\
\hline TSCA & How,Har & A & 0.099 & 2.362 & $3-51$ & 36 & ME & 7 \\
\hline
\end{tabular}

Species: Abbreviations are tirst two letters of genus, tirst two letters of species

Site: Study sites for equations $(\mathrm{HOW}=$ Howland, $\mathrm{HAR}=$ Harvard, FER=Fernow)

Forms are: $\mathrm{A}, \mathrm{M}=\mathrm{a} \times \mathrm{Db}, \mathrm{B}, \ln (\mathrm{M})=\mathrm{a}+\mathrm{b} \times \ln (\mathrm{D})$, where where $\mathrm{a}$ and $\mathrm{b}$ are species-specific coefficients,

$\mathrm{D}$ is $\mathrm{DBH}$, and $\mathrm{M}$ is aboveground dry weight in $\mathrm{kg}$

DBH: Diameter range for which original equations were developed

$\mathrm{n}$ : Sample number of trees included in equation development

Region: Region where equations were developed

Sources are: 1, Brenneman 1978; 2,Chojnacky 2014; 3, Jokela et al. 1986; 4, Smith and Brand 1984; 5,

Wiant 1977; 6, Whittaker 1974; 7, Young 1980. 


\section{Appendix A Works Cited}

Brenneman, B.B., D.J. Frederick, W.E. Gardner, L.H. Schoenhoefen, and P.L. Marsh. 1978. Biomass of species and stands of West Virginia hardwoods. In: P.E. Pope (Ed), Proceedings of Central Hardwood Forest Conference II, West Lafayette, IN. pp. 159-178.

Chojnacky, D.C., L.S. Heath, and J.C. Jenkins. 2014. Updated generalized biomass equations for North American tree species. Forestry 87 (1): 129-51.

Jokela, E.J., K.P. van Gurp, R.D. Briggs, and E.H. White. 1986. Biomass estimation equations for Norway spruce in New York. Canadian Journal of Forest Research 16: 413-415.

Smith, W.B. and G.J. Brand. 1983. Allometric biomass equations for 98 species of herbs, shrubs, and small trees. Research Note NC-299. North Central Forest Experiment Station, USDA Forest Service.

Whittaker, R.H., F.H. Bormann, G.E. Likens, and T.G. Siccama. 1974. The Hubbard Brook ecosystem study: forest biomass and production. Ecological Monographs 44 (2): 233-254.

Wiant, H.V., C.E. Sheetz, A. Colannino, J.C. DeMoss, and F. Castaneda. 1977. Tables and procedures for estimating weights of some Appalachian hardwoods. West Virginia Agricultural Experiment Station Bulletin 659(T): 36.

Young, H., J. Ribe, and K. Wainwright 1980. Weight tables for tree and shrub species in Maine. University of Maine Agricultural and Experimental Station Miscellaneous Report 230, University of Maine, Orono, ME. 


\section{Appendix B.}

Figure B1. aNPP from permanent remeasurement plots at Howland (green line), Harvard Forest (beige line), and Fernow (purple line) without subsetting the dataset to include only trees $>10 \mathrm{~cm} \mathrm{DBH}$. In the primary analysis, we subsetted the permanent plots to include only trees $>10 \mathrm{~cm}$ DBH to match the diameter cutoff used for tree-ring sampling to ensure the most accurate comparison possible.

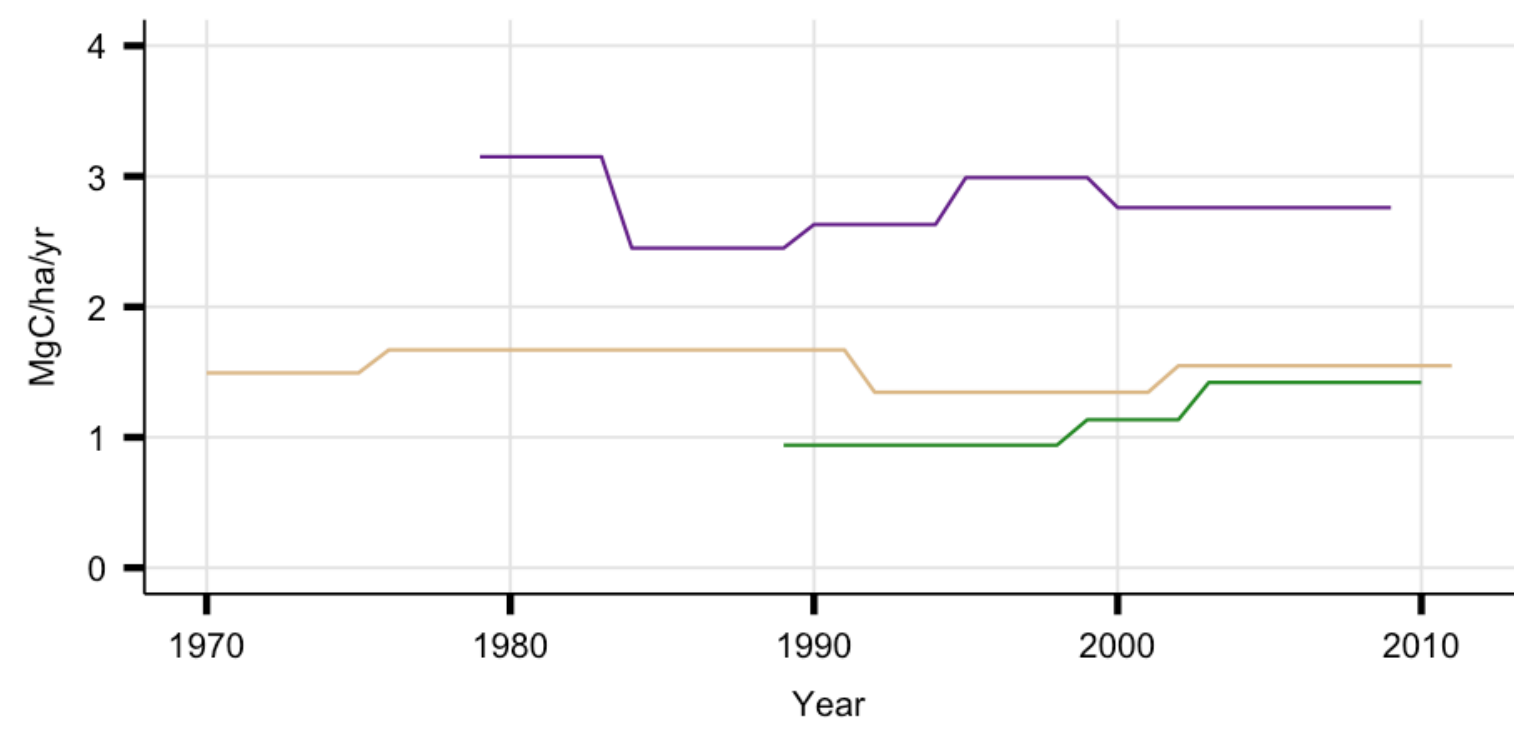




\section{Appendix C.}

Species diversity varies between the three forests studied. We recorded 8 species at Howland, 20 species at Harvard, and 29 species at Fernow. Species composition better matches permanent plot composition for all sites when all tree-ring plots are aggregated (Figure C1). At Howland, most standing biomass in tree-ring plots is distributed between the two dominant species, red spruce (36\% of total biomass) and eastern hemlock (42\%). Red spruce $(46 \%)$ more clearly dominates standing biomass at the permanent plots, however, than does eastern hemlock $(26 \%)$. Other minor differences between the aggregated tree-ring and permanent plots at Howland include a higher percentage of balsam fir and northern white cedar ("other conifer" category, Figure C1) in the permanent plots. Red oak dominates both the Lyford and EMS tree-ring plots at Harvard Forest and is slightly more common in tree-ring plots $(>80 \%)$ than permanent plots (70\%). Red maple and American beech contribute most of the remaining biomass at each plot. At both Howland and Harvard Forest, all representative species were included in both the tree-ring and permanent plots. At Fernow, however, locally common species such as black cherry, shagbark hickory (Carya ovata Mill.) and white ash (Fraxinus americana L.), are prevalent in the permanent plots but were not present in any of the tree-ring plots. Additionally, American basswood, which is prevalent in one tree-ring plot, is nearly absent from the permanent plots.

Variability in species biomass composition between tree-ring plots at Howland and Harvard is minimal but is more pronounced at Fernow, where representative species are not present across all plots (Figure C2). While plot-level compositional differences do exist at Howland (e.g. a higher percentage of red spruce at plot HOW1, and a higher percentage of eastern hemlock at plot HOW3), red spruce and eastern hemlock combine for over $75 \%$ of total biomass at each tree-ring plot. Red maple, eastern white pine, and northern white cedar comprise most of the remaining biomass. At Harvard Forest, red oak overwhelmingly dominates each tree-ring plot (Figure C2). However, the EMS treering plots have a higher percentage biomass of eastern hemlock, eastern white pine, and birch species than do the Lyford tree-ring plots, though these species still contribute a small percentage compared to red oak. Like Howland, the species composition at Harvard is fairly homogeneous, and the variability that does exist is minor compared to Fernow, which is reflected in the lower variability in aNPP estimates. At Fernow, despite high variability in overall species composition between tree-ring plots, oaks (red, black, and chestnut), maples (red and sugar), and American beech are dominant across most plots (Figure C2). However, many species other than oaks and maples are present and can be locally dominant or completely absent in some plots. Standing biomass of tree-ring plot FER1303 is $80 \%$ American basswood, a disproportionately high proportion relative to the other tree-ring plots. Fernow plot FER1301 consists entirely of maple and American beech, and plot FER1305 only contained eight living trees from which a suitable core was obtained relative to the site average of 14 trees per plot.

Size diversity also contributes to both variability between tree-ring plots (Figure

$\mathrm{C} 3$ ) and between aggregated tree-ring and permanent plots (Figure C4), although differences are less pronounced than for species diversity. Mean tree diameters at each Howland tree-ring plot are $23.1 \mathrm{~cm}, 28.0 \mathrm{~cm}$, and $29.5 \mathrm{~cm}$, with fairly symmetrical variability around these means at all plots. At Harvard, mean DBH for each tree-ring plot 
is $30.4 \mathrm{~cm}, 26.1 \mathrm{~cm}$, and $28.2 \mathrm{~cm}$ at the three Lyford plots and $27 \mathrm{~cm}$ and $23 \mathrm{~cm}$ at the two EMS plots. Mean DBH at each Fernow tree-ring plot is $24.8 \mathrm{~cm}, 23.6 \mathrm{~cm}, 25.1 \mathrm{~cm}$, $27.6 \mathrm{~cm}, 25.2 \mathrm{~cm}$, and $34.6 \mathrm{~cm}$. Size distributions at Harvard and Fernow are positively skewed. The relatively similar size distributions of plots within each site suggests that the size distribution of the forest is well captured by the current sample.

Average tree size from aggregated tree-ring plots slightly overestimates tree size from the permanent plots at Howland and Harvard, but underestimates at Fernow (Figure C4). Overestimation of tree-ring plots is most apparent at Howland, where the average DBH of tree-ring plots is $26.7 \mathrm{~cm}$ versus $22.9 \mathrm{~cm}$ in the permanent plots. At Harvard, average DBH from tree-ring plots is $27.9 \mathrm{~cm}$ (Lyford) and $25.2 \mathrm{~cm}$ (EMS) compared to $24.1 \mathrm{~cm}$ in the permanent plots. Fernow average tree-ring DBH is $26.9 \mathrm{~cm}$, underestimating the $28.2 \mathrm{~cm}$ average in the permanent plots. 


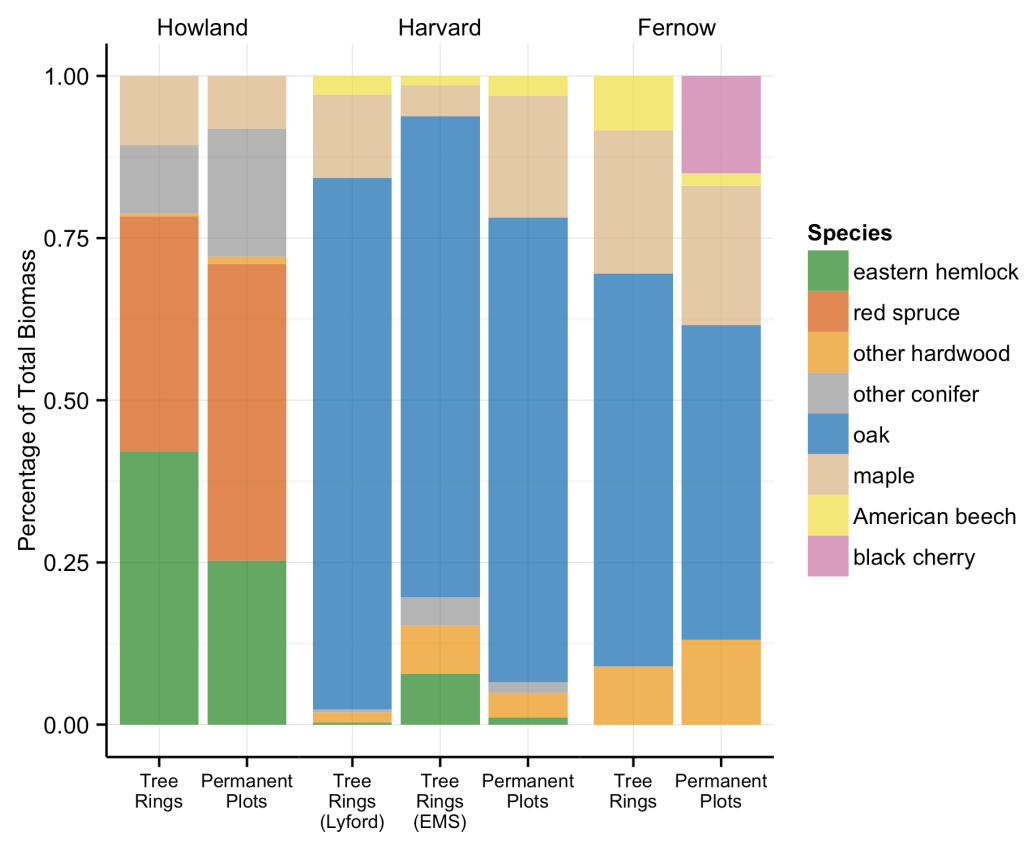

Figure C1. Species percentages of total biomass for all aggregated tree-ring and permanent plots. For simplification, eastern white pine, northern white cedar, and balsam fir were grouped into the "other conifer" category, nondominant hardwoods grouped into the "other hardwood" category, all maples (red and sugar) into the "maple" category, and all oaks (red, white, black, chestnut) grouped into the "oak" category. At Harvard the "oak" category is nearly exclusively red oak.

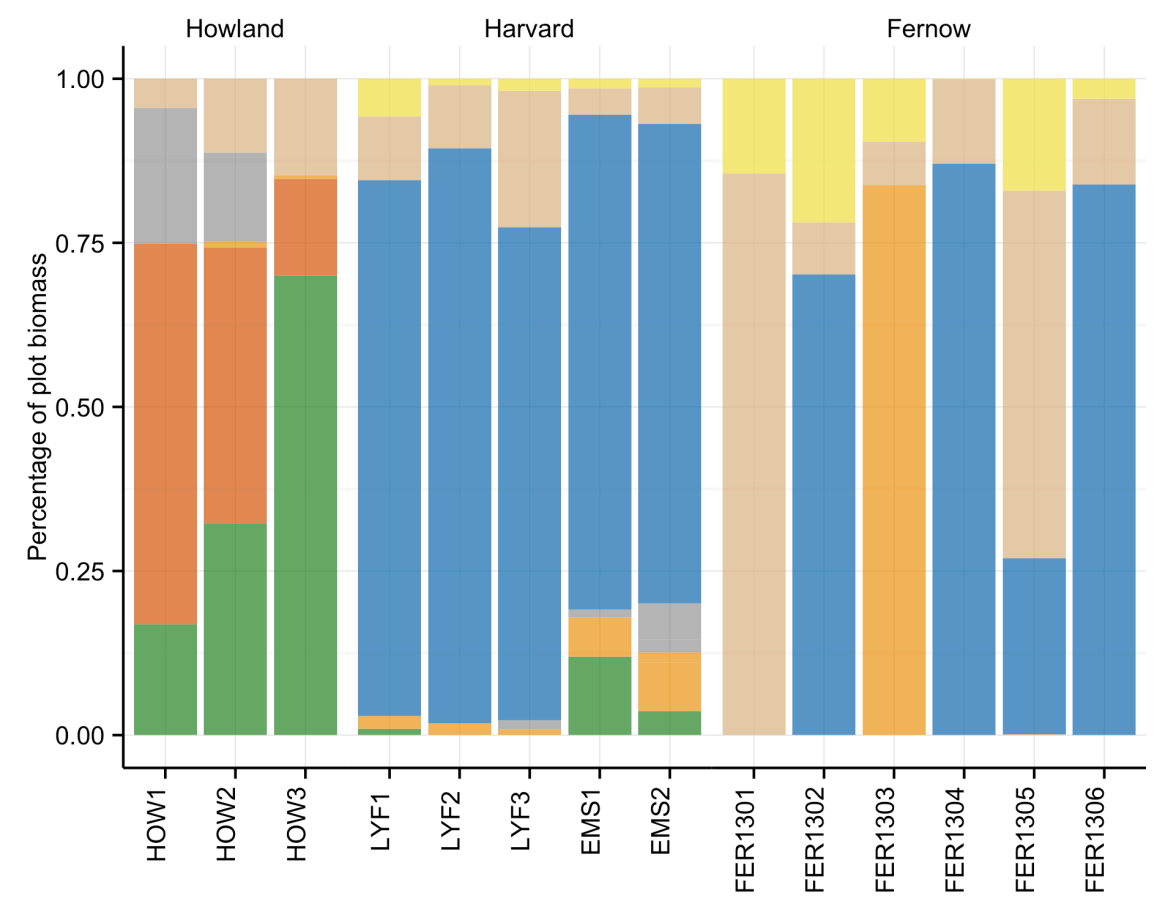

Figure C2. Species percentages of standing biomass at each tree-ring plot. Plot abbreviations are the name of the site followed by the plot number. Species color codes are identical to Figure $\mathrm{C} 1$. 


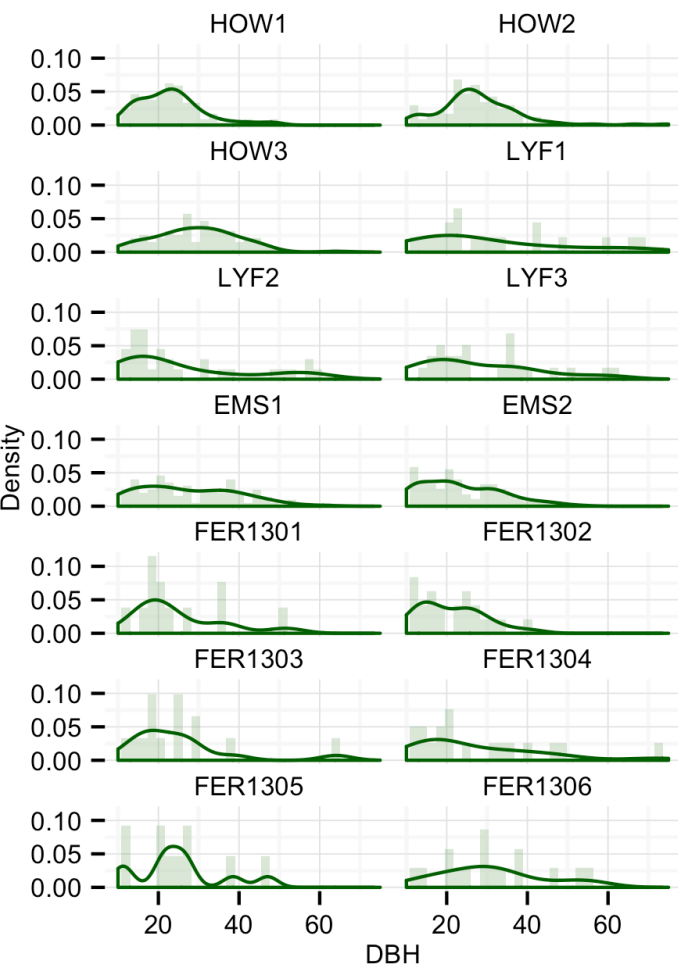

Figure C3. Probability density distribution with histogram of stem diameter at each treering plot. Plot abbreviations are the same as described in Figure C2.

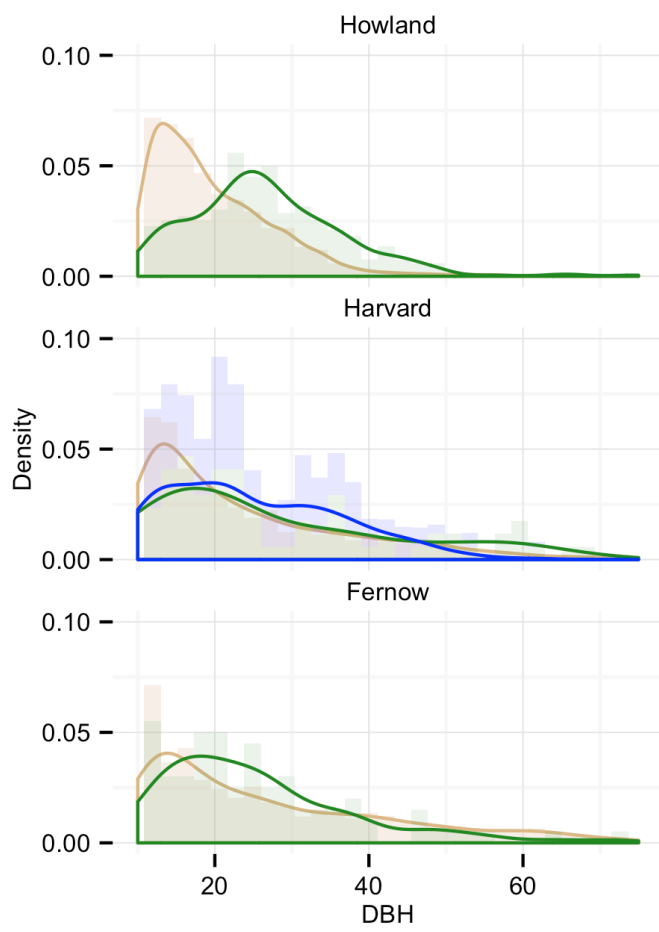

Figure C4. Probability density distribution with histogram of stem diameter for aggregated tree-ring and permanent plots. Green curves are tree-ring diameters and beige curves are permanent plot diameters. At Harvard, the green curve denotes the Lyford tree-ring plots and the blue curve the EMS tree-ring plots. 


\section{Appendix D.}

Figure D1. Here, we plot the full tree-ring chronology of aNPP at Howland (green), Harvard Lyford (biege), Harvard EMS (purple) and Fernow (blue). Though the records go back $>100$ years at Howland and the two Harvard Forest sites, there is an unrealistic crash in aNPP starting around 60 years before present. This is a recognized issue with reconstructing forest growth from tree rings, prominently depicting the "modern sampling bias" and the "fading record bias."

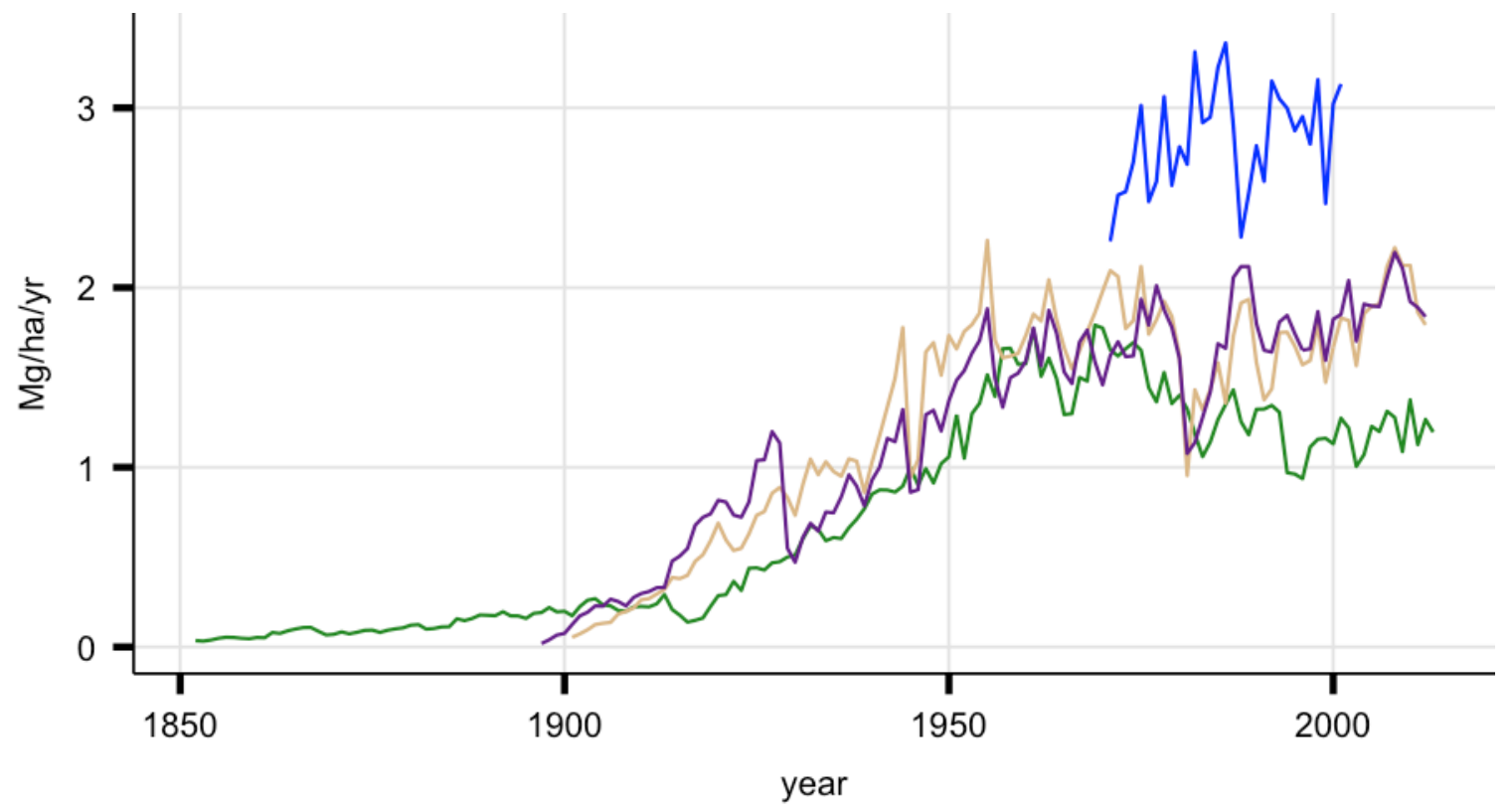




\title{
Chapter 2: Structural distribution of forest productivity in eastern U.S. temperate
} forests

\author{
Alex Dye ${ }^{\dagger}$, M. Ross Alexander ${ }^{\ddagger}$, Daniel Bishop ${ }^{\ddagger}$, Amy Hess ${ }^{\dagger}$, and Neil Pederson ${ }^{\star}$ \\ ${ }^{\dagger}$ Department of Geology and Geography, West Virginia University, Morgantown, WV 2 \\ Harvard Forest, Harvard University, Petersham, MA \\ ${ }^{*}$ Department of Earth and Environmental Sciences, Columbia University, New York, \\ NY
}

To be submitted to: Ecosystems 


\begin{abstract}
Forests of Eastern North America have considerable potential as future carbon sinks, and understanding the destination of biomass growth in these forests has implications for managing these forests to facilitate carbon sequestration. Recent studies have suggested that big trees are important contributors to forest carbon sequestration because of their capacity for both massive storage and accumulation. Here, I compile a diverse dendrochronological network of 16 Eastern U.S. temperate forests. At each site, I compare the diameter frequency distribution with the diameter distribution weighted by annual basal area increment (BAI) over a 42 year study period (1970-2011). For all 16 sites, the mean of the BAI-weighted distribution is greater than the mean diameter, indicating disproportionate growth of big trees. For most sites $(n=12)$, the difference between the means of both distributions increases over time, indicating increased concentration of growth in big trees. Alternatively, the difference between means is decreasing at two sites, indicating decreased concentration of growth in big trees. To nest my findings in the entirety of the Eastern U.S. temperate forest, I duplicated my analyses with the USFS Forest Inventory and Analysis (FIA) plot-level remeasurement data ( $n=34,445$ plots). Typically, the mean diameter of the BAI-weighted distribution remains greater than the mean diameter of the frequency distribution, but has a much larger range than our sampled data. Several FIA plots indicate disproportionate production of smaller trees (i.e. the mean diameter of BAI-weighted distribution is less than the mean diameter), an outcome not seen in any of our sampled sites. Overall, this work provides a unique and highly detailed description of structural biomass dynamics in the eastern U.S. temperate forest region.
\end{abstract}




\section{INTRODUCTION}

Defining the potential of forests as sinks of atmospheric carbon requires a complete understanding of where carbon is allocated in forests. To address this need, scientists must continue to develop and share high-quality scientific information on the interannual dynamics of carbon in forests from an ecological perspective. In the diverse forests of eastern North America, investigating temporal and spatial distributions of biomass allocation according to species (Eisen and Barker Plotkin 2015, Dye et al. 2016) and canopy position (Alexander 2017a) can add valuable information that is lost by grouping total forest carbon sequestration under a single umbrella. Investigating the structural distribution of biomass production also holds potential to add invaluable detail to our understanding of the forest carbon cycle, as forest structure and disturbance has been hypothesized to significantly impact biomass dynamics (Pan et al. 2011, Gough et al. 2016, Holdaway et al. 2017).

Knowing when, where, and why carbon is distributed in forests is of vast practical value. Currently, over 860 trillion $\mathrm{kg}$ of carbon are stored in the world's forest ecosystems (Pan et al. 2011). This mass is of similar magnitude to carbon residing in the atmosphere, predominantly in the form of greenhouse gases like carbon dioxide and methane (Houghton 2007). Forests have remained a net sink of carbon over recent decades, sequestering from 1 - 3.5 trillion kg per year (Pan et al. 2011, Federici et al. 2015), and have been increasing in their rate of sequestration continuously over recent years (Le Quere et al. 2015). Along with oceans, forest ecosystems remove approximately 50-60\% of fossil fuels emitted to the atmosphere (Bousquet 2000, Goodale et al. 2001, Pan et al. 2011). The maintenance and growth of the forest sink is essential as a potential mitigator of greenhouse gas concentrations in the atmosphere, and can be a significant contribution to meeting international economic and management goals of carbon sink shares that are cheaper and simpler than other options (Tubiello et al. 2015, Grassi et al. 2017). In terms of carbon density, tropical forests account for much of the forest carbon sink (Pan et al. 2011), but rapid deforestation in tropical forests has offset the growth of this sink (Archard and House 2015). Alternatively, carbon sequestration rates in the eastern North America temperate forest region have been increasing in recent years (Goodale et al. 2001, Pacala et al. 2001, Woodbury et al. 2007). Recognizing this potential, much research has been directed towards understanding how forest management practices can maintain or increase the carbon sink of eastern U.S. temperate forests (Fahey et al. 2010, D'Amato et al. 2011, McKinley et al. 2011, Birdsey and Pan 2015, Ford and Keeton 2017).

In temperate forests, the majority of carbon resides in one of three pools: soils and woody debris, belowground plant parts (roots), and aboveground plant parts (trunk, branches, trees). Aboveground biomass is the most dynamic of these pools with potential for rapid carbon gains (Fahey et al. 2010). Studies using tree ring and periodic remeasurement census data estimate stand-level aboveground biomass accumulation in forests of the Midwest and Northeastern U.S. on the order of $1000-3000 \mathrm{kgC} / \mathrm{ha} / \mathrm{year}$ (Spetich and Parker 1998, Davis et al. 2010, Xu et al. 2012, Eisen and Barker Plotkin 2014, Foster et al. 2014, Woods 2014, Dye et al. 2016). If the aboveground biomass dynamics of these forests remain active, they can contribute significantly towards continued atmospheric carbon offsets. Empirical evidence of eastern U.S. old growth 
forests shows a wide array of observed biomass accumulation trajectories, including continued accumulation in centuries-old stands (Keeton et al. 2011). Secondary forests have been estimated to contain on average $107,000 \mathrm{~kg} / \mathrm{ha}$ of aboveground biomass (Birdsey and Lewis 2003), with potential to reach maximum values of $250-450,000 \mathrm{~kg} / \mathrm{ha}$ observed in old growth forests (Keeton 2011, Woods 2014, McGarvey et al. 2015). Studies show biomass accumulation of individual trees has potential to continue with increasing tree size, facilitating carbon sequestration for hundreds of years (Sillett et al. 2010, Stephenson et al. 2014, Trotsiuk et al. 2016, Gray 2016, Foster et al. 2016). These numbers indicate potentially significant carbon gains in future years and highlight the importance of definining the structural distribution of biomass growth.

Site-specific studies in the eastern U.S. have shown that the structural distribution of live aboveground biomass is heavily skewed towards the largest trees in secondgrowth (Shuster et al. 2008, Eisen and Barker Plotkin 2016) and old growth forests (Woods 2007, Woods 2014, McGarvey et al. 2015), despite being outnumbered by smaller trees. Additional work suggests that large trees may also sequester carbon at a higher rate than small trees (Trotsiuk et al. 2016, Foster et al. 2016). The significance of large, massive trees for aboveground live carbon storage has been studied globally, but most research has targeted relatively undisturbed forests with bias to the Amazon and northwestern North America (Stegen et al. 2011, Lutz et al. 2012, Slik et al. 2013, Fauset et al. 2015). Temperate forests of the eastern U.S., however, exhibit a wide range of structural characteristics, disturbance histories, and successional development and the structural dynamics of biomass and biomass growth may varies across the forest region. This diversity, combined with high future carbon sequestration potential, demands continued study into forest carbon dynamics of temperate forests.

Here, we use 42 years of dendroecological reconstructions of basal area increment (BAI) to quantify in detail the structural distribution of biomass growth across a network of 16 sites of differing stand age, species composition, stand-level productivity, and disturbance history in the eastern U.S. temperate forest. Because of their unqique spatial and temporal resoultion, dendroecological methods have been shown to be informative and reliable indicators of biomass growth (Davis et al. 2009, Xu et al. 2009, Babst 2014a, Babst et al. 2014b). Additionally, we duplicate our analyses using plot-level data from 34,445 United States Forest Service Forest Inventory and Analysis (FIA) remeasurement plots that are representative of the forest types across the eastern U.S.. To our knowledge, no studies have presented a comprehensive synthesis of the interannual variabillity of the structural distribution of biomass growth across the eastern U.S. temperate forest region. Overall, we are interested in a single overarching question: where, structurally, does biomass growth occur in eastern U.S. forests? Specifically, I support this question by investigating the following hypotheses:

1) The frequency distribution of tree diameters and the distribution of diameters weighted by BAI are statistically identical for our sampled sites. If they are identical, this suggests that the structural distribution of BAI occurs in proportion to the number of trees. Alternatively, there could be disproportionate growth of either big or small trees.

2) Results from hypothesis 1 for our sampled data are identical to highly replicated USFS FIA data that are representative of eastern U.S. forests. 
3) Over time, the slopes of the mean tree diameter and mean tree diameter weighted by BAI are identical. This hypothesis asks whether the difference in both distributions remains constant over time. Alternatively, productivity of big trees is increasing faster (slope of mean diameter weighted by BAI is steeper than mean diameter) or slower (slope of mean diameter is steeper than slope of mean diameter weighted by BAI).

\section{METHODS}

\section{Study Sites}

We included data from circular mapped sampling plots at 17 sites across the eastern United States (Figure 1). Site characteristics, sampling design and references are presented in Table 1. All sites were sampled between 2011-2016. For all sites, we used a variation of a mapped-style sampling design, shown to be most successful in developing dendroecological reconstructions of biomass growth (Nehrbass-Ahles et al. 2014).

\section{Diameter and basal area increment reconstructions}

We took increment cores from all trees according to the sampling designs described in Table 1. When possible, we took 2-3 cores at breast height (approximately $1.4 \mathrm{~m}$ ) to minimize the effects of growth asymmetry. Using standard dendrochronological techniques, we measured annual growth rings to the nearest $0.001 \mathrm{~mm}$ and crossdated by species within a site. When we had multiple cores for a tree, we averaged the ring widths for all radii. We recorded tree diameter $(\mathrm{DBH})$ at time of sampling in the field. By subtracting the ring width in the previous year from the recorded diameter, we retroactively estimated past diameters for each tree. Since all sites had a minimum sampling limit of $10 \mathrm{~cm}$ diameter, we stopped diameter reconstructions for a tree once it became less than $10 \mathrm{~cm}$.

We calculated basal area of each tree using our annually reconstructed diameters. To obtain basal area increment, we then subtracted the basal area in the previous year from basal area in the current year (Davis et al. 2009, Dye et al. 2016). All individual-tree annual increments are presented in units of $\mathrm{cm}^{2}$. Dendroecological methods are ideal for extending the temporal resolution by providing long-term, annual data and are frequently employed to study forest productivity (Davis et al. 2009, Babst et al. 2014b, Dye et al. 2016). Basal area growth is a good metric of aboveground stem productivity because it represents area instead of diameter growth (Babst et al. 2014a), while also avoiding the tenuous assumptions and uncertainties associated with using allometric equations to predict biomass (Fatemi et al. 2011).

\section{FIA dataset}

We included United States Forest Service Forest Inventory and Analysis (FIA) remeasurement data (apps.fs.usda.gov/fia/datamart, accessed Nov. 11 2016) to assess how representative our dataset is of eastern U.S. forests, despite extensive geographical gaps in our sites sampled and a bias towards hemlock-northern hardwood forest types. Although arguments could be made for several alternative definitions of eastern U.S. forests, we opted for a crude delineation based on state boundaries (Figure 1). This encompasses the majority of the range of most of the forest regions in which each of our sampled sites reside. 
A subset of the FIA trees have been remeasured more than once, and we extracted those trees with remeasurements between 2004 and 2014. Since there is not a comprehensive sampling schedule, all trees were not remeasured in the same years, nor were all trees remeasured the same amount of times. To deal with this, we extracted only the most recent remeasurement interval for each tree. In doing this, we degrade our information slightly by assuming that trees growing between 2004-2014 are experiencing similar environmental conditions. This is simply a first-pass attempt to judge whether our data are close to the FIA data. Sampling diameter and previous sampling diameter (if it was remeasured) are recorded by FIA (fia.fs.fed.us/library/database-

documentation/current/ver611

/FIADB_User_Guide_P2_6-1-1_final). FIA protocol inventories all stems $>2.5 \mathrm{~cm}$ diameter. For each county in the FIA, we calculated annual basal area increment of each tree by subtracting the basal area from the subsequent remeasurement and dividing by the number of intervening years.

\section{Size-related distribution of basal area increment}

For each site and year, we constructed two diameter distributions: tree frequency $\left(\mathrm{DBH}_{\mathrm{FREQ}}\right)$ and basal area increment $\left(\mathrm{DBH}_{\mathrm{BAI}}\right)$. $\mathrm{DBH}_{\mathrm{FREQ}}$ is simply the frequency distribution of tree sizes, while $\mathrm{DBH}_{\mathrm{BAI}}$ is the distribution of tree sizes weighted by BAI. Additionally, we constructed identical distributions for each FIA remeasurement plot $(\mathrm{n}=$ $34,445)$. In this paper, we considered diameters as the initial diameter at the beginning of the growing season, coupled with the subsequent BAI over the growing season.

\section{Temporal trends in $D B H_{F R E Q}$ and $D B H_{B A I}$}

Central tendency for both $\mathrm{DBH}_{\mathrm{FREQ}}$ and $\mathrm{DBH}_{\mathrm{BAI}}$ are characterized by the mean $\mathrm{DBH}$; for $\mathrm{DBH}_{\mathrm{FREQ}}$ this is simply the mean diameter, while $\mathrm{DBH}_{\mathrm{BAI}}$ is calculated as the BAI-weighted mean diameter. A mean $\mathrm{DBH}_{\mathrm{BAI}}$ greater than mean $\mathrm{DBH}_{\mathrm{FREQ}}$ indicates that larger trees are disproportionately productive, whereas equal mean $\mathrm{DBH}_{\mathrm{BAI}}$ and mean $\mathrm{DBH}_{\mathrm{FREQ}}$ indicates that all tree sizes are proportionally productive. Since there is a directional increase in tree size over time as trees grow, the mean diameters exhibit a positive trend. We quantify magnitudes of mean diameter trends for both $\mathrm{DBH}_{\mathrm{FREQ}}$ and $\mathrm{DBH}_{\mathrm{BAI}}$ as the slope of the linear regression equation: $\mathrm{DBH}=$ slope $($ Year $)+$ intercept. Comparisons of these trends will fit one of three categories: 1) Slope $\mathrm{DBH}_{\mathrm{BAI}}>$ slope $\mathrm{DBH}_{\mathrm{FREQ}}$, i.e. BAI becomes more concentrated in big trees over time; 2) Slope $\mathrm{DBH}_{\mathrm{BAI}}<$ slope $\mathrm{DBH}_{\mathrm{FREQ}}$, i.e. BAI becomes less concentrated in big trees and more concentrated in smaller trees over time; or 3) Slope $\mathrm{DBH}_{\mathrm{BAI}}=$ slope $\mathrm{DBH}_{\mathrm{FREQ}}$, i.e. the relationship between $\mathrm{DBH}_{\mathrm{FREQ}}$ and $\mathrm{DBH}_{\mathrm{BAI}}$ is constant over time. To test the null hypothesis that there is no difference in the slopes of the two lines, we used an analysis of covariance test between the linear regression lines for $\mathrm{DBH}_{\mathrm{FREQ}}$ and $\mathrm{DBH}_{\mathrm{BAI}}$ using the aov() function in $\mathrm{R}$ to test the null hypothesis that there is no difference in the slopes of the two lines.

\section{Equality of $D B H_{F R E Q}$ and $D B H_{B A I}$ distributions}

To accurately compare between sites, we first standardized the diameters of the trees at each site using a $\mathrm{z}$-score transformation where $\mathrm{z}=\left(\mathrm{DBH}_{\mathrm{i}}-\right.$ mean $\left.\left(\mathrm{DBH}_{\mathrm{i} \ldots . \mathrm{j}}\right)\right) / \mathrm{sd}\left(\mathrm{DBH}_{\mathrm{i} \ldots \mathrm{j}}\right)$. The standardized diameters have a new mean of zero; mean $\mathrm{DBH}_{\mathrm{FREQ}}$ is thus 0 . Mean $\mathrm{DBH}_{\mathrm{BAI}}$ is represented as the mean z-score weighted by 
BAI. The distance of mean $\mathrm{DBH}_{\mathrm{BAI}}$ from 0 provides a measure of the offset between $\mathrm{DBH}_{\mathrm{FREQ}}$ and $\mathrm{DBH}_{\mathrm{BAI}}$ that is comparable between sites. Similarly, I calculated standardized diameters for each of the FIA remeasurement plots included in this study, and calculated the mean $\mathrm{DBH}_{\mathrm{BAI}}$ for each plot. The distribution of all mean differences provides a highly replicated summary of this relationship across the Eastern U.S. forest to compare with our sampled dendroecological data. To statistically define the relationship between both means, I conducted a t-test of equality of means on each sampled site $(n=16$, only for final remeasurement period, 2011). Since the mean is only one estimate of the central tendency, I also conducted a Kolmogorov-Smirnov test for equality of the $\mathrm{DBH}_{\mathrm{FREQ}}$ and $\mathrm{DBH}_{\mathrm{BAI}}$ distributions. It is unlikely that two distributions with statistically different means will come from identical distributions, but two distributions with identical means could alternatively have differently shaped distributions. Significance levels for both the t-test and Kolmogorov-Smirnov test were adjusted with a Bonferonni correction to account for multiple comparisons across 16 sites.

\section{Basal area increment to size quartiles}

To better categorize the size-related distribution of basal increment, we divided our data into diameter size quartiles: Big, Upper Middle, Lower Middle, and Small. We divided into quartiles by ranked percentile rather than as a fixed diameter cutoff to account for the different sampling designs and diameter distributions across sites and years. This allows each year and site to have unique quartiles representative of its specific structural characteristics. Organizing size classes according to these criteria is subjective but gives us valuable information on the extremes (i.e. the upper $25 \%$ and lower $25 \%$ represent the exceptionally large and small) while still retaining information on the midsize trees. The annual proportion of site-level BAI allocated to each quartile is calculated as the sum of the BAI of all trees in each quartile divided by the total BAI of all trees at the site.

\section{RESULTS}

Size-related distribution of basal area increment

Histograms of raw-data, non-standardized $\mathrm{DBH}_{\mathrm{FREQ}}$ and $\mathrm{DBH}_{\mathrm{BAI}}$ for the final growth interval, 2011, show that $\mathrm{DBH}_{\mathrm{BAI}}$ is skewed to the right of $\mathrm{DBH}_{\mathrm{FREQ}}$ for all 16 sampled sites (Figure 2; Supplemental Gifs A and B). The shape of $\mathrm{DBH}_{\mathrm{BAI}}$ as well as the relationship between $\mathrm{DBH}_{\mathrm{BAI}}$ and $\mathrm{DBH}_{\mathrm{FREQ}}$ varies interannually - this variation is depicted as a series of animations (Supplemental Gifs A and B). Each of the 16 site animations cycles through 42 years (1970-2011) of changing $\mathrm{DBH}_{\mathrm{FREQ}}$ and $\mathrm{DBH}_{\mathrm{BAI}}$.

\section{Temporal trends in $D B H_{F R E Q}$ and $D B H_{B A I}$}

Slope of both mean $\mathrm{DBH}_{\mathrm{BAI}}$ and mean $\mathrm{DBH}_{\mathrm{FREQ}}$ are consistently positive from 1970-2011, indicative of the forward growth trajectory of forests over time (Figure 2; Supplemental Gifs A and B). Results of analysis of covariance indicate that slopes of mean $\mathrm{DBH}_{\mathrm{BAI}}$ and mean $\mathrm{DBH}_{\mathrm{FREQ}}$ are statistically different at all sites except Morgan Monroe and UMBS (Table 1). At both of these sites, the difference between mean $\mathrm{DBH}_{\mathrm{BAI}}$ and mean $\mathrm{DBH}_{\mathrm{FREQ}}$ remains constant over time, despite the positive slopes and growth trajectories. At most sites $(\mathrm{n}=12), \mathrm{DBH}_{\mathrm{BAI}}$ has a steeper slope than $\mathrm{DBH}_{\mathrm{FREQ}}$, indicating that mean $\mathrm{DBH}_{\mathrm{BAI}}$ and mean $\mathrm{DBH}_{\mathrm{FREQ}}$ are becoming more disparate over time, 
with increasing quanties of site-level BAI allocated to large trees. Alternatively, the slope of $\mathrm{DBH}_{\mathrm{FREQ}}$ is greater than $\mathrm{DBH}_{\mathrm{BAI}}$ at two sites (Gill Brook and Palmaghatt). At these sites, mean $\mathrm{DBH}_{\mathrm{BAI}}$ and mean $\mathrm{DBH}_{\mathrm{FREQ}}$ are also becoming more disparate over time; but, BAI is becoming increasingly less concentrated in large trees.

\section{Equality of $D B H_{F R E Q}$ and $D B H_{B A I}$ distributions}

Kolmogorov-Smirnov tests for equality of the $\mathrm{DBH}_{\mathrm{FREQ}}$ and $\mathrm{DBH}_{\mathrm{BAI}}$ distributions are significant for 12 of 16 sites after application of a Bonferroni correction to correct for multiple comparisons across the 16 sites (Table 2). T-tests for equality of means are statistically significant for the 2011 growth interval at all 16 sites, even after application of more stringent $\mathrm{p}$-values to account for multiple comparisons. This provides evidence that $D B H_{F R E Q}$ and $D B H_{B A I}$ are statistically different distributions. Standardized z-score transformed mean $D B H_{B A I}$ for the 2011 growth interval are presented in Table 2. Mean $\mathrm{DBH}_{\mathrm{BAI}}$ in 2011 ranges from a low of 0.32 at Palmaghatt to a high of 0.84 at Missouri Ozark. For the FIA remeasurement plots, the average mean $\mathrm{DBH}_{\mathrm{BAI}}$ is 0.48 for the most recent measurement interval (Figure 3). This is less than the average mean $\mathrm{DBH}_{\mathrm{BAI}}$ of 0.64 at the dendrochronological sites in 2011, but still indicates generally disproportionate production of big trees across the eastern United States (Figure 3). However, the variability of mean $\mathrm{DBH}_{\mathrm{BAI}}$ values at FIA plots is higher than our sampled data ( $\mathrm{sd}=0.43$ for FIA versus $\mathrm{sd}=0.15$ for sampled sites) and includes several plots with a negative mean $\mathrm{DBH}_{\mathrm{BAI}}$, indicating that disproportionate production of small trees can frequently still occur.

\section{Basal area increment to size quartiles}

On average, $45 \%$ of annual BAI was distributed to trees in the Big quartile, with $28 \%, 17 \%$, and $10 \%$ to the Upper Middle, Lower Middle, and Small quartiles, respectively (Table $\mathrm{C} 1$ ). Proportional growth of Big trees varies from a high of $58 \%$ on average at Huron Mt. Club-West to a low of 34\% on average at Gill Brook (Figure 4). At all sites, the highest percentage of basal area growth typically occurs in Big trees, followed by Upper Middle, Lower Middle, and Small (Figure 4, Table C1).

\section{DISCUSSION and CONCLUSIONS}

\section{Productivity is concentrated in large trees}

At each of our sampled sites, basal area increment is skewed towards the biggest trees at a site. Mean $\mathrm{DBH}_{\mathrm{BAI}}$ is clearly higher than mean $\mathrm{DBH}_{\mathrm{FREQ}}$ at all 16 sampled plots throughout the 1970-2011 study period (Figure 2, Supplemental Gifs A and B). Stated differently, when trees are grouped into size quartiles, approximately $30 \%-50 \%$ of total site-level BAI is allocated to trees in the Big quartile (Appendix B). Disproportionate production of big trees similar to the results we present are also shown in other studies: in a network of central European forest sites, 40\% of standing biomass in 2009 resided in the largest $20 \%$ of trees, while only $20 \%$ of standing biomass resided in the smallest $40 \%$ of trees (Babst et al. 2014); in a tropical Amazonia study, the largest 50\% of tree species contributed approximately $80 \%$ of total aboveground biomass increment (Fauset et al. 2015); in old-growth forests of the Mid-Atlantic, $60 \%$ of standing aboveground biomass was shown to reside in trees larger than $70 \mathrm{~cm}$ (McGarvey et al. 2015); in a pine-fir forest 
in California, big trees comprised less than $2 \%$ of stems but nearly $50 \%$ of biomass (Lutz et al. 2012); and size-growth relationships have been shown to exhibit asymmetric characteristics at western Canadian (Metsaranta and Leiffers 2010) and central European (Castagneri et al. 2012) forests. In the eastern U.S. specifically, remeasurement surveys have also shown significant quantities of both standing biomass and biomass increment concentrated in the largest trees (Schuster et al. 2008, Woods 2014, Eisen and Barker Plotkin 2015).

Collectively, these works suggest that big trees are major drivers of biomass dynamics in forests. In principle, this makes ecological sense since the largest diameter trees are typically the most dominant trees in a stand (Appendix A). In temperate forests with vertical stratification, dominant trees can preempt incoming light resources, increasing their growth relative to understory trees, while their higher mass, height, leaf area, and access to light facilitates potential for greater carbon storage and accumulation (Craine and Dybzinski 2013, Stephenson et al. 2014). Additionally, while diameter growth rate may decrease with tree size, mass growth can continue to increase as a tree gets bigger (Enquist et al. 1999, Sillett et al. 2010). In structurally diverse forests, such as those of the eastern U.S., big trees are capable of maintaining high levels of biomass growth for many years (Johnson and Abrams 2009, Foster et al. 2014), contrasting the age-related biomass growth decline observed experimentally in monospecific, even-aged stands (Binkley et al. 2002, Ryan et al. 2004). Globally, old-growth forests also may continue to maintain or increase biomass for hundreds of years as trees increase in size (Luyssaert et al. 2008, Stephenson et al. 2014). Some work has suggested that the successional status of a forest plays a role; in central European temperate forests, Trotsiuk et al. (2016) observed a steep increase of biomass growth in big trees in younger forests but a shallow increase in older forests, while in eastern U.S. forests Brown et al. (1997) found that the percent of standing biomass in big trees tends to increase with the age of the stand.

\section{Structural biomass dynamics of sampled sites vs. FIA plots}

Unlike our 16 sampled sites, the scale of the FIA dataset is fairly representative of the wide range of potential forest types across the eastern U.S (Jenkins et al. 2001). Using data from 34,445 remeasurement plots, we show that typically, these forests concentrate biomass in big trees (mean standardized $\mathrm{DBH}_{\mathrm{BAI}}=0.48$ ). This is slightly lower than the mean of 0.64 we found in our sampled data; additionally, the spread of site-level mean $\mathrm{DBH}_{\mathrm{BAI}}$ is much greater for the FIA plots than for our sampled data (Figure 3). While most FIA plots have a positive mean $\mathrm{DBH}_{\mathrm{BAI}}$, several have a negative mean $\mathrm{DBH}_{\mathrm{BAI}}$. A negative mean $\mathrm{DBH}_{\mathrm{BAI}}$ is indicative of higher concentrations of biomass growth in small, rather than big, trees. None of our sampled sites have a negative mean $\mathrm{DBH}_{\mathrm{BAI}}$, suggesting that they might not be entirely representative of the eastern U.S. temperate forest type.

FIA remeasurement plots in the Midwest and Northeastern U.S. are predominately in the 40-80 year age brackets (Pan et al. 2011). Typically, our sampled sites are older than the 40-80 year FIA average, with several second-growth stands in the 100-200 year age range $(\mathrm{n}=10)$, as well as old-growth forests greater than 200 years old $(n=6)$. In a comparison with identified old-growth forests, Brown et al. (1999) observed that FIA plots had at most $20 \%$ less biomass in trees over $70 \mathrm{~cm}$ than separately studied 
old-growth forests not in the FIA network. Most FIA plots had even less than $20 \%$, suggesting that the second-growth and old-growth successional stages present in our sampled plots are not the typical forest type represented by the FIA survey. The lack of late-successional forest stands in the FIA data has been suspected to contribute to an incomplete depiction of biomass dynamics in forest models that rely on FIA data (Gunn et al. 2014). From this standpoint, the additional site-specific detail on late-successional and old-growth stands at our 16 sampled sites is an invaluable contribution.

\section{Potential drivers of structural biomass dynamics}

As a whole, the uneven-aged forests of the eastern U.S. exhibit a variety of structural characteristics (Leak 1996, D'Amato et al. 2008). These structural characteristics are largely influenced by unique disturbance histories (D'Amato et al. 2008, Trotsiuk et al. 2016). In temperate forests, localized gap-scale disturbances tend to be more common than stand-replacing disturbances (Runkle 1982). As a result, these gap-scale disturbances diversify the structural composition of a forest stand, which can have long-lasting consequences for biomass growth dynamics (Holdaway et al. 2017). Following a disturbance, the rate of recovery in terms of carbon sequestration varies widely geographically (Pregitzer and Euskirchen 2004); in particular, forests of the northeastern U.S. have a wide variety of biomass trajectories, which can be especially dependent on disturbance and mortality (Keeton et al. 2011).

In part, the relationship between these fine-scale structural changes and biomass growth may relate to turnover dynamics. Incomplete representation of mortality in eastern temperate forests has been shown to complicate carbon modeling accuracy, since individual stands vary greatly in their site-specific turnover rates (Montane et al. 2017); others have proposed that many of the unknowns related to forest carbon dynamics can potentially be minimized by better defining site-level mortality (Friend et al. 2014). Currently, however, our understanding of how the forest structure created from local disturbances acts to influence biomass changes in eastern U.S. forests is limited (Gough et al. 2016). By defining where, structurally, biomass growth tends to occur, our data has potential to begin clarifying this issue. Further manipulations of this and similar datasets are well-suited to address complicated questions regarding the interaction of disturbance, mortality, structure, and biomass, with widespread implications for understanding and prediciting the size and fluctuations in the forest carbon cycle.

WORKS CITED 
Alexander, M.R. 2017a. Determining the role of stand structure in shaping climategrowth relationships in eastern temperate forests of the US. PhD dissertation, The University of Arizona.

Alexander, M.R., C.R. Rollinson, F. Babst, V. Trouet, and D.J.P. Moore. 2017b. Relative influences of multiple sources of uncertainty on cumulative and incremental treering-derived aboveground biomass estimates. Trees doi: 10.1007/s00468-0171629-0.

Archard, F., and J. House. 2015. Reporting carbon losses from tropical deforestation with pan-tropical biomass maps. Environmental Research Letters 10: 101002.

Babst, F., M.R. Alexander, P. Szejner, O. Bouriaud, S. Klesse, J. Roden, P. Cias, B. Poulter, D. Frank, D.J.P. Moore, and V. Trouet. 2014a. A tree-ring perspective on the terrestrial carbon cycle. Oecologia 176: 307-322.

Babst, F., O. Bouriaud, M.R. Alexander, V. Trouet, and D. Frank. 2014b. Toward consistent measurements of carbon accumulation: a multi-site assessment of biomass and basal area increment across Europe. Dendrochronologia 32: 153-161.

Binkley, D., J.L. Stape, M.G. Ryan, H.R. Barnard, and J. Fownes. 2002. Age-related decline in forest ecosystem growth: and individual-tree, stand-structure hypothesis. Ecosystems 5: 58-67.

Birdsey, R. and Y. Pan. 2015. Trends in management of the world's forests and impacts on carbon stocks. Forest Ecology and Management 355: 83-90.

Bousquet, P., P. Peylin, P. Cias, C. Le Quéré, P. Friedlingstein, and P.P. Tans. 2000. Regional changes in carbon dioxide fluxes of land and oceans since 1980. Science 290: 1342-1346.

Brown, S.L., P. Schroeder, and R. Birdsey. 1997. Aboveground biomass distribution of US eastern hardwood forests and the use of large trees as an indicator of forest development. Forest Ecology and Management 96: 37-47.

Brown, S.L., P. Schroeder, and J.S. Kern. 1999. Spatial distribution of biomass in forests of the eastern USA. Forest Ecology and Management 123: 81-90.

Castagneri, D., P. Nola, P. Cherubini, and R. Motta (2012). Temporal variability of sizegrowth relationships in a Norway spruce forest: the influence of stand structure, logging, and climate. Canadian Journal of Forest Research 42: 550-560

Craine, J.M. and R. Dybzinski (2013). Mechanisms of plant competition for nutrients, water, and light. Functional Ecology 27: 833-840. 
D'Amato, A.W., D.A. Orwig, and D.R. Foster. 2008. The influence of successional processes and disturbance on the structure of Tsuga canadensis forests. Ecological Applications 18: 1182-1199.

D’Amato, A.W., J.B. Bradford, S. Fraver, and B.J. Palik. 2011. Forest management for mitigation and adaptation to climate change: insights from long-term silviculture experiments. Forest Ecology and Management 262: 803-816.

Davis, S.C., Hessl, A.E., Scott, C.J. \& Adams, M.B. 2009. Forest carbon sequestration changes in response to timber harvest. Forest Ecology and Management 258: 2101-2109.

Dye, A., A. Barker Plotkin, D. Bishop, N. Pederson, B. Poulter, and A. Hessl. 2016. Comparing tree-ring and permanent plot estimates of aboveground net primary productivity in three eastern U.S. forests. Ecosphere 7: e01454.

Eisen, K. and A. Barker Plotkin. 2015. Forty years of forest measurements support steadily increasing aboveground biomass in a maturing, Quercus-dominant northeastern forest. Journal of the Torrey Botanical Society 142: 97-112.

Enquist, B.J., G.B. West, E.L. Charnow, and J.H. Brown. 1999. Allometric scaling of production and life-history variation in vascular plants. Nature 401: 907-911.

Fahey, T.J., P.B. Woodbury, J.J. Battles, C.L. Goodale, S.P. Hamburg, S.V. Ollinger, and C.W. Woodall. 2010. Forest carbon storage: ecology, management, and policy. Frontiers in Ecology and the Environment 8: 245-252.

Fauset, S., et al. 2015. Hyperdominance in Amazonian forest carbon cycling. Nature Communications 6 doi:10.1038/ncomms 7857.

Federici, S., F.N. Tubiello, M. Salvatore, H. Jacobs, and J. Schmidhuber. 2015. New estimates of CO2 forest emissions and removals: 1990-2015. Forest Ecology and Management 352: 89-98.

Forest Inventory and Analysis Database. Accessed Nov. 17 2016. U.S. Department of Agriculture, Forest Service, Northern Research Station, St. Paul, MN. apps.fs.fed.us/fiadb-downloads/datamart.

Foster, J.R., A.W. D'Amato, and J.B. Bradford. 2014. Looking for age-related growth decline in natural forests: unexpected biomass patterns from tree rings and simulated mortality. Oecologia 175 (1): 363-74.

Foster, J.R., A.O. Finley, A.W. D'Amato, J.B. Bradford, and S. Banerjee. 2016. Predicting tree biomass growth in the temperate-boreal ecotone: is tree size, age, competition, or climate response most important? Global Change Biology 22: 2138-2151. 
Ford, S.E. and W.S. Keeton. 2017. Enhanced carbon storage through management for old-growth characteristics in northern hardwood-conifer forests. Ecosphere $8: \mathrm{e} 01721$.

Friend, A.D., et al. 2014. Carbon residence time dominates uncertainty in terrestrial vegetation responses to future climate and atmospheric CO2. Proceedings of the National Academy of Science 111: 3280-3285.

Goodale, et al. 2002. Forest carbon sinks in the northern hemisphere. Ecological Applications 12: 891-899.

Gough, C.M., P.S. Curtis, B.S. Hardiman, C.M. Scheuermann, and B. Bond-Lamberty. 2016. Disturbance, complexity, and succession of net ecosystem production in North America's temperate deciduous forests. Ecosphere 7: e01375.

Grassi, G., J. House, F. Dentener, S. Federici, M. den Elzen, and J. Penman. 2017. The key role of forests in meeting climate targets requires science for credible mitigation. Nature Climate Change 7: doi 10.1038/NCLIMATE3227.

Gray, A.N., T.R. Whittier, and M.E. Harmon. 2016. Carbon stocks and accumulation rates in Pacific Northwest forests: role of stand age, plant community, and productivity. Ecosphere 7: e01224.

Gunn, J.S., M.J. Ducey, and A.A. Whitman. 2014. Late-successional and old-growth forest carbon temporal dynamics in the Northern Forest (Northeastern USA). Forest Ecology and Management 312: 40-46.

Grissino-Mayer, H.D. (2001). Evaluating cross-dating accuracy: a manual and tutorial for the computer program COFECHA. Tree Ring Research 57: 205-221.

Holdaway, R.J., T.A. Easdale, F.E. Carswell, S.J. Richardson, D.A. Peltzer, N.W.H. Mason, A.M. Brandon, and D.A. Coomes. 2017. Nationally representative plot network reveals contrasting drivers of net biomass change in secondary and oldgrowth forests. Ecosystems 20: 944-959.

Holmes, R.L. (1983). Computer-assisted quality control in tree-ring dating and measurement. Tree Ring Bulletin 43: 69-78.

Houghton, R.A. 2005. Aboveground forest biomass and th global carbon balance. Global Change Biology 11: 945-958.

Jenkins, J.C., R.A. Birdsey, and Y. Pan. 2001. Biomass and NPP estimation for the MidAtlantic region (USA) using plot-level forest inventory data. Ecological Applications 11: 1174-1193. 
Johnson, S.E., and M.D. Abrams. 2009. Age class, longevity, and growth rate relationships: protracted growth increases in old trees in the eastern United States. Tree Physiology 29: 1317-1328.

Keeton, W.S., A.A. Whitman, G.C. McGee, and C.L. Goodale. 2011. Late-successional biomass development in northern hardwood-conifer forests of the northeastern United States. Forest Science 57: 487-505.

Le Quéré, C., et al. 2015. Global carbon budget 2015. Earth System Science Data 7: 349396.

Leak, W.B. 1996. Long-term structural change in uneven-aged northern hardwoods. Forest Science 42: 160-165.

Lutz, J.A., A.J. Larson, M.E. Swanson, and J.A. Freund. 2012. Ecological importance of large-diameter trees in a temperate mixed-conifer forest. Plos One 7(5): e36131.

Luyssaert, S., E. -Detlef Schulze, A. Börner, A. Knohl, D. Hessenmöller, B.E. Law, P. Ciais, and J. Grace. 2008. Old-growth forests as global carbon sinks. Nature 455: 213-215.

McGarvey, J.C., J.R. Thompson, H.E. Epstein, and H.H. Shugart. 2015. Carbon storage in old-growth forests of the Mid-Atlantic: toward better understanding the eastern forest carbon sink. Ecology 96: 311-317.

McKinley, D.C., M.G. Ryan, R.A. Birdsey, C.P. Giardina, M.E. Harmon, L.S. Heath, R.A. Houghton, R.B. Jackson, and J.F. Morrison. 2011. A synthesis of current knowledge on forests and carbon storage in the United States. Ecological Applications 21: 1902-1924.

Metsaranta, J. and V. Leiffers (2010). Patterns of inter-annual variation in the size asymmetry of growth in Pinus banksiana. Oecologia 163: 737-745.

Montane, F., et al. 2017. Evaluating the effect of alternative carbon allocation schemes in a land surface model on carbon fluxes, pools and turnover in temperate forests. Geoscientific Model Development 10: 3499-3517.

Nehrbass-Ahles, C., F. Babst, S. Klesse, M. Notzli, O. Bouriaud, R. Neukom, M. Dobbertin, and D. Frank. 2014. The influence of sampling design on tree-ring based quantification of forest growth. Global Change Biology 20: 2867-2885.

Pacala, S., et al. 2001. Consistent land- and atmosphere-based U.S. carbon sink estimates. Science 292: 2316-2320.

Pan, Y., J.M. Chen, R. Birdsey, K. McCullough, L. He, and F. Deng. 2011. Age structure and disturbance legacy of North American forests. Biogeosciences 8: 715-732. 
Pan, Y., et al. 2011. A large and persistent carbon sink in the world's forests. Science 333: 988-993.

Pregitzer, K. and E. Euskirchen. 2004. Carbon cycling and storage in world forests: biome patterns related to forest age. Global Change Biology 10: 2052-2077.

Runkle, J.R. 1982. Patterns of disturbance in some old-growth mesic forests of eastern North America. Ecology 63: 1533-1546.

Ryan, M.G., D. Binkley, J.H. Fownes, C.P. Giardina, and R.S. Senock. 2004. An experimental test of the causes of forest growth decline with stand age. Ecological Monographs 74: 393-314.

Schuster, W.S.F., K.L. Griffin, H. Roth, M.H. Turnbull, D. Whitehead, and D.T. Tissue. 2008. Changes in composition, structure, and aboveground biomass over seventysix years (1930-2006) in the Black Rock Forest, Hudson Highlands, southeastern New York State. Tree Physiology 28: 537-549.

Sillett, S. C. et al. 2010. Increasing wood production through old age in tall trees. Forest Ecology and Management. 259: 976-994.

Slik, J.W., et al. 2013. Large trees drive forest aboveground biomass variation in moist lowland forests across the tropics. Global Ecology and Biogeography 22: 12611271.

Spetich, M.A. and G.R. Parker. 1998. Distribution of biomass in an Indiana old-growth forest from 1926 to 1992. The American Midland Naturalist 139: 90-107.

Stephenson, N.L., et al. 2014. Rate of tree carbon accumulation increases continually with tree size. Nature 507: 90-93.

Trotsiuk, V., M. Svoboda, P. Weber, N. Pederson, S. Klesse, P. Janda, D. Martin-Benito, M. Mikolas, M. Seedre, R. Bace, L. Mateju, and D. Frank. 2016. The legacy of disturbance on individual tree and stand-level aboveground biomass accumulation and stocks in primary mountain Picea abies forests. Forest Ecology and Management 373: 108-115.

Tubiello, F.N., et al. 2015. The contribution of agriculture, forestry, and other land-use activities to global warming, 1990-2012. Global Change Biology 21: 2655-2660.

Woodbury, P.B., J.E. Smith, and L.S. Heath. (2007). Carbon sequestration in the US forest sector from 1990 to 2010. Forest Ecology and Management 241: 14-27.

Woods, K.D. 2007. Predictability, contingency, and convergence in late succession: slow systems and complex data sets. Journal of Vegetation Science 18: 543-554. 
Woods, K.D. 2014. Multi-decade biomass dynamics in an old-growth hemlock-northern hardwood forest, Michigan, USA. Peer J 2:e598.

Xu, C., M.H. Turnbull, D.T. Tissue, J.D. Lewis, R. Carson, W.S.F. Schuster, D. Whitehead, A.S. Walcroft, J. Li, and K. Griffin. 2012. Age-related decline of stand biomass accumulation is primarily due to mortality and not to reduction in NPP associated with individual tree physiology, tree growth or stand structure in a Quercus-dominated forest. Journal of Ecology 100: 428-400. 
Table 1. Site characteristics and sampling designs.

\begin{tabular}{|c|c|c|c|c|}
\hline Site, State & Forest Region $\%$ & Sampling design* & $\begin{array}{l}\text { Number } \\
\text { of trees }\end{array}$ & Reference \\
\hline $\begin{array}{l}\text { Duke } \\
\text { Hardwood, NC }\end{array}$ & Oak-pine & $\begin{array}{l}\text { Double nested, } \\
3 \text { plots }\end{array}$ & 59 & Alexander 2017a \\
\hline Gill Brook, NY & $\begin{array}{l}\text { Hemlock- } \\
\text { northern hardwood }\end{array}$ & $\begin{array}{l}\text { Triple nested, } \\
2 \text { plots }\end{array}$ & 153 & $\begin{array}{l}\text { N. Pederson, } \\
\text { unpublished }\end{array}$ \\
\hline Goose Egg, NY & $\begin{array}{l}\text { Hemlock- } \\
\text { northern hardwood }\end{array}$ & $\begin{array}{l}\text { Triple nested, } \\
3 \text { plots }\end{array}$ & 216 & $\begin{array}{l}\text { N. Pederson, } \\
\text { unpublished }\end{array}$ \\
\hline $\begin{array}{l}\text { Harvard Forest- } \\
\text { EMS, MA }\end{array}$ & $\begin{array}{l}\text { Hemlock- } \\
\text { northern hardwood }\end{array}$ & $\begin{array}{l}\text { Double nested, } \\
2 \text { plots }\end{array}$ & 145 & Dye et al. 2016 \\
\hline $\begin{array}{l}\text { Harvard Forest - } \\
\text { Lyford, MA }\end{array}$ & $\begin{array}{l}\text { Hemlock- } \\
\text { northern hardwood }\end{array}$ & $\begin{array}{l}\text { Double nested, } \\
3 \text { plots }\end{array}$ & 133 & Dye et al. 2016 \\
\hline Howland, ME & $\begin{array}{l}\text { Hemlock- } \\
\text { northern hardwood }\end{array}$ & $\begin{array}{l}\text { Double nested, } \\
3 \text { plots }\end{array}$ & 282 & Dye et al. 2016 \\
\hline $\begin{array}{l}\text { Huron Mt. Club- } \\
\text { Rush Lake, MI }\end{array}$ & $\begin{array}{l}\text { Hemlock- } \\
\text { northern hardwood }\end{array}$ & $\begin{array}{l}\text { All trees } \geq 10 \mathrm{~cm} \\
\text { DBH, } 216 \mathrm{~m} \\
\text { radius plots }\end{array}$ & 60 & A. Dye, unpublished \\
\hline $\begin{array}{l}\text { Huron Mt. Club- } \\
\text { West, MI }\end{array}$ & $\begin{array}{l}\text { Hemlock- } \\
\text { northern hardwood }\end{array}$ & $\begin{array}{l}\text { All trees } \geq 10 \mathrm{~cm} \\
\text { DBH, } 216 \mathrm{~m} \\
\text { radius plots }\end{array}$ & 79 & A. Dye, unpublished \\
\hline $\begin{array}{l}\text { Missouri Ozark, } \\
\text { MO }\end{array}$ & Oak-hickory & $\begin{array}{l}\text { Double nested, } \\
3 \text { plots }\end{array}$ & 95 & Alexander 2017a \\
\hline $\begin{array}{l}\text { Morgan } \\
\text { Monroe, IN }\end{array}$ & $\begin{array}{l}\text { Western } \\
\text { mesophytic }\end{array}$ & $\begin{array}{l}\text { Double nested, } \\
3 \text { plots }\end{array}$ & 69 & Alexander 2017a \\
\hline $\begin{array}{l}\text { Pisgah State } \\
\text { Park-North } \\
\text { Round Pond, } \\
\text { NH }\end{array}$ & $\begin{array}{l}\text { Hemlock- } \\
\text { northern hardwood }\end{array}$ & $\begin{array}{l}\text { Triple nested, } \\
3 \text { plots }\end{array}$ & 174 & $\begin{array}{l}\text { N. Pederson, } \\
\text { unpublished }\end{array}$ \\
\hline $\begin{array}{l}\text { Pisgah State } \\
\text { Park- Harvard } \\
\text { Tract, NH }\end{array}$ & $\begin{array}{l}\text { Hemlock- } \\
\text { northern hardwood }\end{array}$ & $\begin{array}{l}\text { Double nested, } \\
2 \text { plots }\end{array}$ & 249 & $\begin{array}{l}\text { N. Pederson, } \\
\text { unpublished }\end{array}$ \\
\hline $\begin{array}{l}\text { Ohio Oak } \\
\text { Openings, } \mathrm{OH}\end{array}$ & Beech-maple & $\begin{array}{l}\text { Double nested, } \\
2 \text { plots }\end{array}$ & 83 & Alexander 2017a \\
\hline Palmaghatt, NY & $\begin{array}{l}\text { Hemlock- } \\
\text { northern hardwood }\end{array}$ & $\begin{array}{l}\text { Triple nested, } \\
4 \text { plots }\end{array}$ & 140 & $\begin{array}{l}\text { N. Pederson, } \\
\text { unpublished }\end{array}$ \\
\hline $\begin{array}{l}\text { Rooster Hill, } \\
\text { NY }\end{array}$ & $\begin{array}{l}\text { Hemlock- } \\
\text { northern hardwood }\end{array}$ & $\begin{array}{l}\text { Triple nested, } \\
2 \text { plots }\end{array}$ & 167 & $\begin{array}{l}\text { N. Pederson, } \\
\text { unpublished }\end{array}$ \\
\hline UMBS, MI & $\begin{array}{l}\text { Hemlock- } \\
\text { northern hardwood }\end{array}$ & $\begin{array}{l}\text { Double nested, } \\
3 \text { plots }\end{array}$ & 161 & Alexander 2017a \\
\hline
\end{tabular}

*Sampling designs: If sampling design is unique to a site, it is described in the table. Otherwise, designs are one of the following: Triple nested for old-growth forests: Trees $\geq 10 \mathrm{~cm}$ within $10 \mathrm{~m}$ radius, $\geq 20 \mathrm{~cm}$ within $20 \mathrm{~m}$ radius, $\geq 30 \mathrm{~cm}$ within $30 \mathrm{~m}$ radius. Double nested in second-growth forests: Trees $\geq 10 \mathrm{~cm}$ within $10 \mathrm{~m}$ radius, $\geq 20 \mathrm{~cm}$ within $20 \mathrm{~m}$ radius. ${ }^{\%}$ Forest regions as defined by Braun 2001. 
Table 2. The slope of the trend line (with standard error) for mean $\mathrm{DBH}_{\mathrm{BAI}}$ and mean $\mathrm{DBH}_{\mathrm{FREQ}}$ over the period 1970-2011 for each of the 16 sampled sites. When slopes are significantly different ( $\mathrm{p}$-value $<0.05$ ), the larger slope is highlighted in bold.

Summaries of the 2011 size-related growth distributions are presented as the standardized mean $\mathrm{DBH}_{\mathrm{BAI}}$. Results of K-S test are presented as p-values. Significance was determined using a Bonferonni correction applied to account for the 16 duplicated tests. To maintain significance at an original $\alpha=0.05$, the p-value must be $<0.003$, or $16 / 0.05$. Significant sites are bolded in the table. Results for the t-test for equality of means are not shown because all tests are significant, even after correction for multiple comparisons.

\begin{tabular}{|c|c|c|c|c|c|}
\hline \multicolumn{4}{|c|}{$\begin{array}{c}\text { Temporal trends } \mathrm{DBH}_{\mathrm{BAI}} \text { and } \\
\text { DBH }_{\text {FREQ }}, 1970-2011\end{array}$} & \multirow[b]{2}{*}{$\begin{array}{l}\text { Standardized } \\
\text { Mean DBH }{ }_{\text {BAI }}\end{array}$} & \multirow[b]{2}{*}{$\begin{array}{l}\text { K-S test } \\
\text { p-values }\end{array}$} \\
\hline Site & $\begin{array}{l}\text { Slope } \\
\text { DBH }_{\text {BAI }}\end{array}$ & $\begin{array}{l}\text { Slope } \\
\text { DBH }_{\text {FREQ }}\end{array}$ & $\begin{array}{l}\mathrm{p}- \\
\text { value }\end{array}$ & & \\
\hline Duke Hardwood & $0.30(0.01)$ & $0.27(0.00)$ & 0.01 & 0.59 & 0.03 \\
\hline Gill Brook & $0.02(0.02)$ & $0.22(0.01)$ & 0.00 & 0.38 & 0.02 \\
\hline Goose Egg & $0.31(0.01)$ & $0.24(0.00)$ & 0.00 & 0.67 & $<0.003^{*}$ \\
\hline Harvard Forest-EMS & $0.24(0.01)$ & $0.2(0.00)$ & 0.00 & 0.50 & $<0.003^{*}$ \\
\hline $\begin{array}{l}\text { Harvard Forest- } \\
\text { Lyford }\end{array}$ & $0.23(0.01)$ & $0.2(0.00)$ & 0.00 & 0.65 & $<0.003^{*}$ \\
\hline Howland & $0.19(0.01)$ & $0.15(0.00)$ & 0.00 & 0.59 & $<0.003^{*}$ \\
\hline $\begin{array}{l}\text { Huron Mt. Club- } \\
\text { Rush Lake }\end{array}$ & $0.24(0.01)$ & $0.17(0.00)$ & 0.00 & 0.65 & \\
\hline Huron Mt. Club- & & & & & 0.004 \\
\hline West & $0.19(0.01)$ & $0.13(0.00)$ & 0.00 & 0.75 & $<0.003^{*}$ \\
\hline Missouri Ozark & $0.31(0.01)$ & $0.24(0.00)$ & 0.00 & 0.84 & $<0.003^{*}$ \\
\hline Morgan Monroe & $0.42(0.02)$ & $0.45(0.00)$ & 0.14 & 0.71 & $<0.003^{*}$ \\
\hline Ohio Oak Openings & $0.3(0.01)$ & $0.23(0.00)$ & 0.00 & 0.83 & $<0.003^{*}$ \\
\hline Palmaghatt & $0.09(0.02)$ & $0.23(0.00)$ & 0.00 & 0.32 & 0.05 \\
\hline $\begin{array}{l}\text { Pisgah State Park- } \\
\text { Harvard Tract }\end{array}$ & $0.25(0.01)$ & $0.19(0.00)$ & 0.00 & 0.58 & $<0.003^{*}$ \\
\hline $\begin{array}{l}\text { Pisgah State Park- } \\
\text { North Round Pond }\end{array}$ & $0.41(0.01)$ & $0.28(0.00)$ & 0.00 & 0.68 & $<0.003^{*}$ \\
\hline Rooster Hill & $0.26(0.01)$ & $0.2(0.00)$ & 0.00 & 0.82 & $<0.003^{*}$ \\
\hline UMBS & $0.18(0.01)$ & $0.19(0.00)$ & 0.48 & 0.64 & $<0.003^{*}$ \\
\hline Mean & 0.25 & 0.22 & - & 0.64 & \\
\hline
\end{tabular}




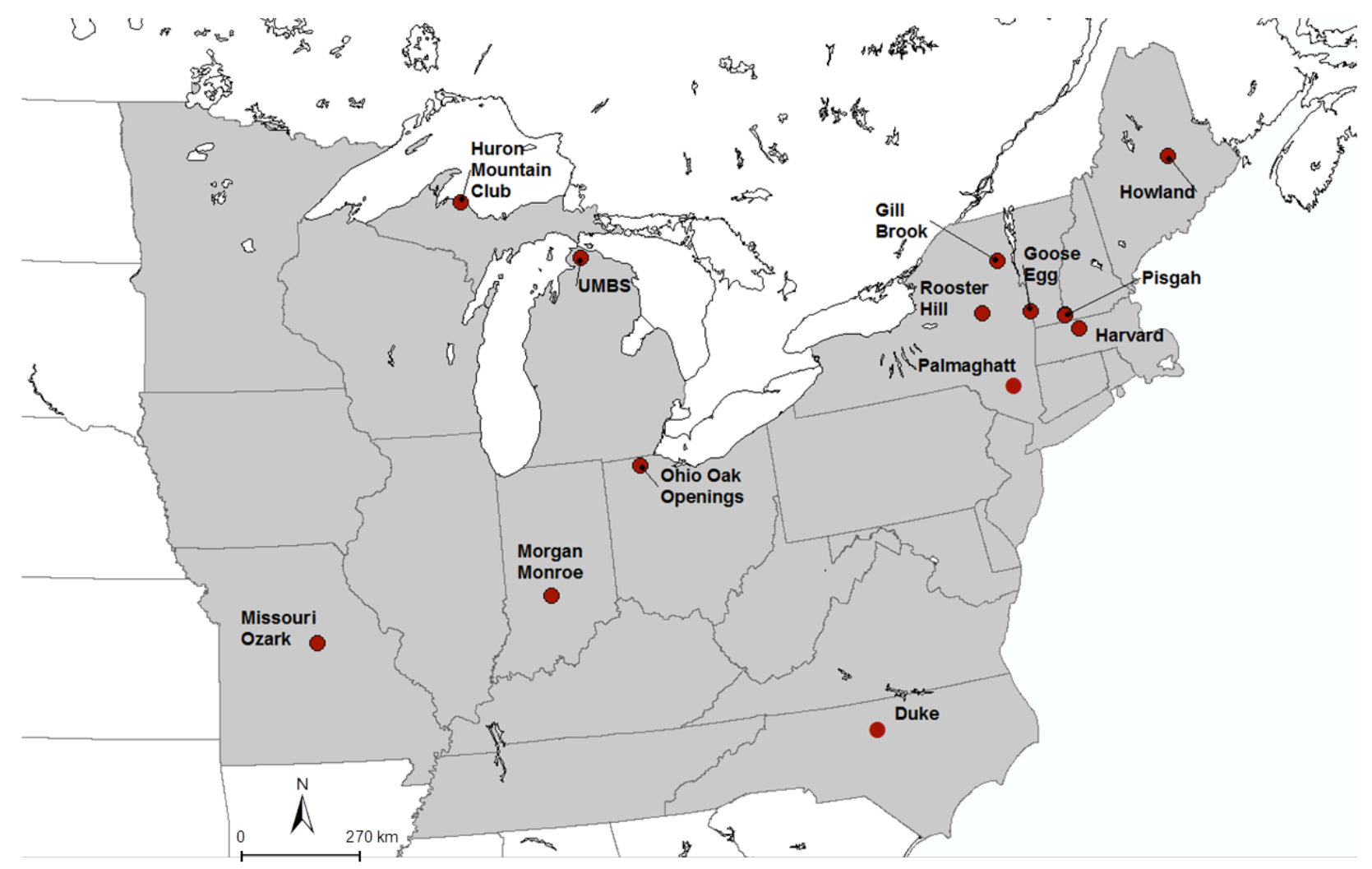

Figure 1. Map of the 16 sampled dendrochronological sites used in this study. Huron Mt. Club-Rush Lake and West are included in the "Huron Mountain Club" point; Pisgah State Park-North Round Pond and Harvard Tract are included in the "Pisgah" point; Harvard Forest-Lyford and EMS are included in the "Harvard" point. States from which we included FIA data are colored in gray. 
Figure 2. A) mean $\mathrm{DBH}_{\mathrm{FREQ}}$ (black) and $\mathrm{DBH}_{\mathrm{BAI}}$ (green) from 1970-2011. B) $\mathrm{DBH}_{\mathrm{FREQ}}$ and $\mathrm{DBH}_{\mathrm{BAI}}$ distributions in 2011 (5-year bins); black - tree count/bin, green - total BAI $\left(\mathrm{cm}^{2}\right) / \mathrm{bin}$. Vertical dashed lines match the final value for 2011 on the left graph. Temporal changes in the histograms are visualized in the attached "Supplemental Gifs A" and Supplemental Gifs B."

A)
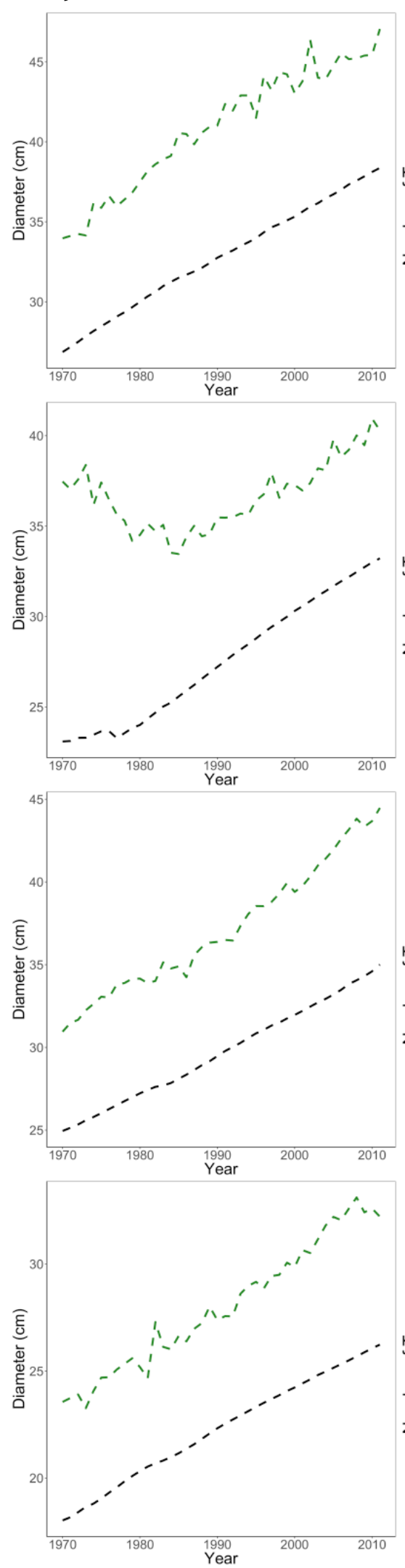

B)
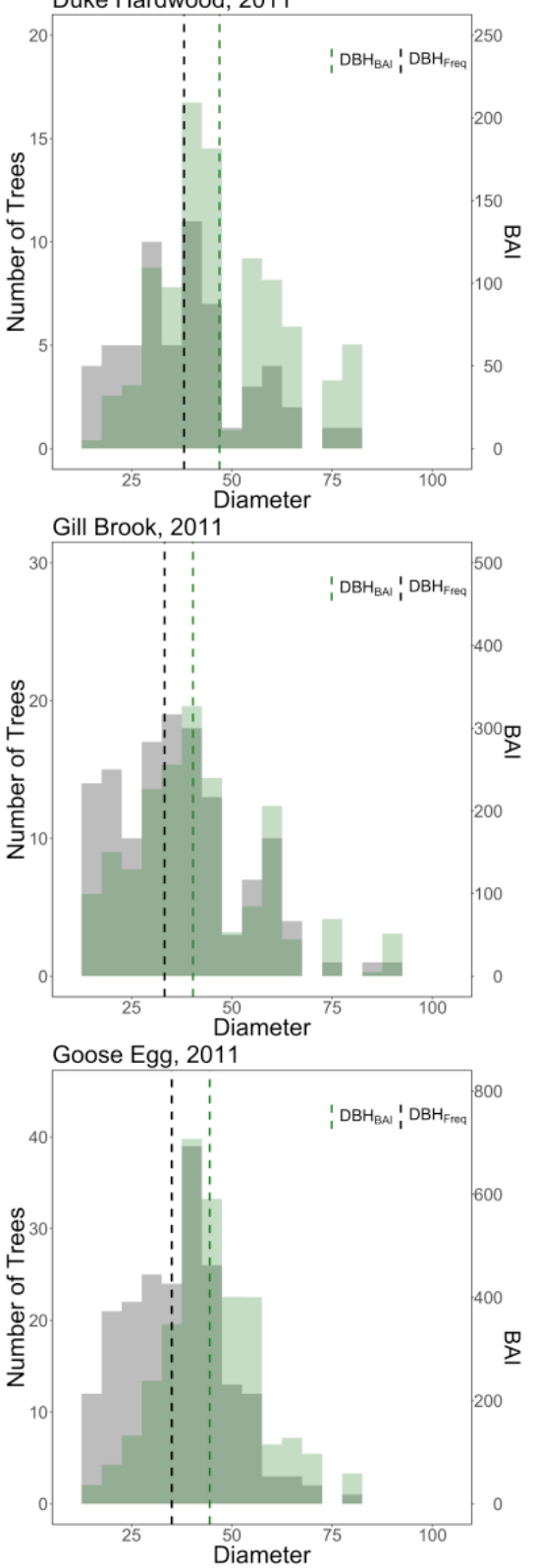

Harvard Forest-EMS, 2011

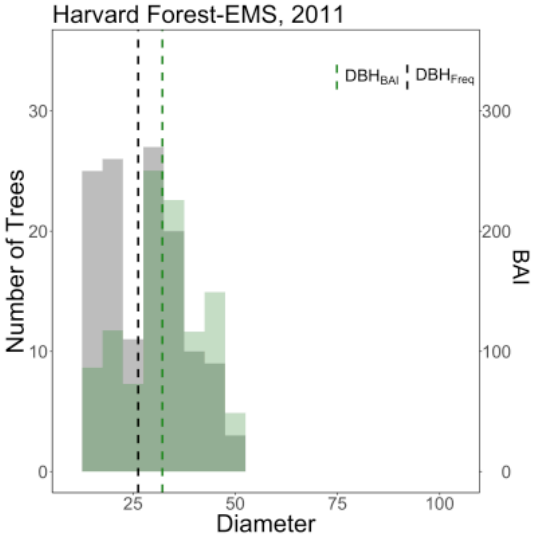


Figure 2 (cont.)

A)
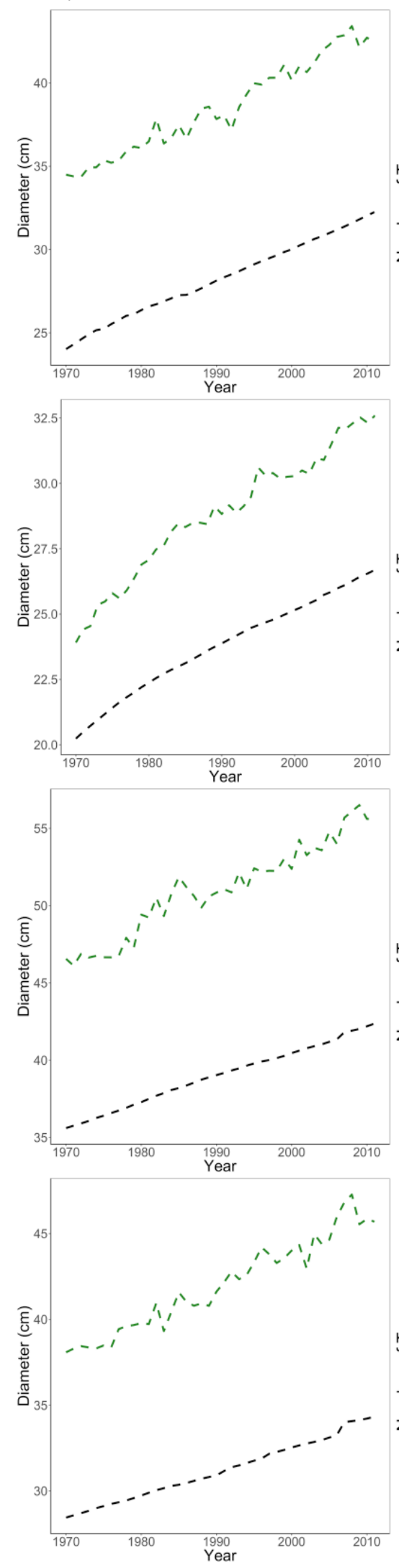

B)
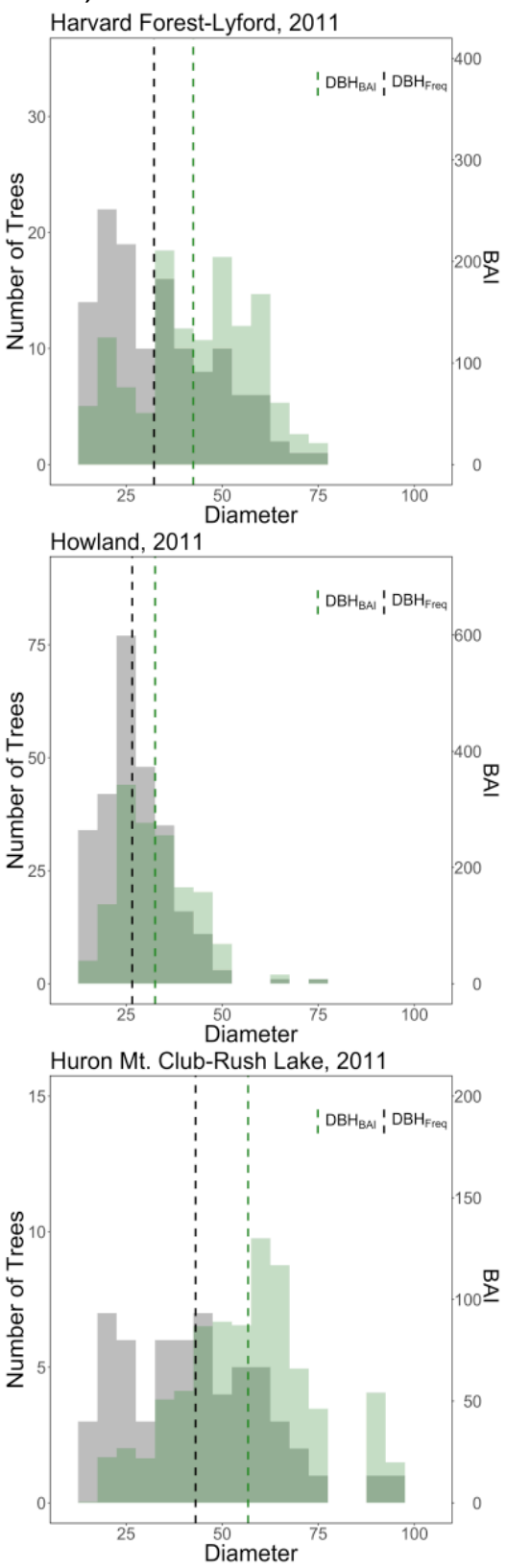

Huron Mt. Club-West, 2011

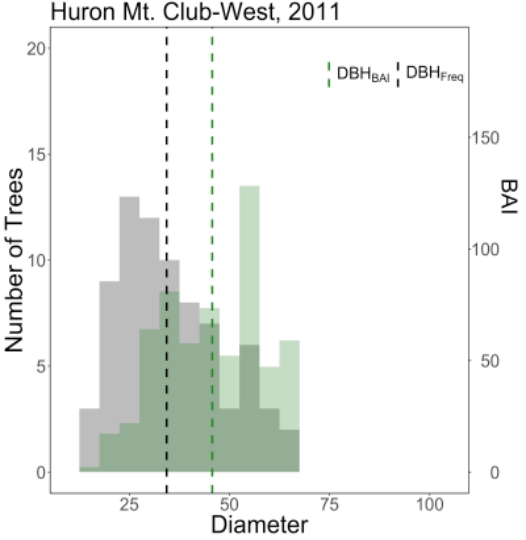


Figure 2 (cont.)

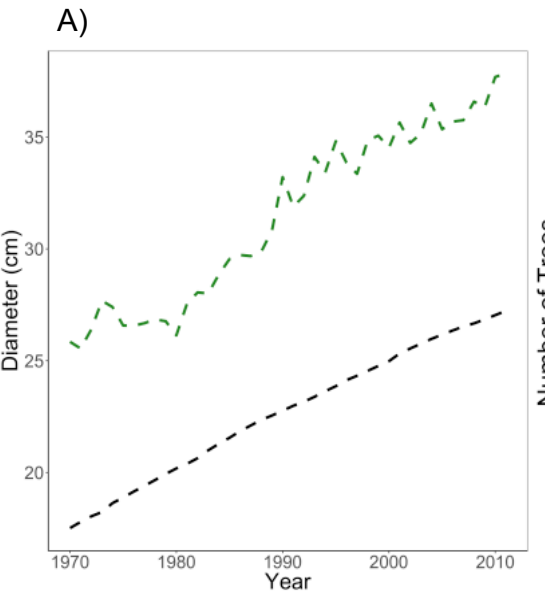

B)
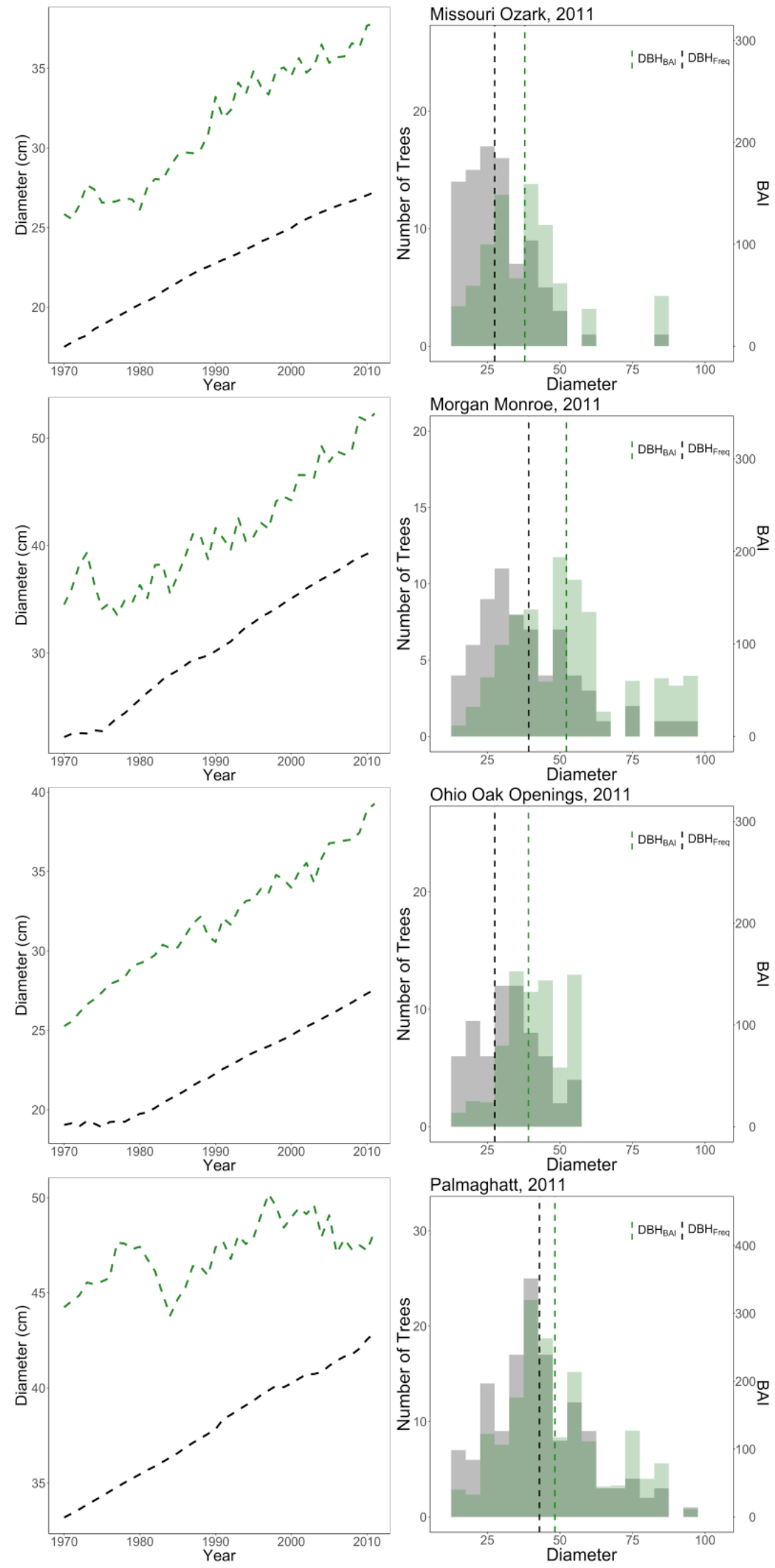
Figure 2 (cont.)

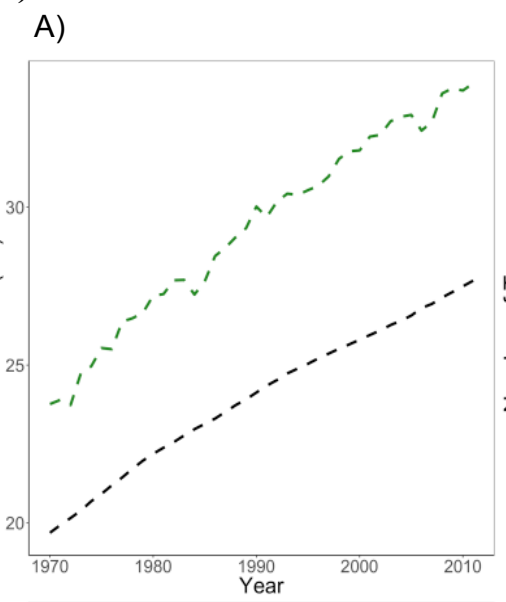

B)
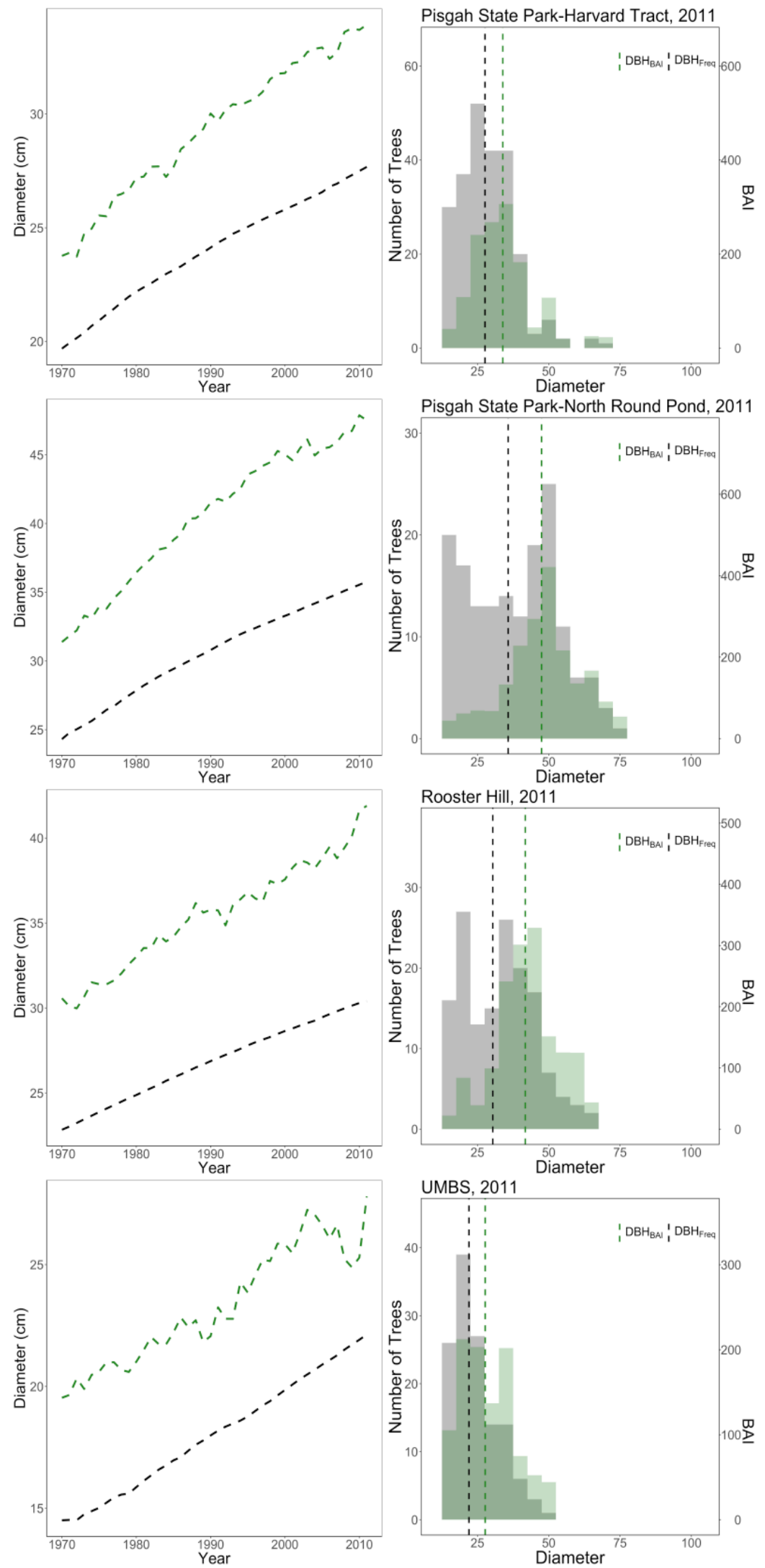


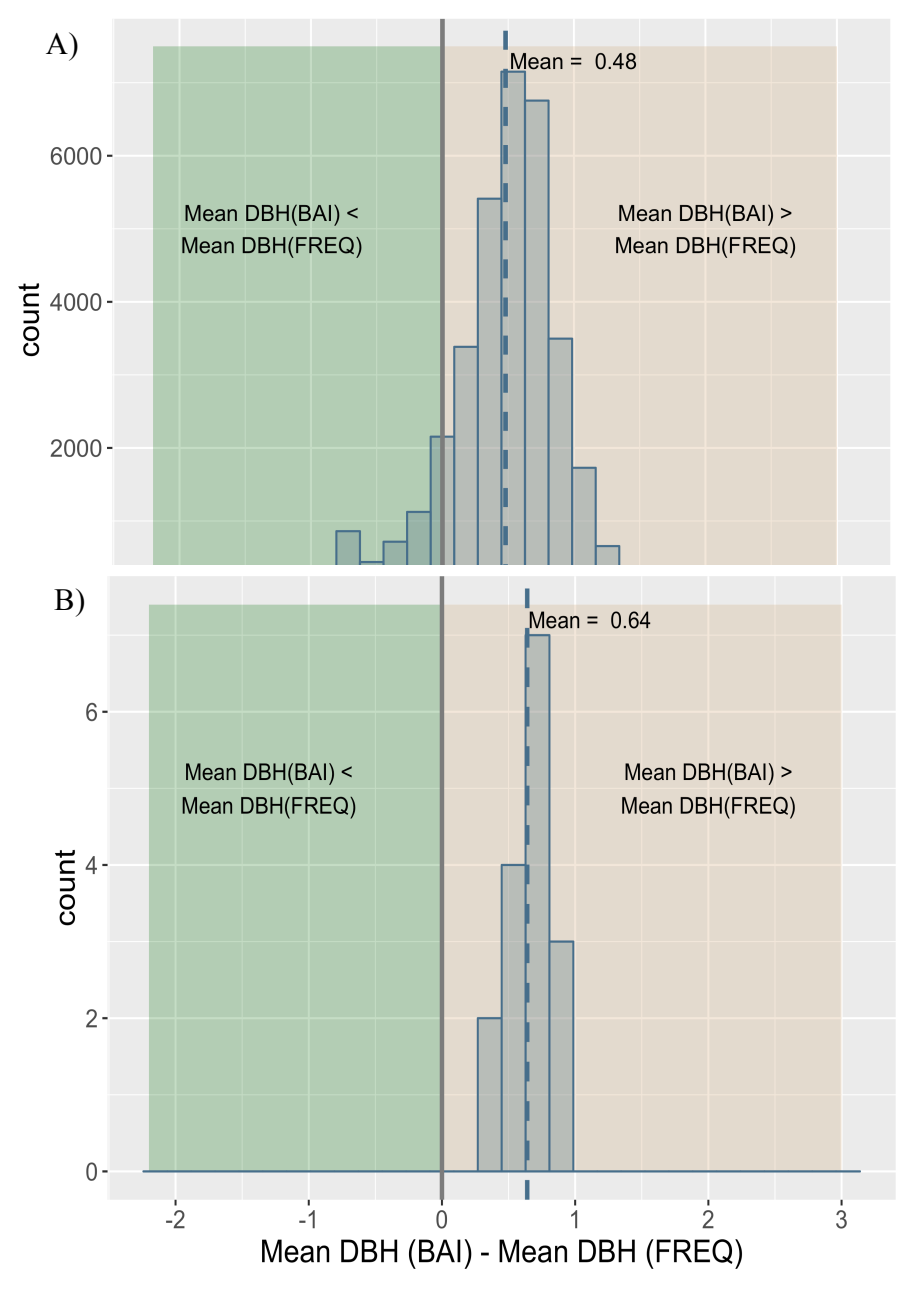

Figure 3. The distribution of standardized mean $\mathrm{DBH}_{\mathrm{BAI}}$ for a) 34,445 FIA plots from the eastern United States and b) 16 sampled dendrochronological sites in the year 2011. Mean presented as the vertical dashed line. No difference is indicated by the vertical gray line at "0". Mean $\mathrm{DBH}_{\mathrm{BAI}}$ exceeds mean $\mathrm{DBH}_{\mathrm{FREQ}}$ for sites to the right (disproportionate big tree growth), and mean $\mathrm{DBH}_{\mathrm{FREQ}}$ exceeds mean $\mathrm{DBH}_{\mathrm{BAI}}$ for sites to the right of 0 . 


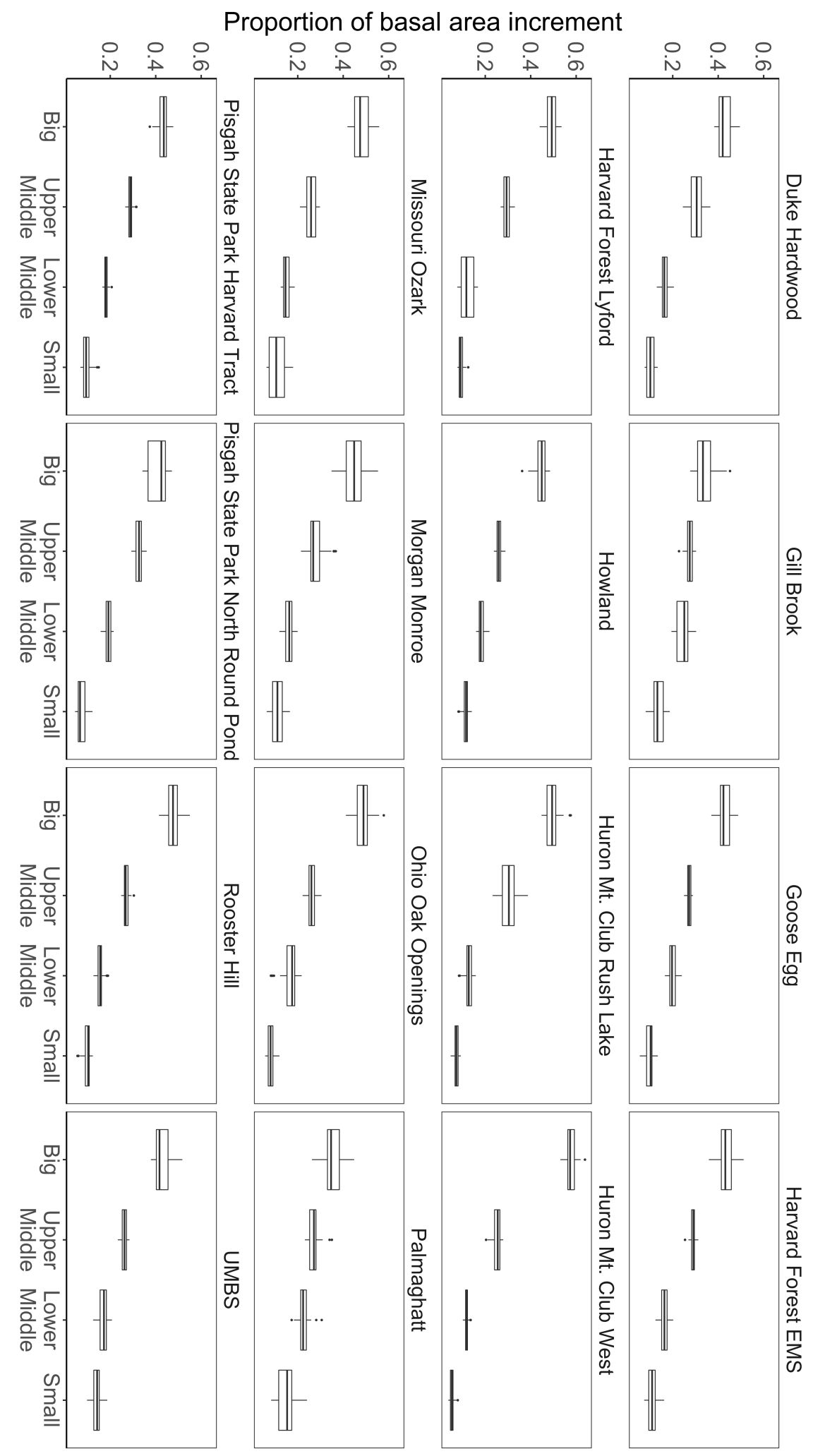

Figure 4. Site-level means and spread in the proportion of annual basal area growth allocated to each size quartile from 1970-2011. 


\section{Appendix A.}

Figure A1. The percent of Dominant, Codominant, Intermediate, and Suppressed trees within each diameter size quartile. This is a reference figure to show that typically, the biggest trees at a site are also canopy dominant or codominant.

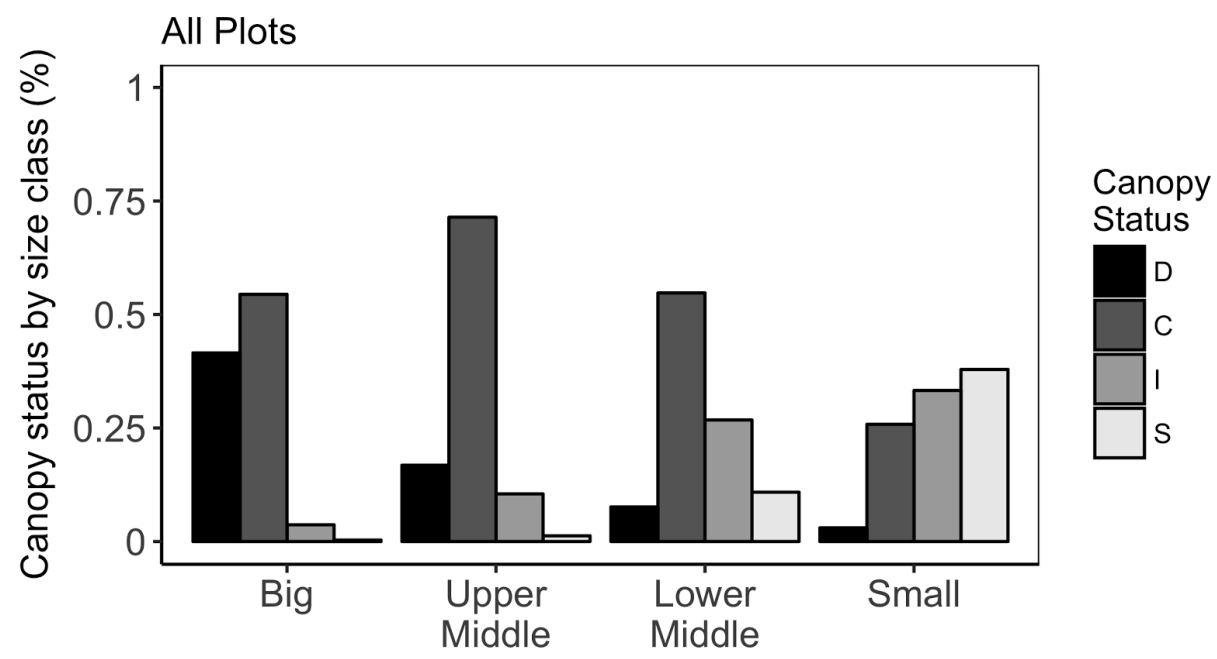


Appendix B. BAI quartile proportions by site, 1970-2011.

Figure B1. BAI proportions to (a) Big, (b) Upper Middle, (c) Lower Middle, and (d) Small quartiles

(a)

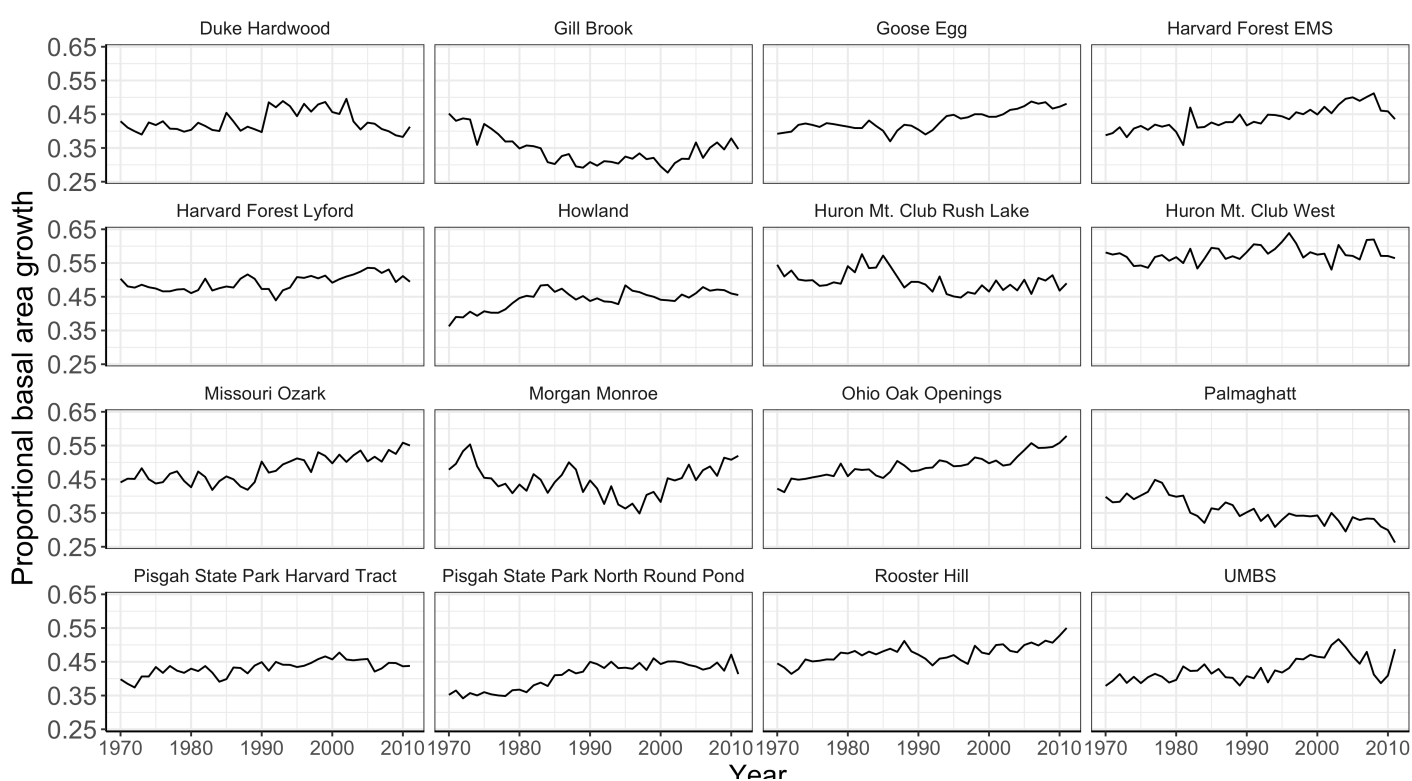

(b)

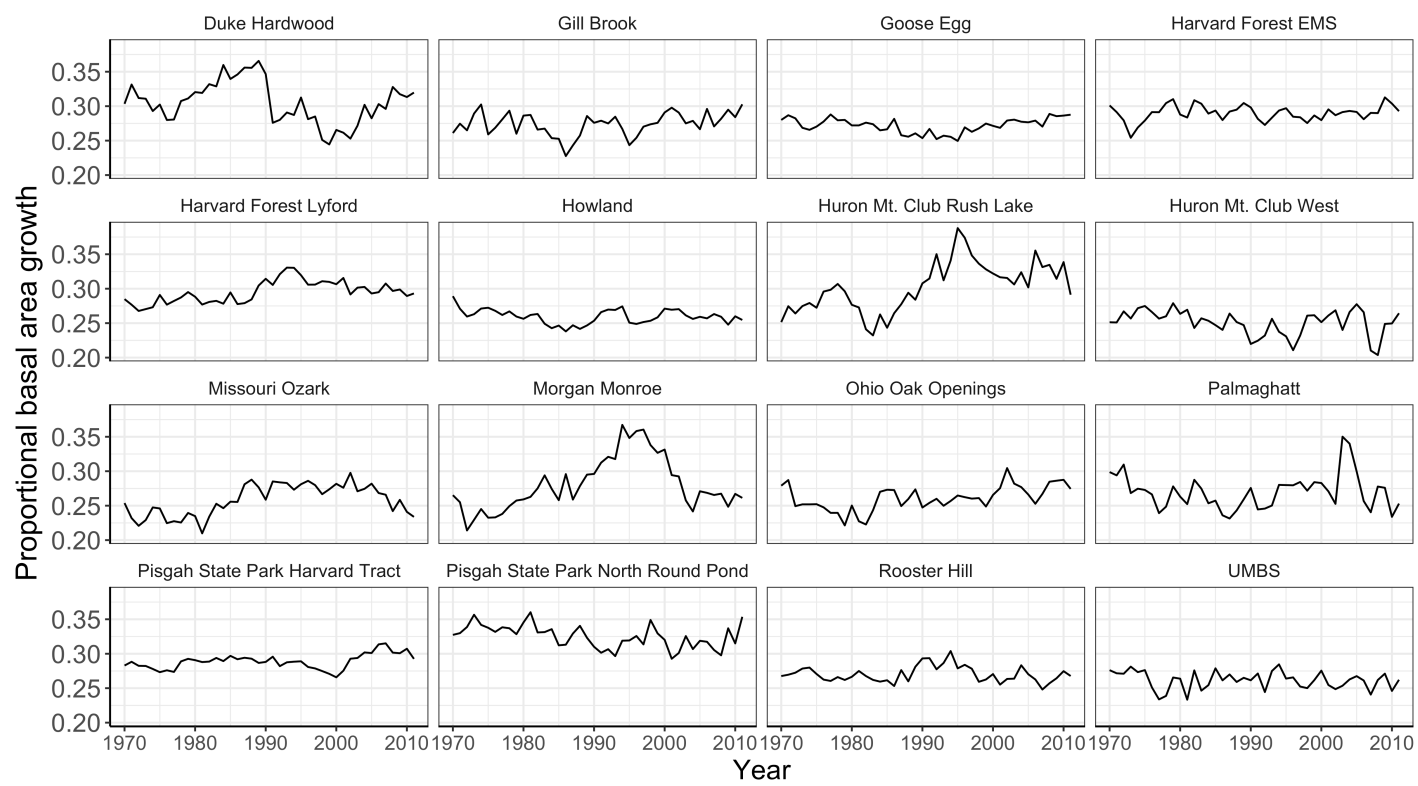




\section{Figure B1 (cont.)}

(c)

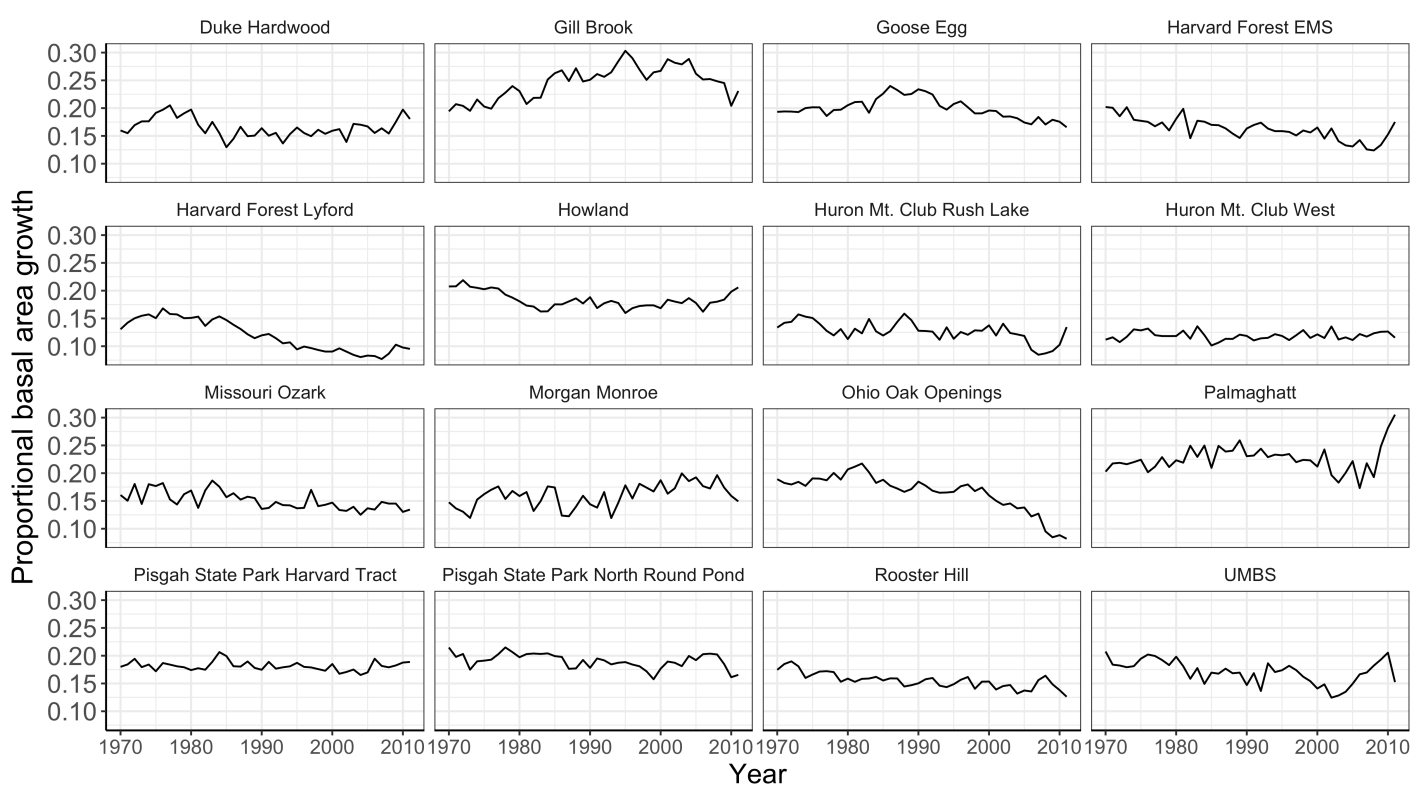

(d)

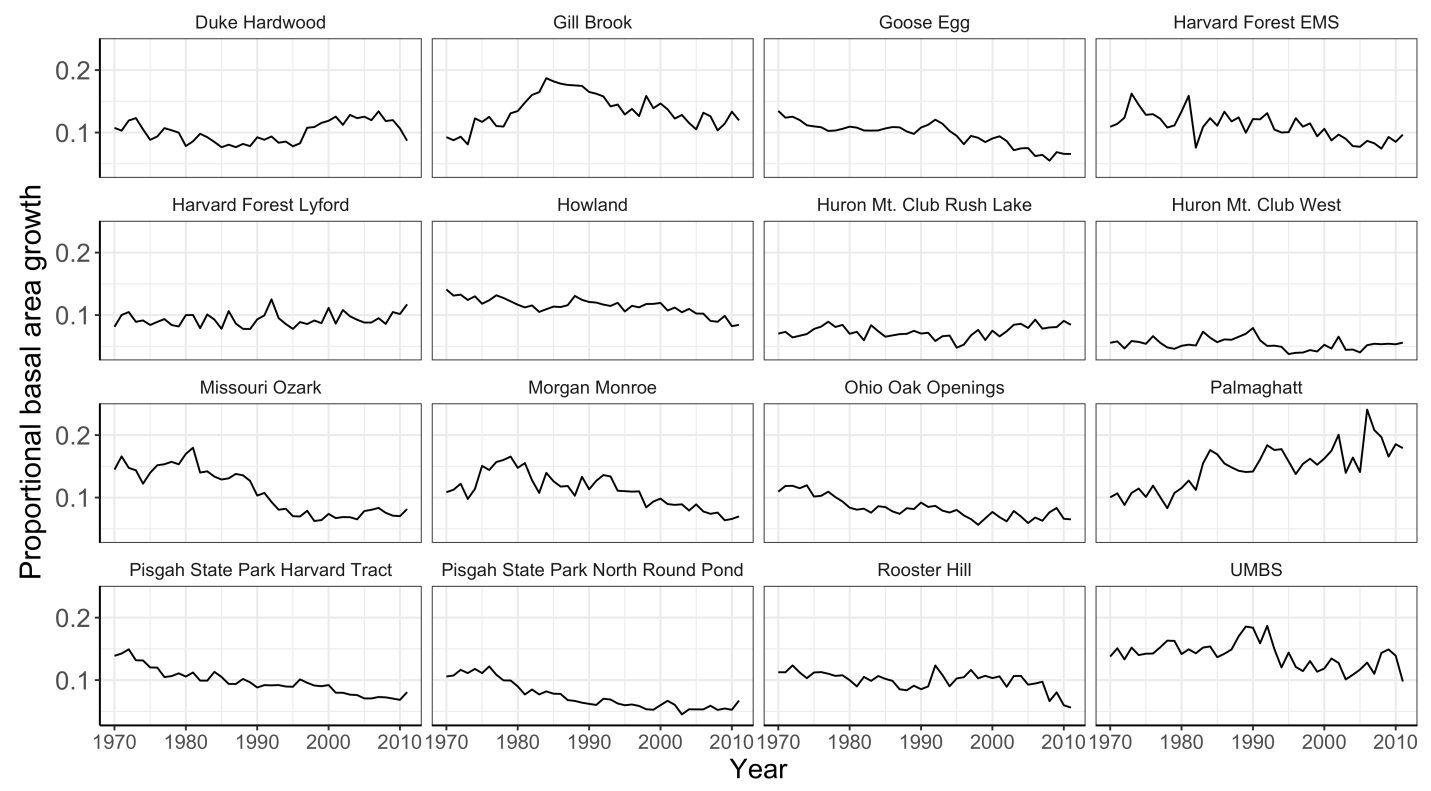


I further investigated the within- and between-site variability in the size-related distribution of productivity. Here, I present informative analyses that are not part of the primary manuscript to be submitted for publication.

I quantified within-site variability of the proportion of biomass growth to each size quartile using the coefficient of variation (CV) of all 42 annual values at a site. Because it is a unitless metric not influenced by the magnitude of the mean, the $\mathrm{CV}$ is a more informative indicator of variability between quartiles with dissimilar means. Between-site $(n=16)$ variability in proportional basal area growth is highest in the Small $(\mathrm{CV}=0.25)$ and Lower Middle $(\mathrm{CV}=0.22)$ quartiles, with less variability in the Upper Middle $(\mathrm{CV}=$ $0.07)$ and $\mathrm{Big}(\mathrm{CV}=0.13)$ quartiles (Table $\mathrm{C} 1)$. Within-site variability of annual proportions ( $\mathrm{n}=42$ years) is consistently highest in the Small size quartile for most sites (Figure C1). The exception is Harvard Forest-Lyford, where the Lower Middle is most variable.

I performed a Mann-Kendall test to identify the presence and direction of monotonic trends in the proportion of basal area increment to each size quartile from 1970-2011. For the full dataset, I first tested for trends in the mean proportional growth of each quartile over time. Second, I tested for trends in between-site variability (CV of all 16 sites), of each quartile over time. Additionally, I tested for trends in proportional growth of each quartile individually at all 16 sites. Since 1970, our dataset as a whole is allocating increasingly higher proportions of basal area growth to bigger trees (Figure $\mathrm{C} 2)$. The average proportional basal area growth allocated to Big $(\tau=0.67)$ and Upper Middle $(\tau=0.48)$ trees have each significantly increased, while Lower Middle $(\tau=-0.70)$ and Small $(\tau=-0.71)$ have significantly decreased. Individual sites tend to follow similar trends with some exceptions. Of the 13 sites that have a significant trend in proportional growth of Big trees, 10 are increasing while only 3 (Palmaghatt, Gill Brook, and Huron Mt. Club-Rush Lake) are decreasing (Table C1). Only 7 sites have a significant trend in the Upper Middle quartile, 6 of which are a positive trend. The lone exception is Pisgah State Park-North Round Pond $(\tau=-0.35)$. Site-level trends in the Upper Middle quartile tend to be weaker in general, which is also seen in the dataset as a whole (Figure C2). A significant trend is present in the Lower Middle quartile at 13 sites, all of which are decreasing with the exception of Gill Brook $(\tau=0.43)$. Proportional growth of the Small quartile is decreasing at 12 sites, with Palmaghatt the only site with an increasing trend in the Small quartile.

Between-site variability (CV) in annual basal area increment proportions has experienced a strong positive trend since 1970 for both Small $(\tau=0.57)$ and Lower Middle $(\tau=0.68)$ size quartiles (Figure C3). Variability in the Big quartile has been moderately increasing $(\tau=0.30)$, while variability in the Upper Middle quartile has remained more or less constant (Figure C3). 
Table C1. Mean proportion of BAI for each size quartile, with coefficient of variation (CV) across all annual values in parentheses. "Across-site" includes the mean and CV of all 16 sites presented in this dataset. Also listed are the results from the Mann-Kendall test for a monotonic trend over time. Positive tau values indicate positive trend from 1970-201; negative tau values indicate negative trend. Only significantly significant $(\mathrm{p}$-value $<0.05)$ trends were listed.

\begin{tabular}{|c|c|c|c|c|c|}
\hline \multicolumn{2}{|l|}{ Across sites } & Big & Upper Middle & Lower Middle & Small \\
\hline \multirow[t]{2}{*}{ Tree-ring } & Mean (CV) & $0.45(0.13)$ & $0.28(0.07)$ & $0.17(0.22)$ & $0.10(0.25)$ \\
\hline & Trend & 0.67 & 0.48 & -0.70 & -0.71 \\
\hline \multicolumn{6}{|l|}{ Within sites } \\
\hline \multirow{2}{*}{$\begin{array}{l}\text { Duke } \\
\text { Hardwood }\end{array}$} & Mean (CV) & $0.43(0.07)$ & $0.31(0.10)$ & $0.17(0.10)$ & $0.10(0.17)$ \\
\hline & Trend & -- & -- & -- & -- \\
\hline \multirow[t]{2}{*}{ Gill Brook } & Mean (CV) & $0.34(0.13)$ & $0.27(0.06)$ & $0.25(0.12)$ & $0.14(0.20)$ \\
\hline & Trend & -0.31 & -- & 0.43 & -- \\
\hline \multirow[t]{2}{*}{ Goose Egg } & Mean (CV) & $0.43(0.07)$ & $0.27(0.04)$ & $0.20(0.09)$ & $0.10(0.20)$ \\
\hline & Trend & 0.60 & -- & -0.31 & -0.70 \\
\hline \multirow{2}{*}{$\begin{array}{l}\text { Harvard } \\
\text { Forest (EMS) }\end{array}$} & Mean (CV) & $0.44(0.08)$ & $0.29(0.04)$ & $0.16(0.12)$ & $0.11(0.19)$ \\
\hline & Trend & 0.70 & -- & -0.63 & -0.53 \\
\hline \multirow{2}{*}{$\begin{array}{l}\text { Harvard } \\
\text { Forest (Lyford) }\end{array}$} & Mean (CV) & $0.49(0.05)$ & $0.30(0.05)$ & $0.12(0.24)$ & $0.09(0.12)$ \\
\hline & Trend & 0.43 & 0.39 & -0.72 & -- \\
\hline \multirow[t]{2}{*}{ HMC Rush Lake } & Mean (CV) & $0.50(0.06)$ & $0.30(0.12)$ & $0.13(0.14)$ & $0.07(0.14)$ \\
\hline & Trend & -0.29 & 0.46 & -0.41 & -- \\
\hline \multirow[t]{2}{*}{ HMC West } & Mean (CV) & $0.58(0.04)$ & $0.25(0.07)$ & $0.12(0.06)$ & $0.05(0.17)$ \\
\hline & Trend & -- & -- & -- & -- \\
\hline \multirow[t]{2}{*}{ Howland } & Mean (CV) & $0.44(0.07)$ & $0.26(0.04)$ & $0.18(0.08)$ & $0.11(0.11)$ \\
\hline & Trend & 0.43 & - & -0.23 & -0.62 \\
\hline \multirow{2}{*}{$\begin{array}{l}\text { Missouri } \\
\text { Ozark }\end{array}$} & Mean (CV) & $0.48(0.08)$ & $0.26(0.09)$ & $0.15(0.11)$ & $0.11(0.34)$ \\
\hline & Trend & 0.59 & 0.31 & -0.48 & -0.63 \\
\hline \multirow{2}{*}{$\begin{array}{l}\text { Morgan } \\
\text { Monroe }\end{array}$} & Mean (CV) & $0.45(0.11)$ & $0.28(0.14)$ & $0.16(0.13)$ & $0.11(0.25)$ \\
\hline & Trend & -- & 0.31 & -0.33 & -0.60 \\
\hline \multirow{2}{*}{$\begin{array}{l}\text { Ohio Oak } \\
\text { Openings }\end{array}$} & Mean (CV) & $0.49(0.07)$ & $0.26(0.07)$ & $0.17(0.20)$ & $0.08(0.21)$ \\
\hline & Trend & 0.77 & 0.39 & -0.68 & -0.64 \\
\hline \multirow[t]{2}{*}{ Palmaghatt } & Mean (CV) & $0.36(0.11)$ & $0.27(0.09)$ & $0.23(0.11)$ & $0.15(0.24)$ \\
\hline & Trend & -0.62 & -- & -- & 0.59 \\
\hline \multirow{2}{*}{$\begin{array}{l}\text { Pisgah (North } \\
\text { Round Pond) }\end{array}$} & Mean (CV) & $0.41(0.10)$ & $0.33(0.05)$ & $0.19(0.07)$ & $0.08(0.30)$ \\
\hline & Trend & 0.62 & -0.35 & -0.29 & -0.75 \\
\hline \multirow{2}{*}{$\begin{array}{l}\text { Pisgah } \\
\text { (Harvard Tract) }\end{array}$} & Mean (CV) & $0.43(0.05)$ & $0.29(0.04)$ & $0.18(0.05)$ & $0.10(0.21)$ \\
\hline & Trend & 0.51 & 0.28 & -- & -0.81 \\
\hline \multirow[t]{2}{*}{ Rooster Hill } & Mean (CV) & $0.48(0.06)$ & $0.27(0.04)$ & $0.16(0.09)$ & $0.10(0.15)$ \\
\hline & Trend & 0.55 & -- & -0.57 & -0.40 \\
\hline \multirow{2}{*}{$\begin{array}{l}\text { U. of Michigan } \\
\text { Biological Station }\end{array}$} & Mean (CV) & $0.43(0.08)$ & $0.26(0.05)$ & $0.17(0.12)$ & $0.14(0.15)$ \\
\hline & Trend & 0.45 & -- & -0.36 & -0.31 \\
\hline
\end{tabular}




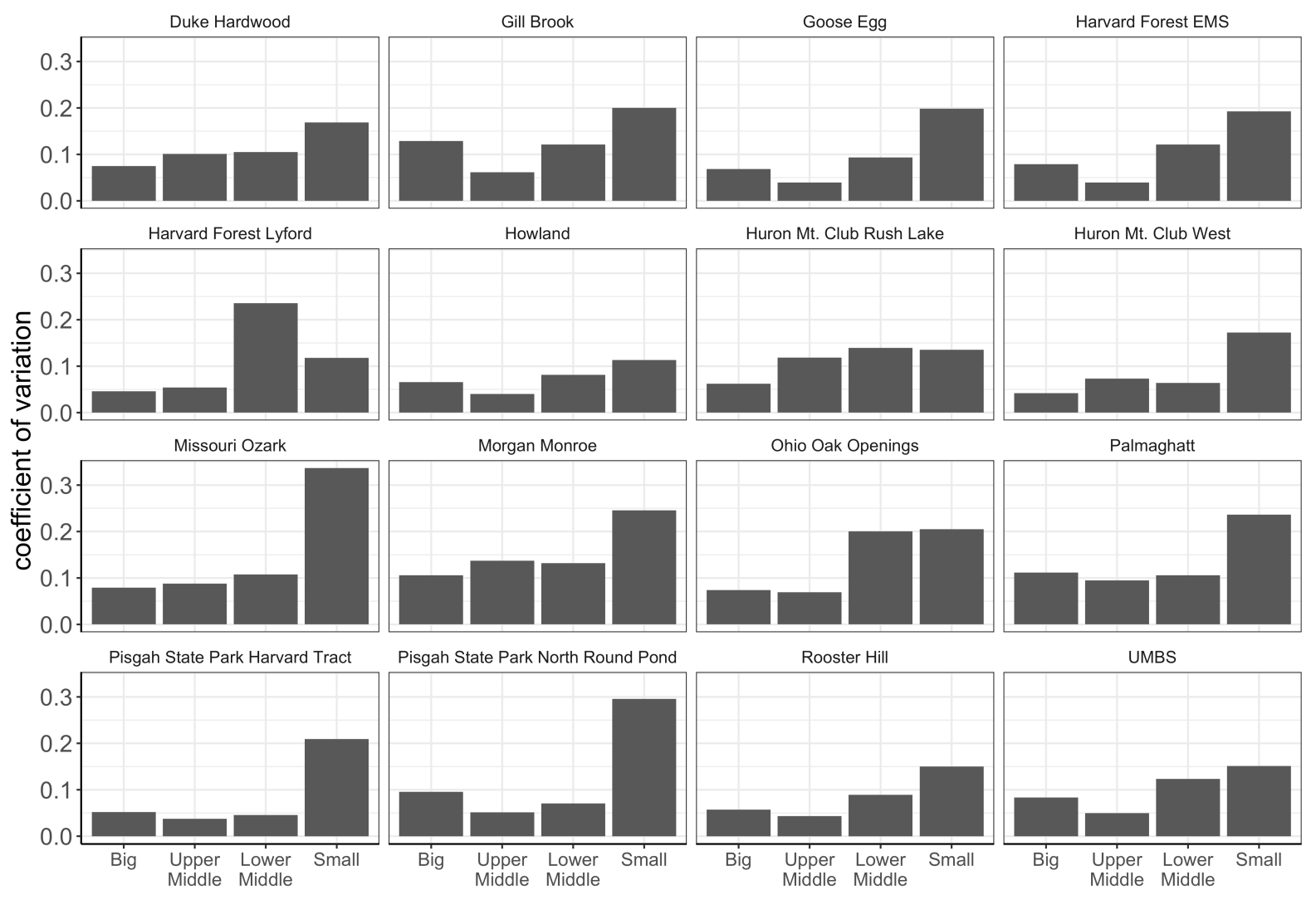

Figure C1. Within-site variability in the proportion of basal area growth to each size quartile, represented as the coefficient of variation. 


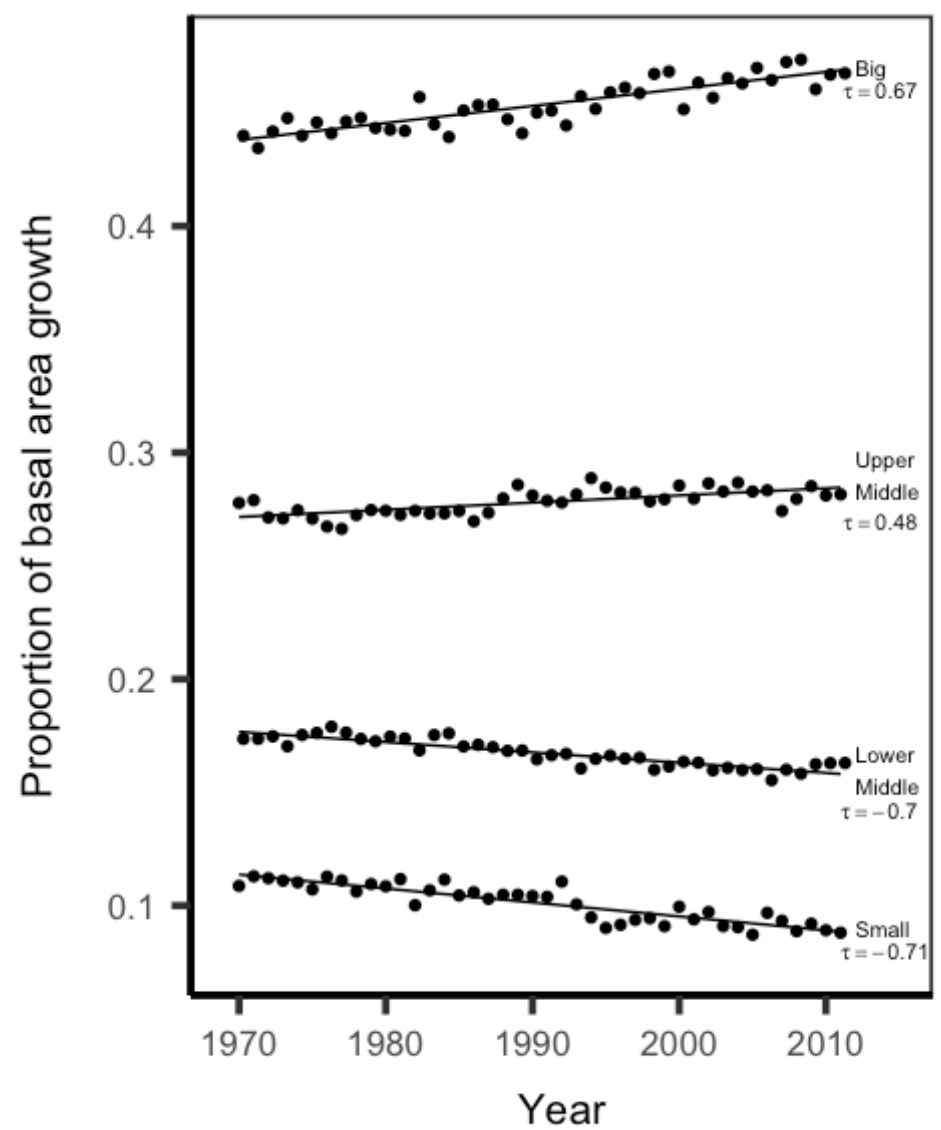

Figure C2. The proportion of basal area growth (17-site average) allocated to each size quartile from 1970-2011. Trend lines and tau values are included for quartiles that exhibit a significantly positive or negative trend over the study period, as determined by the Mann-Kendall test for monotonic trend.

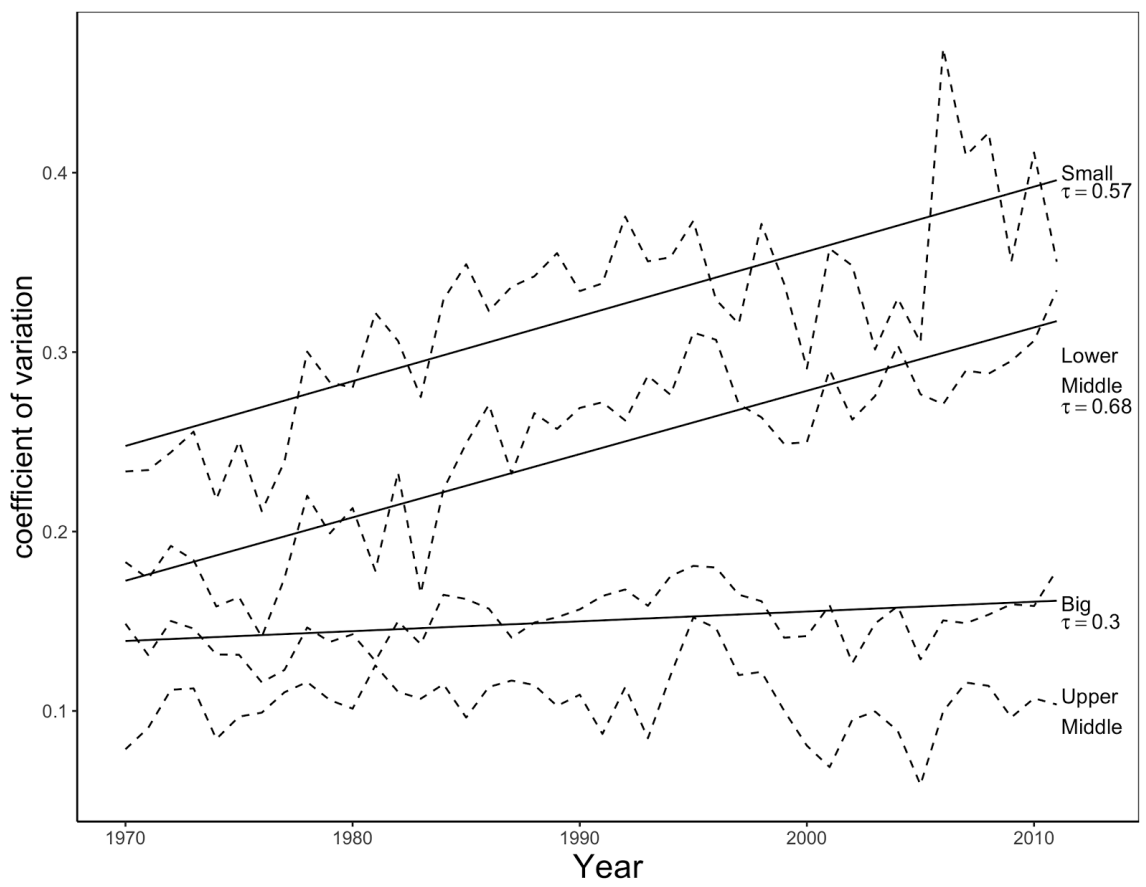

Figure C3. Between-site variability (coefficient of variation for 17 sites) in the proportion of basal area growth to each size quartile, 1970-2011. Trend lines and tau statistics are included for quartiles with a significantly positive or negative trend over the study period as determined by the Mann-Kendall test for monotonic trend in a time series. 
Chapter 3: Size-growth asymmetry is not consistently related to basal area growth across an eastern U.S. temperate forest network Alex Dye ${ }^{\dagger}$, M. Ross Alexander ${ }^{\ddagger}$, Daniel Bishop ${ }^{\ddagger}$, Daniel Druckenbrod ${ }^{\S}$, Amy Hessl ${ }^{\dagger}$, and Neil Pederson

${ }^{\dagger}$ Department of Geology and Geography, West Virginia University, Morgantown, WV 2

${ }^{\ddagger}$ Harvard Forest, Harvard University, Petersham, MA

${ }^{\psi}$ Department of Earth and Environmental Sciences, Columbia University, New York, NY

${ }^{\S}$ Department of Geological, Environmental, and Marine Sciences, Rider University, Lawrenceville, NJ

To be submitted to: Oecologia 


\begin{abstract}
Modeling and forecasting forests as carbon sinks requires that we understand the primary factors affecting productivity. One factor thought to be positively related to stand productivity is the degree of asymmetry, or the slope of the relationship between tree diameter and biomass growth. Steeper slopes indicate disproportionate productivity of big trees relative to small trees. Theoretically, big trees outcompete smaller trees during favorable growth conditions because they maintain better access to light. For this reason, high productivity forests are expected to have asymmetric growth. However, empirical studies do not consistently support this expectation, and those that do are limited in spatial or temporal scope. Here, we analyze size-growth relationships from 1970-2011 across a diverse network of Eastern U.S. sites $(n=16)$ to test whether asymmetry is consistently related to basal area growth. We conduct between-site analyses at nonoverlapping annual, 2-, 5-, 10-, and 20-year sampling intervals and find that asymmetry can be either positively, negatively, or unrelated to productivity depending on the specific interval considered. Most sites $(n=14)$ exhibit asymmetric growth (slope $>1$ ), although inverse asymmetry (slope $<1$ ) can emerge over longer sampling intervals. Additionally, within-site interannual variability in asymmetry and productivity are not consistently related, but isolated sites can have a significantly positive or negative relationship. Rather than confirm or refute the existence of a positive relationship between asymmetry and productivity, our findings suggest caution interpreting these metrics since the relationship may vary across forest types and temporal scales.
\end{abstract}

Keywords: temperate forests, dendroecology, growth asymmetry, basal area growth, biomass, carbon sequestration 


\section{INTRODUCTION}

Worldwide, forests store nearly as much carbon as resides in the atmosphere (Houghton 2007, Pan et al. 2011). There is potential to increase and manage the forest carbon sink, particularly in the temperate forests of eastern North America where carbon sequestration rates have been increasing in recent years (Woodbury et al. 2007). But, this requires a more complete understanding of the ecological conditions that are responsible for driving forest productivity (Urbano and Keeton 2017). One factor thought to be positively related to forest productivity is the degree of asymmetry, or the linear slope of the regression between tree diameter and growth, where a higher degree of asymmetry indicates disproportionate production of big trees relative to small trees (Weiner 1990, Schwinning and Weiner 1998). Because the degree of asymmetry uniquely couples forest structural characteristics with productivity, it has the potential to serve as a valuable tool to monitor and manage resources for carbon gain and model forest carbon dynamics. However, its efficacy as a reliable indicator of forest productivity remains unclear.

A large body of work provides evidence for a positive association between degree of asymmetry and productivity (e.g. carbon gain or basal area increment) or site conditions (e.g. PDSI, soil moisture) in both empirical (Wichmann 2001, Metsaranta and Leiffers 2010, Pretzsch and Biber 2010, Coomes et al. 2011, Zang et al. 2011, Prior and Bowman 2014) and modeling research (Nord-Larsen et al. 2006, DeMalach et al. 2016). These studies suggest that forest productivity is in part influenced by the structural distribution of tree growth within a stand, that is, forests with disproportionate growth of big trees tend to be more productive. However, there is also contradictory evidence suggesting this relationship is not consistent. Studies have found no discernible relationship (Castageneri et al. 2012), inconsistent relationships (Looney et al. 2016), or negative relationships (Bourdier et al. 2016) between asymmetry and either productivity or site conditions. Further complicating the issue is a lack of studies that take advantage of a diversity of species, age, and size structures that characterize global forests; many of the studies mentioned above are conducted in single locales (Wichmann 2001, Zang et al. 2011, Castagneri et al. 2012), subsets of a megaplot (Coomes et al. 2011, Prior and Bowman 2014) or across similar forest types (Metsaranta and Leiffers 2010, Pretzsch and Biber 2010, Bourdier et al. 2016, Looney et al. 2016). Data from a wider range of forest types is needed to further address the efficacy of the productivity-asymmetry relationship.

The positive relationship between productivity and asymmetry might be driven by competition for light. Since light is a directional resource, big trees with canopy dominance can preempt incoming light at the expense of small, understory trees (Craine and Dybzinski 2013). In this case, big trees may grow disproportionately to smaller trees (size-growth asymmetry) when light is the primary limiting factor to growth and other resources like water and nutrients are sufficiently available. Alternatively, the advantage of big trees could be neutralized when competition for below-ground resources exceeds competition for light, such as might occur in poor growing conditions when overall productivity is low, resulting in size-growth curves that tend toward symmetric. For these reasons, the degree of asymmetry is often expected to be positively associated with forest productivity, site conditions, or water availability (e.g. Wichmann 2001). However, these explanations assume a simplistic and unrealistically dichotomous interpretation of above versus below-ground competition that likely does not always exist in dynamic forests (Casper and Jackson 1997, Laroque et al. 2013). In forests, competition is usually neither 
dominated solely by light nor solely by below ground resources, but is more realistically driven by an unknown or incompletely defined interaction of both (Cahill 1999).

Furthermore, it is too simplistic to assume that all trees have size-proportional access to below ground resources because soil nutrients are not homogeneously distributed, and trees vary in their belowground competitive ability (Casper and Jackson 1997, Rajaniemi 2003, Rewald and Leuschner 2009). Thus, across forest sites, forest types, or over time, the relationship between productivity and asymmetry may not be stable. Addressing this issue is a key step towards assessing the limitations and potential for interpreting asymmetry as a means of modeling and forecasting carbon sequestration in forests.

In this paper, we analyze 42 years (1970-2011) of annually resolved dendroecological reconstructions of asymmetry and productivity across a network of 16 eastern U.S. temperate forests. The main objective of this study is to evaluate the stability of the productivity-asymmetry relationship across forest types and over time using a set of structurally and species-diverse forests over a large area. Specifically, I address this objective by asking the following: 1) do these forests typically exhibit asymmetric growth, indicating disproportionate production of big trees?; 2) are within-site temporal variations in productivity and asymmetry consistently correlated, and does this relationship vary with the scale of remeasurement interval?; and 3) are more productive sites consistently more or less asymmetric, and does this relationship vary over time and with the temporal scale of the remeasurement interval? Addressing these questions is important for understanding how structural growth dynamics in a stand impact the overall carbon sequestration in a forest; if a stable relationship exists, size-growth asymmetry can serve as a quantitative indicator of forest productivity and aid in development of carbon management and modeling protocols.

\section{METHODS}

Dendroecological methods are ideal for extending temporal length and resolution by providing long-term, annual data and are frequently employed to study forest productivity (Davis et al. 2009, Babst et al. 2014b, Dye et al. 2016). Basal area increment is an informative index of aboveground stem productivity because it represents area instead of radial increment (Babst et al. 2014a), while also avoiding the tenuous assumptions and uncertainties associated with using allometric equations to predict biomass (Alexander et al. 2017b).

\section{Study Sites}

To study a variety of eastern US forest types, we included data from 16 sites, sampled between 2011-2016. Site characteristics are described in detail in Table 1 and Appendix A.

\section{Diameter and basal area increment reconstructions}

At each site, we collected increment cores following the sampling designs described in Table 1. All sampling designs were variations of the stem-mapped sampling design that is the suggested method for developing dendroecological reconstructions of biomass growth (Nehrbass-Ahles et al. 2014, Dye et al. 2016, Alexander et al. 2017). When possible, we collected 2-3 cores to minimize the effects of unequal growth around the tree radius. Standard dendrochronological techniques were used to mount, sand, and 
analyze the cores (Stokes and Smiley 1968). We measured annual growth rings to the nearest $0.001 \mathrm{~mm}$ with a sliding stage micrometer (Velmex Inc., Bloomfield, NY, USA) and confirmed annual dating using the program COFECHA (Holmes 1983, GrissinoMayer 2001). In cases of multiple cores for a tree, we averaged the ring widths for all radii by tree. Tree diameter was recorded at the time of sampling in the field. By subtracting the averaged ring width in the previous year from the recorded diameter, we estimated historical diameters for each tree. Since all sites had a minimum sampling limit of $10 \mathrm{~cm}$ diameter at breast height, we stopped diameter reconstructions for a tree once its diameter was less than $10 \mathrm{~cm}$.

We calculated past basal area of each tree using our annually reconstructed diameters. Using methods previously described in Davis et al. (2009) and Dye et al. (2016), we subtracted the basal area in the previous year from basal area in the current year to obtain annual basal area growth (aka basal area increment). Basal area increment for each plot was calculated as the average basal area growth of all individual trees at a plot and a site-level estimate was obtained by averaging all plots within a site. We use site-level basal area increment as our unit of measurement for forest productivity.

\section{Size-growth relationships}

The slope of a linear regression between diameter and growth, or the degree of asymmetry, indicates which tree sizes are disproportionately productive (e.g. Wiener 1990, Wichmann 2001, Pretzsch and Biber 2010, Coomes et al. 2011). To quantify degree of asymmetry, we constructed linear regression models at non-overlapping annual, 2-, 5-, 10-, 20-, and 42-year intervals, between diameter (size) and basal area increment (productivity). These are common intervals used in forest remeasurement studies and are included to reveal stability of the size-growth relationships. We include all consecutive intervals possible in our dataset (e.g. 1970-1974, 1975-1979,.., 2005-2009). The 42-year interval represents the entirety of our study period. To calculate asymmetry, we first divided basal area increment of each tree by total basal area increment (sum of all trees) for each site to determine proportional basal area increment of each tree. Likewise, we divided the diameter of each tree by the sum of all diameters to obtain proportional diameter. In this way, we can compare parameters across sites without misinterpreting differences in diameter distributions. Because proportional data are constrained between 0 and 1 , we apply a center log transformation to each of the size-growth proportions, following the methodology presented in Metsaranta and Leiffers (2010). Diameter is defined as the initial diameter at the beginning of the interval and basal area increment as the total incremental growth over the entire interval. For example, for the 1970-1979 10year interval we calculate the slope between diameters at the start of the 1970 growing season and subsequent accumulated growth until the end of 1979. In the remainder of the paper, we classify the degree of asymmetry in one of three ways:

1) Degree of asymmetry $=1$, proportionally symmetric

2) Degree of asymmetry $>1$, asymmetric, driven by big trees

3) Degree of asymmetry $<1$, inversely asymmetric, driven by small trees A higher degree of asymmetry indicates that big trees are disproportionately productive relative to their size, while inverse asymmetry indicates small trees are disproportionately productive relative to their size. A degree of asymmetry equal to 1 indicates that trees are growing directly proportional to their size. 


\section{Between site comparisons of asymmetry and productivity}

In order to test whether more asymmetric sites tend to be more productive, we calculated Pearson's correlation coefficients of both variables across our study region ( $\mathrm{n}=$ 16 sites). We assessed this relationship separately for each of our non-overlapping annual, 2-year, 5-year, 10-year, 20-year, and 41-year remeasurement intervals. An additional correlation was performed for each unique interval (e.g. 41 correlations at the annual interval, or one for each year 1970-2011).

We assess the validity of each of these correlations in the context of multiple comparisons (e.g. Miller 1981). Assuming a null hypothesis of no relationship between productivity and asymmetry is true, we can expect to find $n * p$ falsely significant relationships, where $n$ is the number of comparisons and $p$ is the significance level. For example, at a significance level of $5 \%$, we should expect 2 comparisons to be falsely significant at the annual interval $(41 * 0.05)$. Additionally, we adjust the p-value required to achieve a significant result using a Bonferroni correction.

\section{Within-site comparisons of asymmetry and productivity}

As a measure of variability within sites, we calculated first differences on both the productivity and asymmetry series $(\mathrm{t}-(\mathrm{t}-1)$, where $\mathrm{t}$ is the current measurement interval), to correct for dependence of consecutive years. This is similar to methods employed by Metsaranta and Leiffers (2010) to study asymmetry. In the first-differenced data, a positive value indicates that asymmetry or productivity increased from the previous interval and a negative value that it decreased from the previous interval. We then calculated the cross-correlation function between annual, 2-year, and 5-year firstdifferenced productivity and asymmetry over the study period (1970-2011) within each of the 16 sites individually. We did not conduct within-site comparisons for the 10-, 20-, and 41-year intervals for this analysis since these series only have 3,1 , and 0 first differences, respectively.

\section{RESULTS}

Size-growth relationships

Over the period 1970-2011, annual size-growth relationships at all sites were largely asymmetric (Table 2), but symmetric or inverse asymmetric growth can occur in isolated years (Figure 1). This indicates that the basal area increment of big trees is typically disproportionate to their size at the annual scale. At most sites, basal area increment remains asymmetric regardless of the remeasurement interval considered (Table 2). Notable exceptions include Gill Brook, which averages inverse asymmetric growth at all intervals except annual, and Palmaghatt, which exhibits inverse asymmetric growth at the full 42-year interval. Gill Brook is particularly inverse asymmetric at longer remeasurement intervals (slope $=0.36$ and 0.60 at the 42 -year and 20-year, respectively). The remaining 14 sites are asymmetric regardless of the remeasurement interval applied; however, the magnitude of asymmetry does not remain constant. For example, at Duke Hardwood, Gill Brook, Goose Egg, EMS, Missouri Ozark, Morgan Monroe, North Round Pond, and UMBS, the degree of asymmetry decreases steadily as the remeasurement interval length increases. This suggests that over longer time periods, trees that were small at the start of the interval become disproportionately productive. 


\section{Between-site correlations of asymmetry and productivity}

Asymmetry and productivity are not consistently correlated between sites at any of the remeasurement intervals. The between-site correlation of the full study period (41year asymmetry and productivity) is moderately negative but not significant at the $95 \%$ level $(\mathrm{R} 2=0.16, \mathrm{p}$-value $=0.13$, Figure 2$)$. Morgan Monroe had a noticeably higher mean basal area increment $\left(24.24 \mathrm{~cm}^{2} / y e a r\right)$ than other sites, so we conducted the correlation analysis a second time with Morgan Monroe removed. Removing Morgan Monroe did not improve the relationship $(\mathrm{R} 2=0.14$, $\mathrm{p}$-value $=0.17)$.

Annually, there is a significant positive and negative between-site correlation for only 3 and 2 out of 41 annual comparisons, respectively (Figure B1). All other annual comparisons exhibit no discernible relationship. Given that we conduct 41 multiple comparisons, we would expect approximately two of the annual comparisons to be falsely significant if there is not actually a measurable relationship. When a Bonferroni correction is applied to adjust the required significance level (p-value $<0.001$ for $95 \%$ significance), none of the 41 annual comparisons meet the criteria for statistical significance $(\mathrm{p}>=0.001)$.

At longer time scales, there is qualitative evidence that asymmetry and productivity are moderately negatively correlated. At the 2-year interval, 5 out of 21 comparisons are significantly negative (Figure B2). In the context of multiple comparisons, we would expect one of these to be falsely significant if there is no real relationship. After application of a Bonferroni correction (p-value $<0.001$ for $95 \%$ significance), no comparisons were significant at the 2-year interval. At the 5-year (Figure B3), 10-year (Figure B4), and 20-year intervals (Figure B5), we observe 2 out of 8,1 out of 4 , and 1 out of 2 significantly negative relationships, respectively. However, none of these comparisons meet the required criteria once the Bonferroni corrections are applied (p-value $<0.006$ for 50-year, $<0.01$ for 10 -year, and $<0.03$ for 20 -year). There are no indications that the productivity-asymmetry relationship between sites is strengthening or weakening over time at any of the remeasurement intervals. For the most part, relationships lack consistency and are relatively weak throughout the study period.

\section{Within-site correlations of asymmetry and productivity}

Within-site correlations of temporal variations in asymmetry and productivity are also inconsistent. Annual first-differenced productivity and asymmetry $(n=41)$ are significantly positively correlated at Missouri Ozark $(\mathrm{R} 2=0.14$, $\mathrm{p}$-value $=0.01)$ and Ohio Oak Openings $(\mathrm{R} 2=0.13$, $\mathrm{p}$-value $=0.02)$ and negatively correlated at Duke Hardwood $(\mathrm{R} 2=0.12$, p-value $=0.03)$ and Huron Mt. Club-West $(\mathrm{R} 2=0.10$, $\mathrm{p}$-value $=$ $0.04)$. The other 12 sites do not exhibit a significantly positive or negative relationship (Figure 3). Application of a Bonferroni correction reduced the p-value required for significance at the $95 \%$ level to 0.003 ; none of the annual first-differenced comparisons met this more stringent criteria.

First-differenced 2-year intervals $(\mathrm{n}=20)$ are significantly positively correlated at 5 sites: Harvard Forest-Lyford $(\mathrm{R} 2=0.41$, $\mathrm{p}$-value $=0.00)$; Huron Mt. Club-West $(\mathrm{R} 2=$ 0.30 , $\mathrm{p}$-value $=0.01)$; Ohio Oak Openings $(\mathrm{R} 2=0.43$, $\mathrm{p}$-value $=0.00)$; Pisgah-Harvard Tract $(\mathrm{R} 2=0.24, \mathrm{p}$-value $=0.03)$; and UMBS $(\mathrm{R} 2=0.26$, $\mathrm{p}$-value $=0.02)($ Figure $\mathrm{C} 1)$. After application of the Bonferroni correction, Harvard Forest-Lyford and Ohio Oak Openings continued to meet criteria for statistical significance. First-differenced 5-year 
intervals comparisons $(\mathrm{n}=7)$ are significant only at Huron Mt. Club-West $(\mathrm{R} 2=0.57, \mathrm{p}$ value $=0.05)$ and Harvard Forest-EMS $(\mathrm{R} 2=0.62$, p-value $=0.04)($ Figure $C 2)$. Neither of these sites met criteria for statistical significance after the Bonferroni correction was applied. Due to the short span of our study period, we had only 3 first-differenced 10year intervals and 1 first-differenced 20-year interval and do not report those correlations here.

\section{DISCUSSION and CONCLUSIONS}

Relationship between growth and size is typically asymmetric at annual scale but inverse asymmetry can emerge over longer remeasurement intervals

Growth at all sites is typically asymmetric in any given year, indicating disproportionate production of big trees. This confirms parallel work based on the same dataset, which found that annually, trees in the largest diameter quartile are responsible for $40-60 \%$ of total site-level basal area growth (Dye et al., in prep.). Other studies have also found characteristic growth asymmetry at the annual scale, with individual years deviating in magnitude of asymmetry (Metsaranta and Leiffers 2010, Castagneri et al. 2012). Alternatively, inverse asymmetry has been observed for periods of time in forests of the U.S. Southwest (Biondi 1996) and black ash forests in northern Minnesota (Looney et al. 2016).

Asymmetric growth has been interpreted as indicating competition for light (Weiner 1990, Wichmann 2001, Pretzsch and Biber 2010, Coomes et al. 2011). The assumption is that competition for light favors growth of large trees, because these trees have more direct light access due to possession of a larger share of canopy space. Using the degree of asymmetry alone, our data support competition for light as an emergent factor in any given year at the stand scale, consistent with a traditional understanding that competition for light governs the size-related dynamics of structural growth in closed canopy forests of the eastern U.S. (Williams 1998, Druckenbrod et al. 2005). At longer remeasurement intervals, however, all sites do not remain asymmetric. This is most pronounced at Gill Brook and Palmaghatt, which are characterized by inverse asymmetry at the longest remeasurement intervals. Although asymmetry remains predominate annually, over the long-term, small trees at these two sites grow disproportionately to their original size at the beginning of the growth interval. Inverse asymmetry could emerge if trees that were small at the start of a growth interval were released from the understory and gained canopy dominance over time (Biondi 1999). The specific histories of these two sites support this explanation. In the mid-1970s at Gill Brook, productivity nearly doubles; such a significant increase in tree growth has been associated with canopy tree mortality in other eastern U.S. forests (Lorimer and Frelich 1989). In the event of canopy mortality at Gill Brook, small trees released from competition may have slowly accumulated growth over time. Annually, the disproportionate growth of small trees is not visible, but as these small trees likely gain canopy dominance over the course of 5, 10, 20, or 40 years, they exhibit disproportionate growth. In the Palmaghatt region, a series of severe winter ice storms in 2003 caused mortality with particular damage to large trees (Kocin and Uccellini 2004, Neil Pederson personal comm.). Following 2003, Palmaghatt shifts towards inverse asymmetry at all remeasurement scales. This shift is particularly evident in the longer intervals. Potentially, big trees damaged by the 2003 storms facilitate growth of smaller trees, resulting in inverse growth asymmetry. The 
observed asymmetry patterns at both Gill Brook and Palmaghatt are supported by declining proportional productivity of the two largest diameter size quartiles at these sites over time (Dye et al., in prep). Although the other 14 sites retain asymmetric growth at all remeasurement intervals, the degree of asymmetry varies (Table 2). This suggests that calculations of asymmetry are highly dependent on the remeasurement interval used, which may limit the comparability of studies that have adopted alternative measurement intervals to calculate asymmetry, including 4-year (Prior and Bowman 2014), 5-year (Pretszch and Biber 2010), 20-year (Coomes et al. 2011), or annual intervals (Wichmann 2001, Metsaranta and Leiffers 2010, Castagneri et al. 2012, Looney et al. 2016).

Potentially, disturbance history plays a major role as well (D'Amato and Orwig 2008).

\section{Productivity and asymmetry are not consistently related}

To date, four studies have examined the within-site productivity-asymmetry relationship over multi-decadal time scales using an annually resolved dendroecological dataset similar to what we present in the current paper. Originally, Wichmann (2001) presented evidence in support of a theory that asymmetry should increase with productivity and/or site conditions using 60 years of growth and precipitation records from a Sitka spruce forest in Denmark. Wichmann showed that annual degree of asymmetry was modestly and positively correlated with total precipitation. However, the observations form a wide triangular envelope with several high precipitation years associated with low asymmetry. Metsaranta and Leiffers (2010), showed that annual first-differenced site productivity was significantly correlated with annual firstdifferenced asymmetry at 8 of 10 study sites in a monospecific jack pine forest in Western Canada. In contrast to these studies, Castagneri et al. (2012) showed similar records of productivity, but widely varying asymmetry, for three nearby plots in a central European Norway spruce forest. In five northern Minnesota black ash forests, Looney et al. (2016) found inconsistent relationships between asymmetry and Palmer Drought Severity Index, used as an indicator of site conditions. Collectively, these studies present inconclusive evidence either for or against an emergent asymmetry-productivity relationship. Likewise, our current study does not lend support for or against - rather, our results further confirm the inconclusiveness resulting from these studies.

Of our sites, only four exhibit either a positive or negative relationship in the annual change in asymmetry and productivity over time, none of which possess any obvious common characteristics. Though not statistically significant after the Bonferroni correction ( $\mathrm{p}$-value $<0.003$ ), four sites individually exhibit a fairly strong positive or negative asymmetry-productivity relationship. This distinction is important, because If we had only studied interannual variations at one site, say Missouri Ozark $(\mathrm{R} 2=0.15)$, instead of across a network of sites, we could have interpreted this as evidence for a productivity-asymmetry relationship.

Similarly, we also observed weak within-site correlations at the 5-year remeasurement interval. At the 2-year interval, both Harvard Forest-Lyford and Ohio Oak Openings maintain strong within-site correlations, even after application of the Bonferroni correction. This still does not provide strong evidence of an emergent productivity-asymmetry relationship at the 2-year scale; rather, the strong correlations at Lyford and Ohio further highlight the inconsistency. For example, if we had conducted this study only at Harvard Forest-Lyford, and remeasured tree diameters every two years 
since 1970, we would have concluded that there was a strongly positive relationship between asymmetry and productivity. Instead, by analyzing the additional 15 sites in our dataset, we show that asymmetry is actually not consistently related to productivity, suggesting that the Lyford and Ohio 2-year interval results are anomalous or site-specific. This is the case even between nearby sites - despite being roughly $1 \mathrm{~km}$ removed from Lyford and having similar productivity, age, and composition, the Harvard Forest-EMS site has a starkly different asymmetry record (Figure 3). Similarly, Castagneri et al. (2012) also show that nearby stands can have nearly identical productivity records but dissimilar asymmetry. Other studies that present a positive association between productivity and asymmetry are sometimes drawn from a single interval or site. For example, Zang et al. (2011) attributed increased asymmetry of Norway spruce and common oak growth over the 2002-2003 growth period to wet conditions in 2003. Whether asymmetry continues to oscillate in tandem with moisture conditions over time at their site remains unclear, but the inconsistent correlations seen in our data suggest that such an extrapolation should not be taken for granted.

We also find little evidence that more productive sites are more asymmetric. In fact, most of our between-site comparisons reveal a moderately negative, not positive, relationship. Although none of the correlation statistics meet stringent criteria for statistical significance after application of the Bonferroni correction there is a persistent qualitative negative relationship for all between-site comparisons in the 2-, 5-, 10-, 20-, and 41-year remeasurement intervals (Figure 2, Appendix B). This differs from the annual intervals, where productivity is positively associated with asymmetry during several years (e.g. 1981, 1991, 2005).

Interestingly, some known ecological disturbance events are clearly visible in both the asymmetry and productivity records. For example, the 1981 gypsy moth outbreak at Harvard Forest (Elkinton and Liebhold 1990) is recorded as a strong dip in both the productivity and asymmetry records at Lyford and EMS (Figure 3). This is particularly evident in the 1980-1982 2-year interval (Figure C1). The outbreak clearly resulted in decreased basal area increment, and the simultaneous decrease in asymmetry suggests that this event may have negatively affected big trees relative to small trees. During short periods of disturbance, such as the 1981 Harvard Forest gypsy moth outbreak or the abrupt change in drought conditions from 2002-2003 analyzed by Zang et al. (2011), it may be possible to use asymmetry to elicit information on the structural response of trees to these events. Future work looking at asymmetry responses of several sites to similar disturbances would be useful to determine whether certain events alter asymmetry in characteristic ways. However, our data show that expecting asymmetry to consistently follow regular variations in productivity is at best a tenuous assumption.

\section{Implications for interpreting forest biomass growth}

In diverse, structurally complex forests, such as those of the Eastern U.S., we show that it is likely unrealistic to assume a stable relationship between productivity and asymmetry. Additional evidence supports this claim from a variety of perspectives. For example, Bassow and Bazzazz (1997) found inter-specific variation in photosynthetic uptake of canopy dominant trees at the Harvard Forest; this implies that photosynthetic capacity could be a key driver of asymmetry, instead of or in addition to light competition. An assumption that productivity increases with asymmetry requires 
competitive advantages to be primarily vertically stratified. When a canopy consists of many species of trees with different capacities to acquire available light, as occurs in most eastern U.S. forests, the direct and simplistic link between light competition and asymmetry may not hold. In part, this may explain the strong correlations found in less diverse forests, such as the monospecific jack pine stands studied by Metsaranta and Leiffers (2010).

Another major assumption of the expected positive relationship between asymmetry and productivity requires that belowground competitive ability is homogeneously distributed between trees. When belowground resources are the limiting factor for the stand, this homogeneity is thought to result in symmetric size-growth relationships because preemptive light acquisition is no longer an advantage for the dominant trees (Weiner 1990). However, the capacity of a tree to succeed in belowground competition has been shown to be highly variable between individuals of same and different species (Rajaniemi 2003, Rewald and Leuschner 2009), suggesting that correlating belowground competition with size-growth symmetry is a simplistic, and potentially erroneous, assumption. Additionally, the distribution of belowground nutrients throughout the soil is not usually heterogeneous, resulting in unequal access to these nutrients (Craine et al. 2013).

Further evidence across the temperate forest region shows that structural biomass growth dynamics are driven by a complicated mix of climate, competition, and disturbance history. Using a subset of the same sites presented in our current analysis, Alexander (2017) showed that the growth response of trees to climate variability can vary by canopy position, with dominant, intermediate, and suppressed trees each uniquely responding to periods of increased temperature or drought. Similar conclusions support the findings of Alexander (2017) at other sites in the eastern U.S. and temperate forests of Western Europe (Jacquart et al. 1992, Orwig and Abrams 1997, Lebourgeois et al. 2014). Differential canopy responses to climate undermine the expectation of a consistently positive asymmetry-productivity relationship, which relies on interpreting light competition as the main driver of structural biomass growth. We cannot expect productivity to be strictly associated with asymmetry if factors other than vertical competition for light play a major role in creating stand biomass growth dynamics. To date, no clear consensus has emerged regarding the primary factor driving structural biomass growth in diverse temperate forests, although evidence suggests climate (Pederson et al. 2014), disturbance legacies (Trotsiuk et al. 2016), competition (Zhang et al. 2015), and stand age (Foster et al. 2016) can be important factors. Most likely, structural growth dynamics result from a complicated interaction of each of these factors and others, and our representation of forest carbon gain in ecological models needs to reflect this to accurately predict biomass responses to global change (Foster et al. 2016). In light of these complicated interactions and the results presented in this paper, we conclude that a metric solely based on structural competition for light, such as the degree of asymmetry, should not be used as a standalone predictor of forest productivity. However, the degree of asymmetry uniquely characterizes size-related biomass growth, and can serve as a useful indicator of the structural allocation of new wood growth in forests, particularly in response to disturbance events. This application alone makes continued study and interpretation of size-growth asymmetry in diverse forests a worthy topic of future research. 


\section{Works Cited}

Alexander, M.R. (2017a). Determining the role of stand structure in shaping climategrowth relationships in eastern temperate forests of the US. PhD dissertation, The University of Arizona.

Alexander, M.R., C.R. Rollinson, F. Babst, V. Trouet, and D.J.P. Moore (2017b). Relative influences of multiple sources of uncertainty on cumulative and incremental tree-ring-derived aboveground biomass estimates. Trees doi: 10.1007/s00468-017-1629-0.

Babst, F., O. Bouriaud, M.R. Alexander, V. Trouet, and D. Frank (2014). Towards consistent measurements of carbon accumulation: a multi-site assessment of biomass and basal area increment across Europe. Dendrochronologia 32: 153161.

Bassow, S.L, and F.A. Bazzazz (1997). Intra- and inter-specific variation in canopy photosynthesis in a mixed deciduous forest. Oecologia 109: 507-515.

Biondi, F. (1996). Decadal-scale dynamics at the Gus Pearson Natural Area: evidence for inverse (a)symmetric competition? Canadian Journal of Forest Research 26: 1397-1406.

Bourdier, T., T. Cordonnier, G. Kunstler, C. Piedallu, G. Lagarrigues, and B. Courbaud (2016). Tree size inequality reduces forest productivity: an analysis combining inventory data for ten European species and a light competition model. PlosOne doi: 10.1371/journal.pone.0151852.

Cahill, J. (1999). Fertilization effects on interactions between above- and belowground competition in an old field. Ecology 80: 466-480.

Casper, B.B. and R.B. Jackson (1997). Plant competition underground. Annual Review of Ecology and Systematics 28: 545-570.

Castagneri, D., P. Nola, P. Cherubini, and R. Motta (2012). Temporal variability of sizegrowth relationships in a Norway spruce forest: the influence of stand structure, logging, and climate. Canadian Journal of Forest Research 42: 550-560.

Coomes, D.A., E.R. Lines, and R.B. Allen (2011). Moving on from metabolic scaling theory: hierarchical models of tree growth and asymmetric competition for light. Journal of Ecology 99: 748-756.

Craine, J.M. and R. Dybzinski (2013). Mechanisms of plant competition for nutrients, water, and light. Functional Ecology 27: 833-840.

D’Amato, A.W., D.A. Orwig, and D.R. Foster (2008). The influence of successional processes and disturbance on the structure of Tsuga canadensis forests.

Ecological Applications 18: 1182-1199. 
Davis, S.C., A.E. Hessl, C.J. Scott, M.B. Adams, and R.B. Thomas (2009). Forest carbon sequestration changes in response to timber harvest. Forest Ecology and Management 258: 2101-2109.

DeMalach, N., E. Zaady, J. Weiner, and R. Kadmon (2016). Size asymmetry of resource competition and the structure of plant communities. Journal of Ecology 104: 899910.

Druckenbrod, D., H.H. Shugart, and I. Davies (2005). Spatial pattern and process in forest stands within the Virginia piedmont. Journal of Vegetation Science 16: 3748 .

Dye, A., A. Barker Plotkin, D. Bishop, N. Pederson, B. Poulter, and A. Hessl. (2016). Comparing tree-ring and permanent plot estimates of aboveground net primary productivity in three Eastern U.S. forests. Ecosphere 7: e01454.

Elkinton, J.S. and A.W. Liebhold (1990). Population dynamics of gypsy moth in North America. Annual Review of Entomology 35: 571-596.

Foster, J.R., A.O. Finley, A.W. D’Amato, J.B. Bradford, S. Banerjee. (2016). Predicting tree biomass growth in the temperate-boreal ecotone: is tree size, age, competition, or climate response more important? Global Change Biology 22: 2138-2151.

Grissino-Mayer, H.D. (2001). Evaluating cross-dating accuracy: a manual and tutorial for the computer program COFECHA. Tree Ring Research 57: 205-221.

Holmes, R.L. (1983). Computer-assisted quality control in tree-ring dating and measurement. Tree Ring Bulletin 43: 69-78.

Jacquart, E.M., T.V. Armentano, and A.L. Spingarn (1992). Spatial and temporal tree responses to water stress in an old-growth deciduous forest. American Midland Naturalist 127: 158-171.

Kocin, P.J. and L.W. Uccellini (2004). A snowfall impact scale derived from northeast storm snowfall distributions. Bulletin of the American Meteorological Society DOI: 10.1175/BAMS-85-2-177.

Larocque, G., N. Luckai, S.N. Adhikary, A. Groot, F. W. Bell, and M. Sharma (2013). Competition theory - science and application in mixed forest stands: review of experimental and modelling methods and suggestions for future research. Environmental Reviews 21: 71-84.

Lebourgeois, F., P. Eberle, P. Merian, and I. Seynave. (2014). Social status-mediated tree-ring responses to climate of Abies alba and Fagus sylvatica shift in importance with increasing stand basal area. Forest Ecology and Management 328: 209-218. 
Looney, C.E., A.W. D'Amato, S. Fraver, B.J. Palik, and M.R. Reinikainen (2016). Examining the influences of tree-to-tree competition and climate on size-growth relationships in hydric, multi-aged Fraxinus nigra stands. Forest Ecology and Management 375: 238-248.

Lorimer, C.G. and L.E. Frelich (1989). A methodology for estimating canopy disturbance frequency and intensity in dense temperate forests. Canadian Journal of Forest Research 19: 651-663.

Metsaranta, J. and V. Leiffers (2010). Patterns of inter-annual variation in the size asymmetry of growth in Pinus banksiana. Oecologia 163: 737-745.

Nehrbass-Ahles, C., F. Babst, S. Klesse, M. Notzli, O. Bouriaud, R. Neukom, M. Dobbertin, and D. Frank. (2014). The influence of sampling design on tree-ring based quantification of forest growth. Global Change Biology 20: 2867-2885.

Nord-Larsen, T., C. Damgaard, and J. Weiner (2006). Quantifying size-asymmetric growth among individual beech trees. Canadian Journal of Forest Research 36: 418-425.

Orwig, D.A. and M.D. Abrams (1997). Variation in radial growth responses to drought among species, site, and canopy strata. Trees 11: 474-484.

Pan, Y., et al. (2011). A large and persistent carbon sink in the world's forests. Science 333: 988-993.

Pederson, N., J.M. Dyer, R.W. McEwan, A.E. Hessl, C.J. Mock, D.A. Orwig, H.E. Rieder, and B.I. Cook. (2014). The legacy of episodic climatic events in shaping temperate, broadleaf forests. Ecological Monographs 84: 599-620.

Pretzsch, H. and P. Biber (2010). Size-symmetric versus size-asymmetric competition and growth partitioning among trees in forest stands along an ecological gradient in central Europe. Canadian Journal of Forest Research 40: 370-384.

Prior, L.D., and D.M.J.S. Bowman (2014). Across a macro-ecological gradient forest competition is strongest at the most productive sites. Frontiers in Plant Science 5: Article 260.

Rajaniemi, T.K. (2003). Evidence for size-asymmetry of belowground competition. Basic and Applied Ecology 4: 239-247.

Rewald, B. and C. Leuschner (2009). Belowground competition in a broad-leaved temperate mixed forest: pattern analysis and experiments in a four-species stand. European Journal of Forest Research 128: 387-398. 
Schwinning, S. and J. Weiner (1998). Mechanisms determining the degree of size asymmetry in competition among plants. Oecologia 113: 447-455.

Trotsiuk, V., M. Svoboda, P. Weber, N. Pederson, S. Klesse, P. Janda, D. Martin-Benito, M. Mikolas, M. Seedre, R. Bace, L. Mateju, and D. Frank. (2016). The legacy of disturbance on individual tree and stand-level aboveground biomass accumulation and stocks in primary Picea abies forests. Forest Ecology and Management 373: 108-115.

Urbano, A.R. and W.S. Keeton (2017). Carbon dynamics and structural development in recovering secondary forests of the northeastern United States. Forest Ecology and Management 392: 21-35.

Wichmann, L. (2001). Annual variations in competition symmetry in even-aged Sitka spruce. Annals of Botany 88: 145-151.

Wiener, J. (1990). Asymmetric competition in plant populations. Trends in Ecology and Evolution 5: 360-364.

Williams, M. (1996). A three-dimensional model of forest development and competition. Ecological Modelling 89: 73-98.

Woodbury, P.B., J.E. Smith, and L.S. Heath. (2007). Carbon sequestration in the US forest sector from 1990 to 2010. Forest Ecology and Management 241: 14-27.

Zang, C., H. Pretzsch, and A. Rothe (2011). Size-dependent responses to summer drought in Scots pine, Norway spruce, and common oak. Trees doi: 10.1007/s00468-0110617-z 
Table 1. Site characteristics and sampling designs.

\begin{tabular}{|c|c|c|c|c|}
\hline Site, State & Forest Region $\%$ & Sampling design* & $\begin{array}{l}\text { Number } \\
\text { of trees }\end{array}$ & Reference \\
\hline $\begin{array}{l}\text { Duke } \\
\text { Hardwood, NC }\end{array}$ & Oak-pine & $\begin{array}{l}\text { Double nested, } \\
3 \text { plots }\end{array}$ & 59 & Alexander 2017a \\
\hline Gill Brook, NY & $\begin{array}{l}\text { Hemlock- } \\
\text { northern hardwood }\end{array}$ & $\begin{array}{l}\text { Triple nested, } \\
2 \text { plots }\end{array}$ & 153 & $\begin{array}{l}\text { N. Pederson, } \\
\text { unpublished }\end{array}$ \\
\hline Goose Egg, NY & $\begin{array}{l}\text { Hemlock- } \\
\text { northern hardwood }\end{array}$ & $\begin{array}{l}\text { Triple nested, } \\
3 \text { plots }\end{array}$ & 216 & $\begin{array}{l}\text { N. Pederson, } \\
\text { unpublished }\end{array}$ \\
\hline $\begin{array}{l}\text { Harvard Forest- } \\
\text { EMS, MA }\end{array}$ & $\begin{array}{l}\text { Hemlock- } \\
\text { northern hardwood }\end{array}$ & $\begin{array}{l}\text { Double nested, } \\
2 \text { plots }\end{array}$ & 145 & Dye et al. 2016 \\
\hline $\begin{array}{l}\text { Harvard Forest } \\
\text {-Lyford, MA }\end{array}$ & $\begin{array}{l}\text { Hemlock- } \\
\text { northern hardwood }\end{array}$ & $\begin{array}{l}\text { Double nested, } \\
3 \text { plots }\end{array}$ & 133 & Dye et al. 2016 \\
\hline Howland, ME & $\begin{array}{l}\text { Hemlock- } \\
\text { northern hardwood }\end{array}$ & $\begin{array}{l}\text { Double nested, } \\
3 \text { plots }\end{array}$ & 282 & Dye et al. 2016 \\
\hline $\begin{array}{l}\text { Huron Mt. } \\
\text { Club-Rush } \\
\text { Lake, MI }\end{array}$ & $\begin{array}{l}\text { Hemlock- } \\
\text { northern hardwood }\end{array}$ & $\begin{array}{l}\text { All trees } \geq 10 \mathrm{~cm} \\
\mathrm{DBH}, 216 \mathrm{~m} \\
\text { radius plots }\end{array}$ & 60 & A. Dye, unpublished \\
\hline $\begin{array}{l}\text { Huron Mt. } \\
\text { Club- } \\
\text { West, MI }\end{array}$ & $\begin{array}{l}\text { Hemlock- } \\
\text { northern hardwood }\end{array}$ & $\begin{array}{l}\text { All trees } \geq 10 \mathrm{~cm} \\
\mathrm{DBH}, 216 \mathrm{~m} \\
\text { radius plots }\end{array}$ & 79 & A. Dye, unpublished \\
\hline $\begin{array}{l}\text { Missouri Ozark, } \\
\text { MO }\end{array}$ & Oak-hickory & $\begin{array}{l}\text { Double nested, } \\
3 \text { plots }\end{array}$ & 95 & Alexander $2017 \mathrm{a}$ \\
\hline $\begin{array}{l}\text { Morgan } \\
\text { Monroe, IN }\end{array}$ & $\begin{array}{l}\text { Western } \\
\text { mesophytic }\end{array}$ & $\begin{array}{l}\text { Double nested, } \\
3 \text { plots }\end{array}$ & 69 & Alexander $2017 \mathrm{a}$ \\
\hline $\begin{array}{l}\text { Pisgah State } \\
\text { Park-North } \\
\text { Round Pond, } \\
\text { NH }\end{array}$ & $\begin{array}{l}\text { Hemlock- } \\
\text { northern hardwood }\end{array}$ & $\begin{array}{l}\text { Triple nested, } \\
3 \text { plots }\end{array}$ & 174 & $\begin{array}{l}\text { N. Pederson, } \\
\text { unpublished }\end{array}$ \\
\hline $\begin{array}{l}\text { Pisgah State } \\
\text { Park- Harvard } \\
\text { Tract, NH }\end{array}$ & $\begin{array}{l}\text { Hemlock- } \\
\text { northern hardwood }\end{array}$ & $\begin{array}{l}\text { Double nested, } \\
2 \text { plots }\end{array}$ & 249 & $\begin{array}{l}\text { N. Pederson, } \\
\text { unpublished }\end{array}$ \\
\hline $\begin{array}{l}\text { Ohio Oak } \\
\text { Openings, OH }\end{array}$ & Beech-maple & $\begin{array}{l}\text { Double nested, } \\
2 \text { plots }\end{array}$ & 83 & Alexander $2017 \mathrm{a}$ \\
\hline Palmaghatt, NY & $\begin{array}{l}\text { Hemlock- } \\
\text { northern hardwood }\end{array}$ & $\begin{array}{l}\text { Triple nested, } \\
4 \text { plots }\end{array}$ & 140 & $\begin{array}{l}\text { N. Pederson, } \\
\text { unpublished }\end{array}$ \\
\hline $\begin{array}{l}\text { Rooster Hill, } \\
\text { NY }\end{array}$ & $\begin{array}{l}\text { Hemlock- } \\
\text { northern hardwood }\end{array}$ & $\begin{array}{l}\text { Triple nested, } \\
2 \text { plots }\end{array}$ & 167 & $\begin{array}{l}\text { N. Pederson, } \\
\text { unpublished }\end{array}$ \\
\hline UMBS, MI & $\begin{array}{l}\text { Hemlock- } \\
\text { northern hardwood }\end{array}$ & $\begin{array}{l}\text { Double nested, } \\
3 \text { plots }\end{array}$ & 161 & Alexander $2017 \mathrm{a}$ \\
\hline
\end{tabular}

*Sampling designs: If sampling design is unique to a site, it is described in the table. Otherwise, designs are one of the following: Triple nested for old-growth forests: Trees $\geq 10 \mathrm{~cm}$ within $10 \mathrm{~m}$ radius, $\geq 20 \mathrm{~cm}$ within $20 \mathrm{~m}$ radius, $\geq 30 \mathrm{~cm}$ within $30 \mathrm{~m}$ radius. Double nested in second-growth forests: Trees $\geq 10 \mathrm{~cm}$ within $10 \mathrm{~m}$ radius, $\geq 20 \mathrm{~cm}$ within $20 \mathrm{~m}$ radius. ${ }^{\%}$ Forest regions as defined by Braun 2001. 
Table 2. Mean basal area growth and degree of asymmetry for annual, 2-year, 5-year, 10-year, 20-year, and 41-year remeasurement intervals. Since average annual basal area growth remains unchanged regardless of the length of the remeasurement interval, this value is only reported once.

\begin{tabular}{|c|c|c|c|c|c|c|c|}
\hline & $\begin{array}{l}\text { Mean basal } \\
\text { area growth } \\
\left(\mathrm{cm}^{2} / \mathrm{yr}\right)\end{array}$ & $\begin{array}{l}\text { Mean degree } \\
\text { of asymmetry } \\
\text { (annual) }\end{array}$ & $\begin{array}{l}\text { Mean } \\
\text { degree of } \\
\text { asymmetry } \\
\text { (2-year) } \\
\end{array}$ & $\begin{array}{l}\text { Mean } \\
\text { degree of } \\
\text { asymmetry } \\
\text { (5-year) } \\
\end{array}$ & $\begin{array}{l}\text { Mean } \\
\text { degree of } \\
\text { asymmetry } \\
(10 \text {-year }) \\
\end{array}$ & $\begin{array}{l}\text { Mean } \\
\text { degree of } \\
\text { asymmetry } \\
\text { (20-year) }\end{array}$ & $\begin{array}{l}\text { Mean } \\
\text { degree of } \\
\text { asymmetry } \\
\text { (41-year) }\end{array}$ \\
\hline Duke Hardwood & 16.02 & 1.61 & 1.59 & 1.55 & 1.49 & 1.39 & 1.19 \\
\hline Gill Brook & 14.21 & 1.52 & 0.87 & 0.84 & 0.73 & 0.6 & 0.36 \\
\hline Goose Egg & 13.21 & 1.59 & 1.58 & 1.53 & 1.46 & 1.35 & 1.03 \\
\hline $\begin{array}{l}\text { Harvard Forest - } \\
\text { EMS }\end{array}$ & 8.25 & 1.73 & 1.82 & 1.84 & 1.8 & 1.69 & 1.65 \\
\hline $\begin{array}{l}\text { Harvard Forest - } \\
\text { Lyford }\end{array}$ & 11.48 & 1.68 & 1.75 & 1.74 & 1.75 & 1.72 & 1.78 \\
\hline Howland & 6.28 & 1.62 & 1.82 & 1.78 & 1.72 & 1.59 & 1.26 \\
\hline $\begin{array}{l}\text { Huron Mt. Club - } \\
\text { Rush Lake }\end{array}$ & 11.66 & 1.63 & 2.29 & 2.31 & 2.29 & 2.25 & 2.05 \\
\hline $\begin{array}{l}\text { Huron Mt. Club - } \\
\text { West }\end{array}$ & 6.95 & 1.63 & 2.45 & 2.55 & 2.63 & 2.69 & 2.65 \\
\hline Missouri Ozark & 9.72 & 1.74 & 1.64 & 1.63 & 1.62 & 1.63 & 1.62 \\
\hline Morgan Monroe & 24.24 & 1.73 & 1.41 & 1.34 & 1.27 & 1.14 & 1.05 \\
\hline $\begin{array}{l}\text { Ohio Oak } \\
\text { Openings }\end{array}$ & 12.99 & 1.72 & 2.24 & 2.28 & 2.34 & 2.38 & 2.34 \\
\hline Palmaghatt & 13.01 & 1.73 & 1.2 & 1.2 & 1.19 & 1.13 & 0.89 \\
\hline $\begin{array}{l}\text { Pisgah St. Park - } \\
\text { Harvard Tract }\end{array}$ & 7.94 & 1.79 & 1.92 & 1.9 & 1.89 & 1.79 & 1.44 \\
\hline $\begin{array}{l}\text { Pisgah St. Park - } \\
\text { North Round } \\
\text { Pond }\end{array}$ & 16.96 & 1.8 & 1.76 & 1.74 & 1.7 & 1.54 & 1.27 \\
\hline Rooster Hill & 9.07 & 1.79 & 1.68 & 1.64 & 1.6 & 1.57 & 1.49 \\
\hline UMBS & 7.52 & 1.7 & 1.46 & 1.47 & 1.47 & 1.5 & 1.37 \\
\hline
\end{tabular}



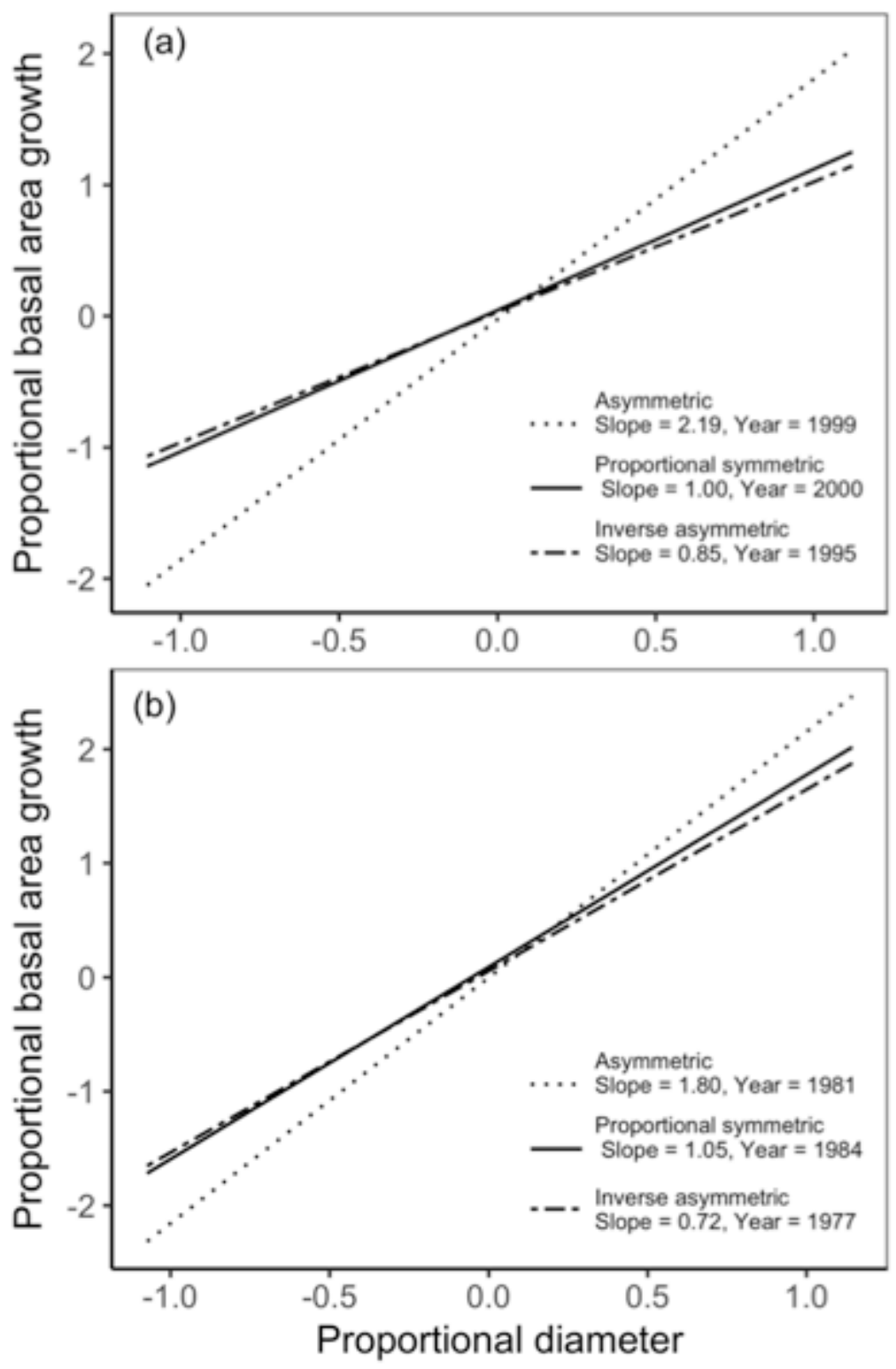

Figure 1. Annual regression lines between proportional diameter and proportional basal area growth in years when degree of asymmetry is asymmetric (slope $>1$ ), proportional symmetric (slope $=1$ ), and inverse asymmetric (slope $<1$ ) for a) Huron Mt. Club-Rush Lake and b) Ohio Oak Openings. 


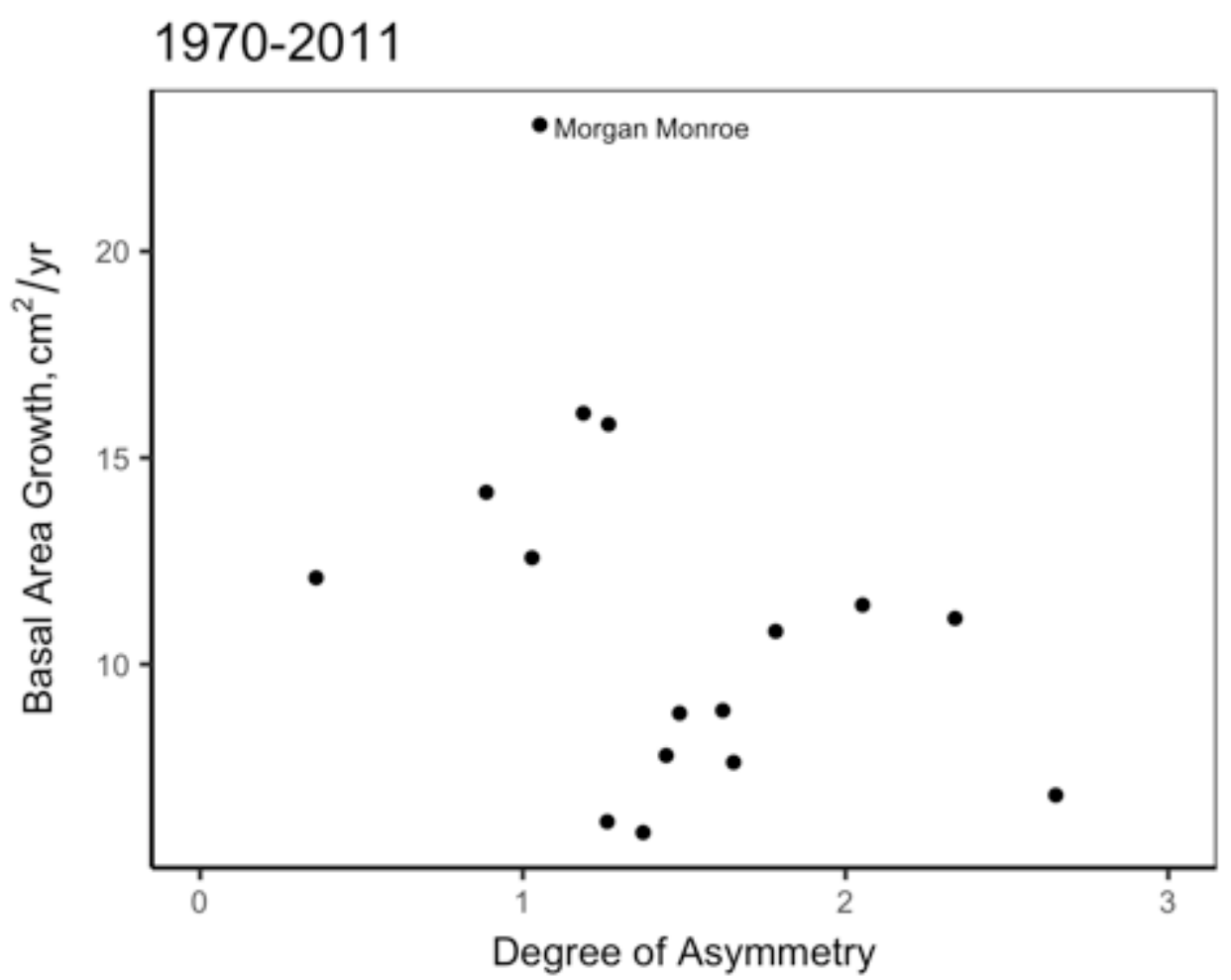

Figure 2. Degree of asymmetry plotted against basal area growth for the full 41-year time span of our study. At this time scale, asymmetry and productivity are moderately but non-significantly negatively correlated $(\mathrm{R} 2=0.16, \mathrm{p}$-value $=0.13)$. The point representing Morgan Monroe is indicated, since this site has a noticeably higher basal area growth $(24.24 \mathrm{~cm} 2 /$ year $)$ than other sites. However, conducting the correlation with Morgan Monroe removed only slightly degrades the relationship $(\mathrm{R} 2=0.14, \mathrm{p}$-value $=$ $0.17)$. 


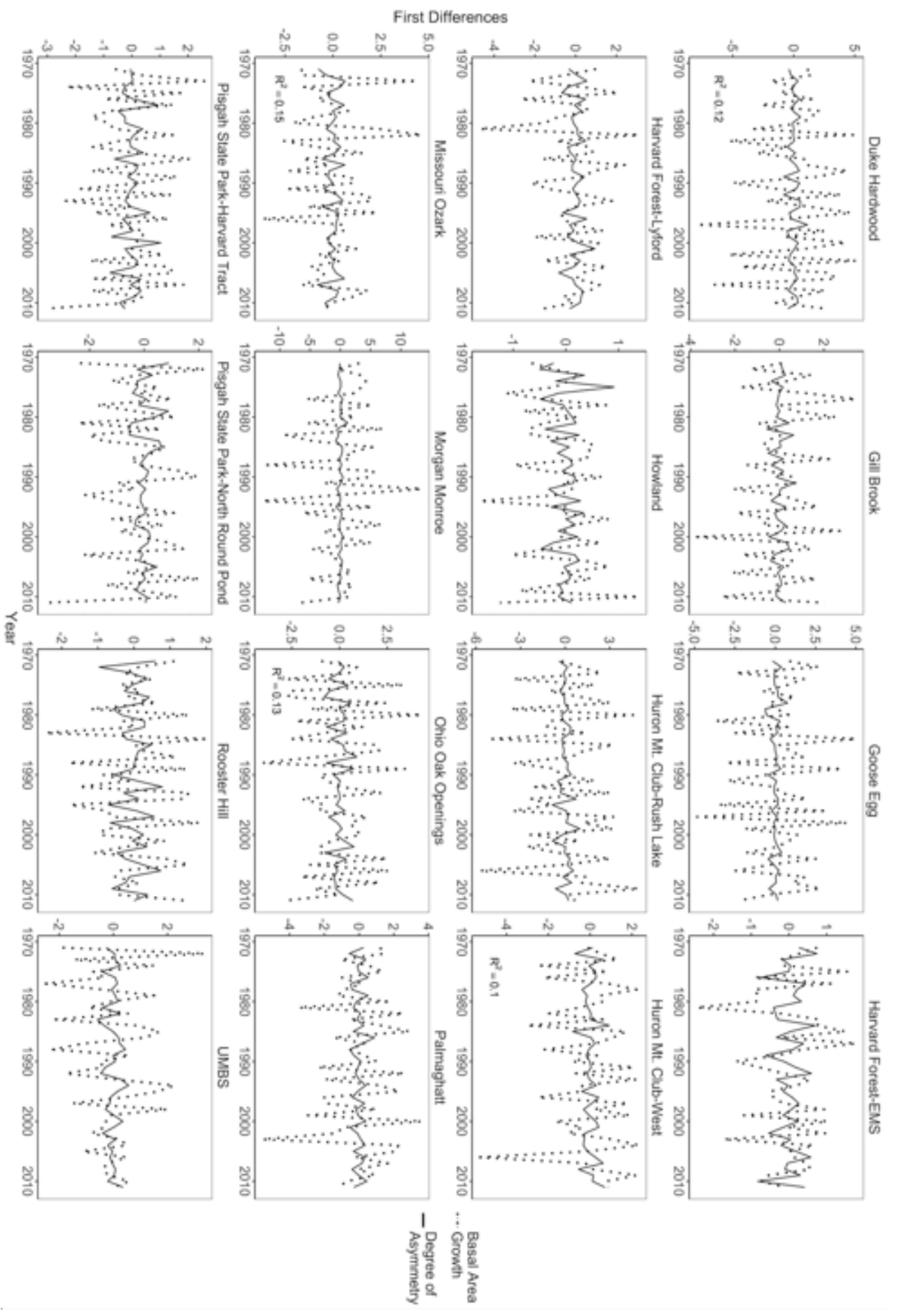

Figure 3. First-differenced basal area growth (dotted) plotted against first-differenced degree of asymmetry for annual remeasurement intervals, 1970-2011. To enable visualization, degree of asymmetry values are multiplied by a factor of 10 in the graph. $\mathrm{R}^{2}$ values are labelled only on panels for sites where a statistical relationship was discovered. 


\section{Appendix A.}

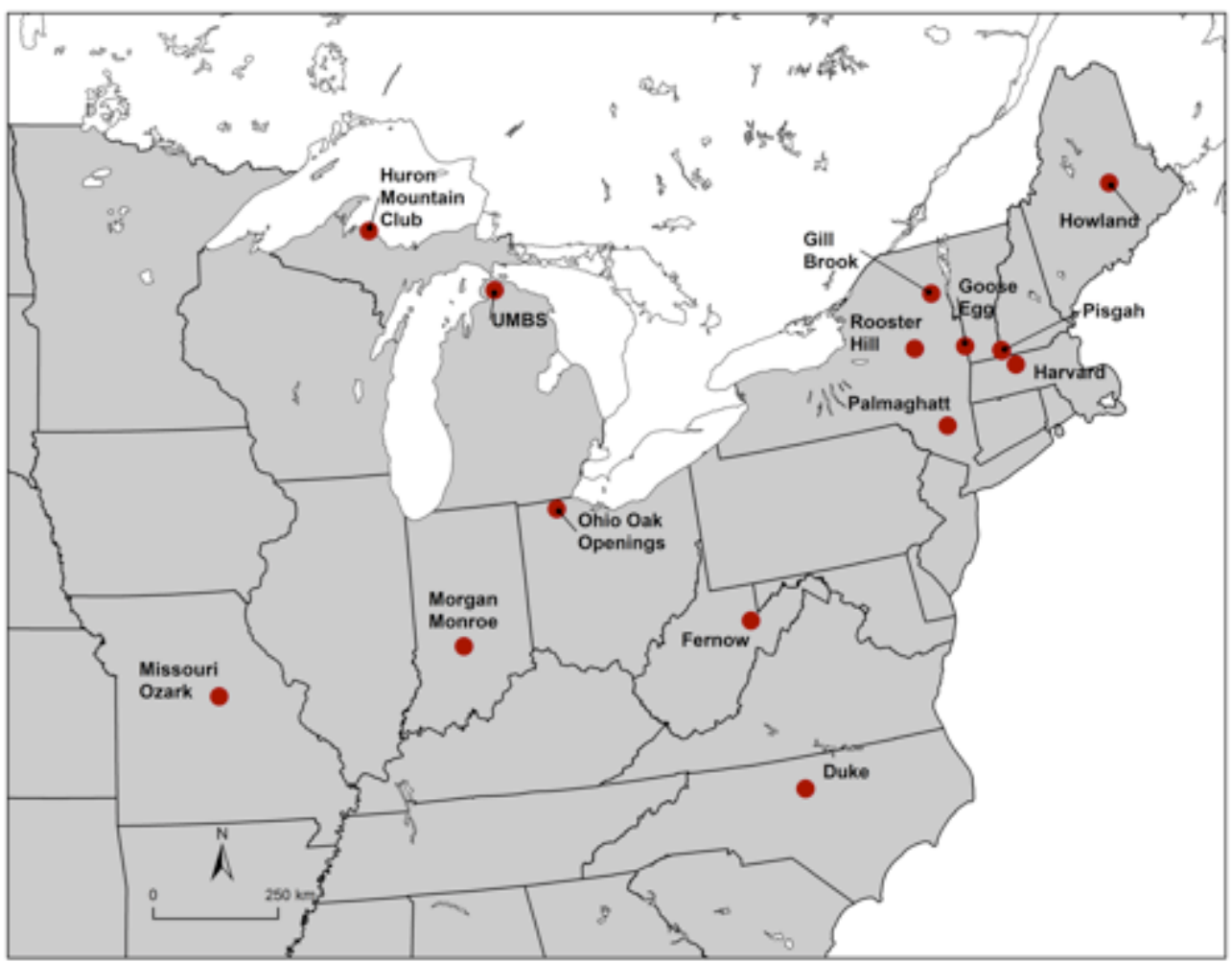

Figure A1. Map of study sites included in this paper. 
Appendix B. Between-site comparisons of productivity and asymmetry for 2-, 5-, 10-, and 20-year remeasurement intervals.

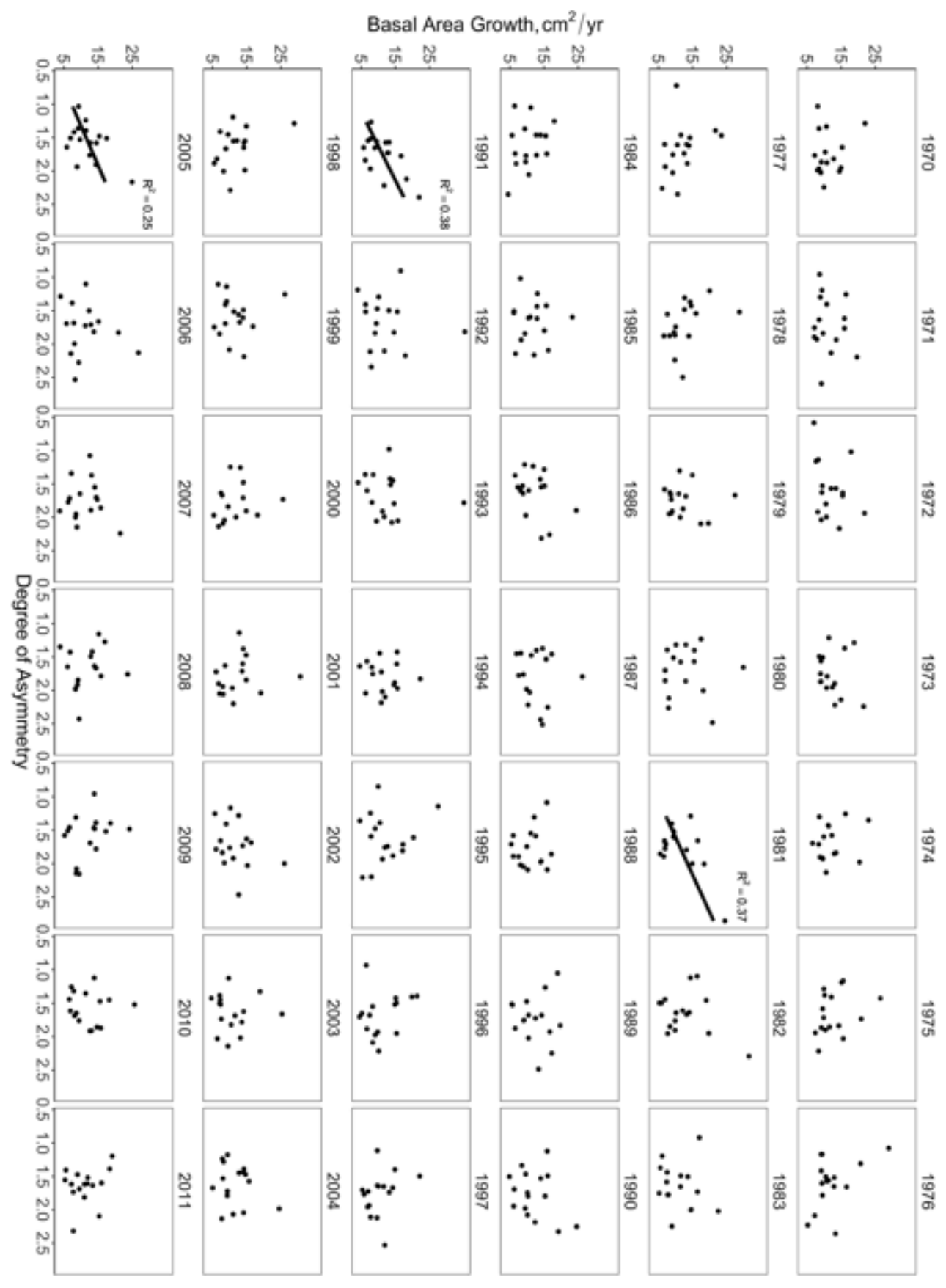

Figure B1. Annual between-site relationships between asymmetry and basal area growth 1970-2011. Linear trend lines are plotted only for years with a significant ( $\mathrm{p}$ value $<$ 0.05 ) positive or negative correlation. However, once a Bonferroni correction is applied, none of the comparisons exhibit a statistically significant relationship. 


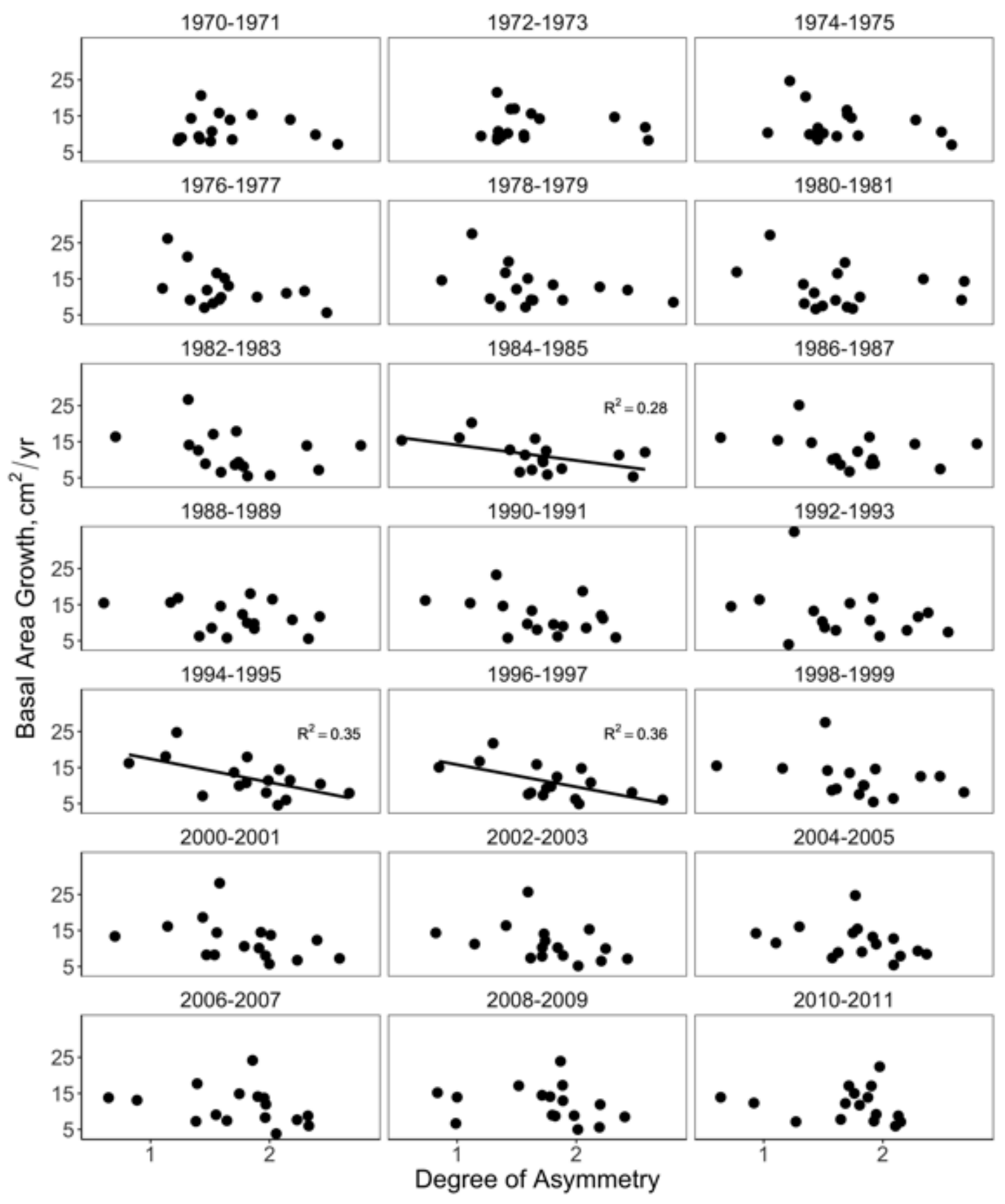

Figure B2. Between-site relationships for asymmetry and basal area growth grouped in 2-year remeasurement intervals, 1970-2011. Linear trend lines are plotted only for years with a significant ( $p$ value $<0.05$ ) positive or negative correlation. None of the 2-year between site relationships are significant once a Bonferroni correction is applied. 


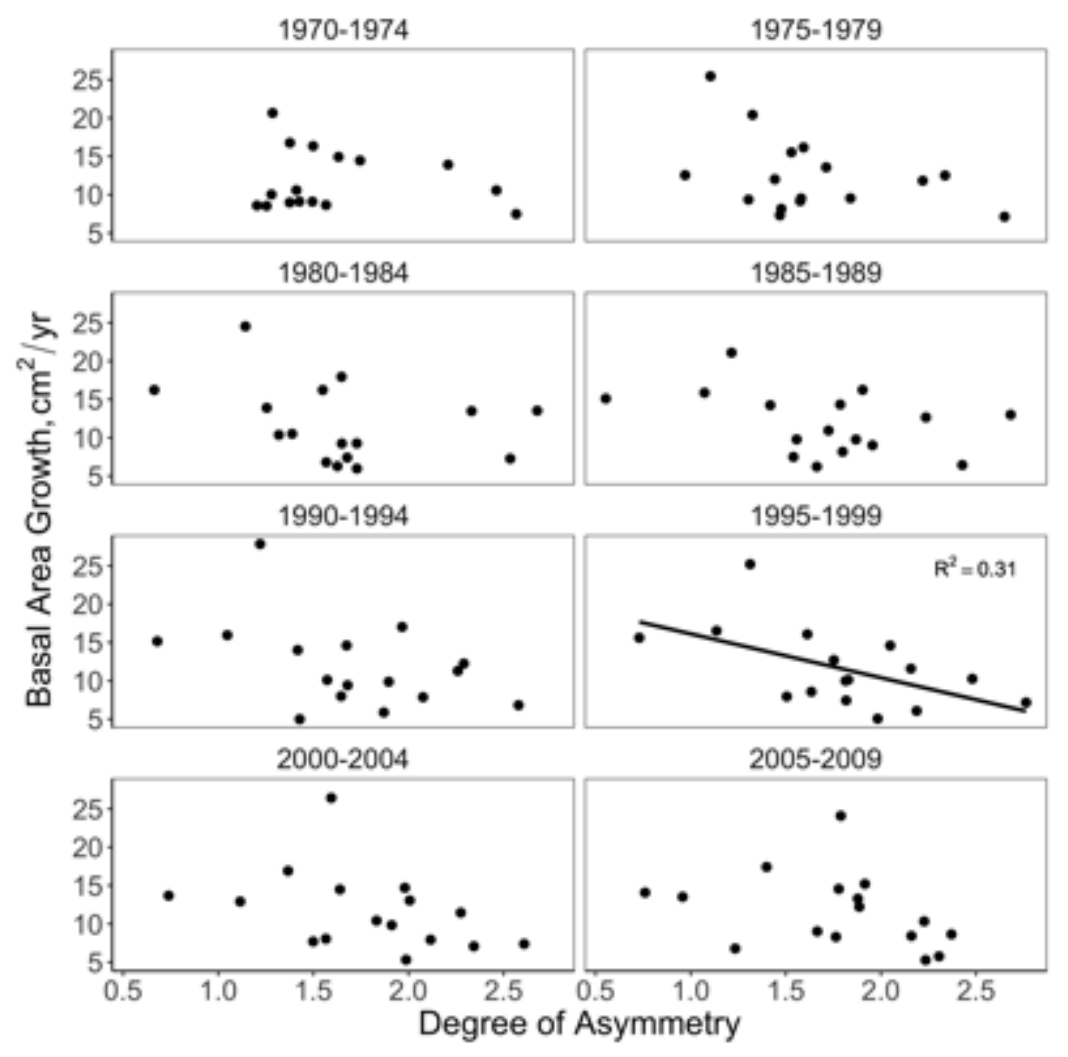

Figure B3. Between-site relationships for asymmetry and basal area growth grouped in non-overlapping 5-year remeasurement intervals, 1970-2011. Linear trend lines are plotted only for years with a significant ( $\mathrm{p}$ value $<0.05$ ) positive or negative correlation. None are significant when a Bonferroni correction is applied. 


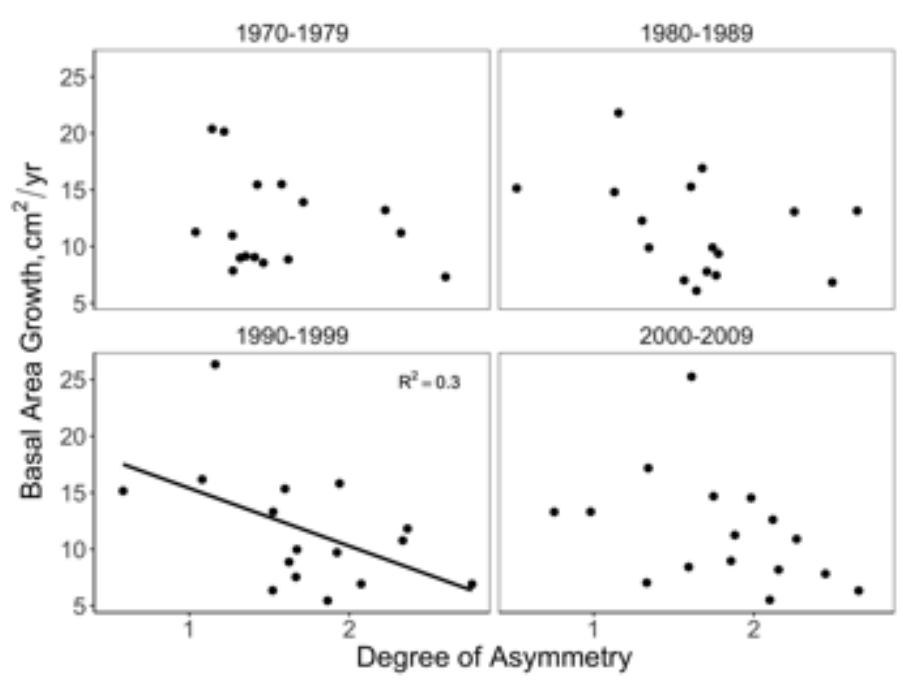

Figure B4. Between-site relationships for asymmetry and basal area growth grouped in non-overlapping 10-year remeasurement intervals, 1970-2011. Linear trend lines are plotted only for years with a significant $(\mathrm{p}$ value $<0.05$ ) positive or negative correlation.

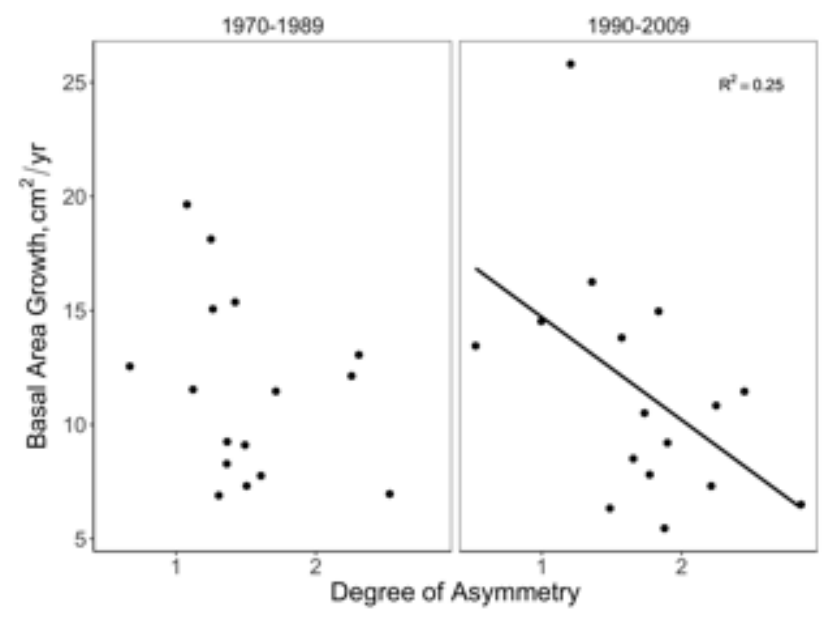

Figure B5. Between-site relationships for asymmetry and basal area growth grouped in non-overlapping 20-year remeasurement intervals, 1970-2011. Linear trend lines are plotted only for years with a significant $(\mathrm{p}$ value $<0.05$ ) positive or negative correlation. 
Appendix C. Within-site comparisons of first differenced productivity and asymmetry at 2- and 5-year intervals.

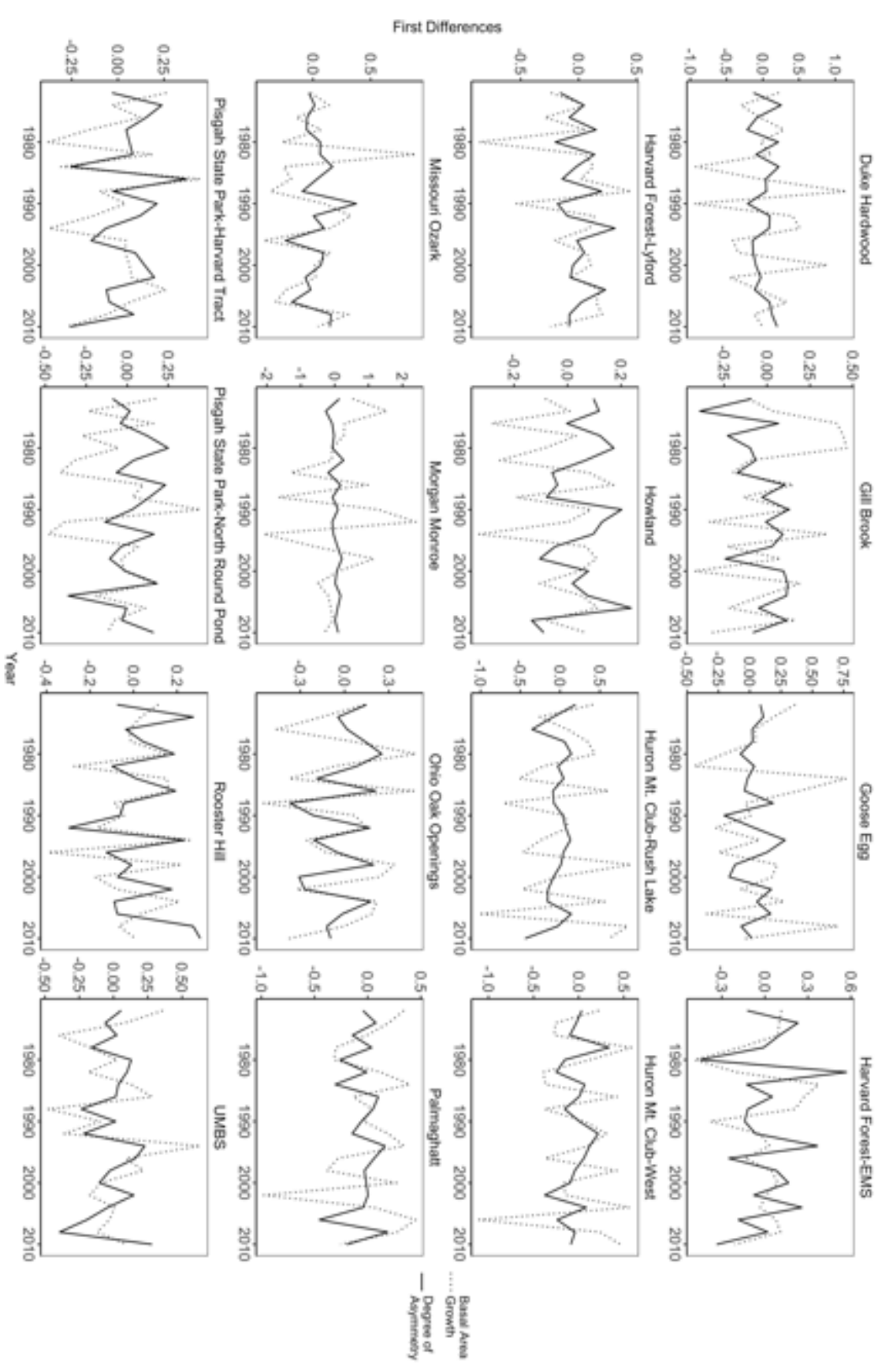

Figure C1. First-differenced basal area growth (dotted) plotted against firstdifferenced degree of asymmetry for 2-year remeasurement intervals, 1970-2011. To enable visualization, degree of asymmetry values are multiplied by a factor of 10 in the graph. 

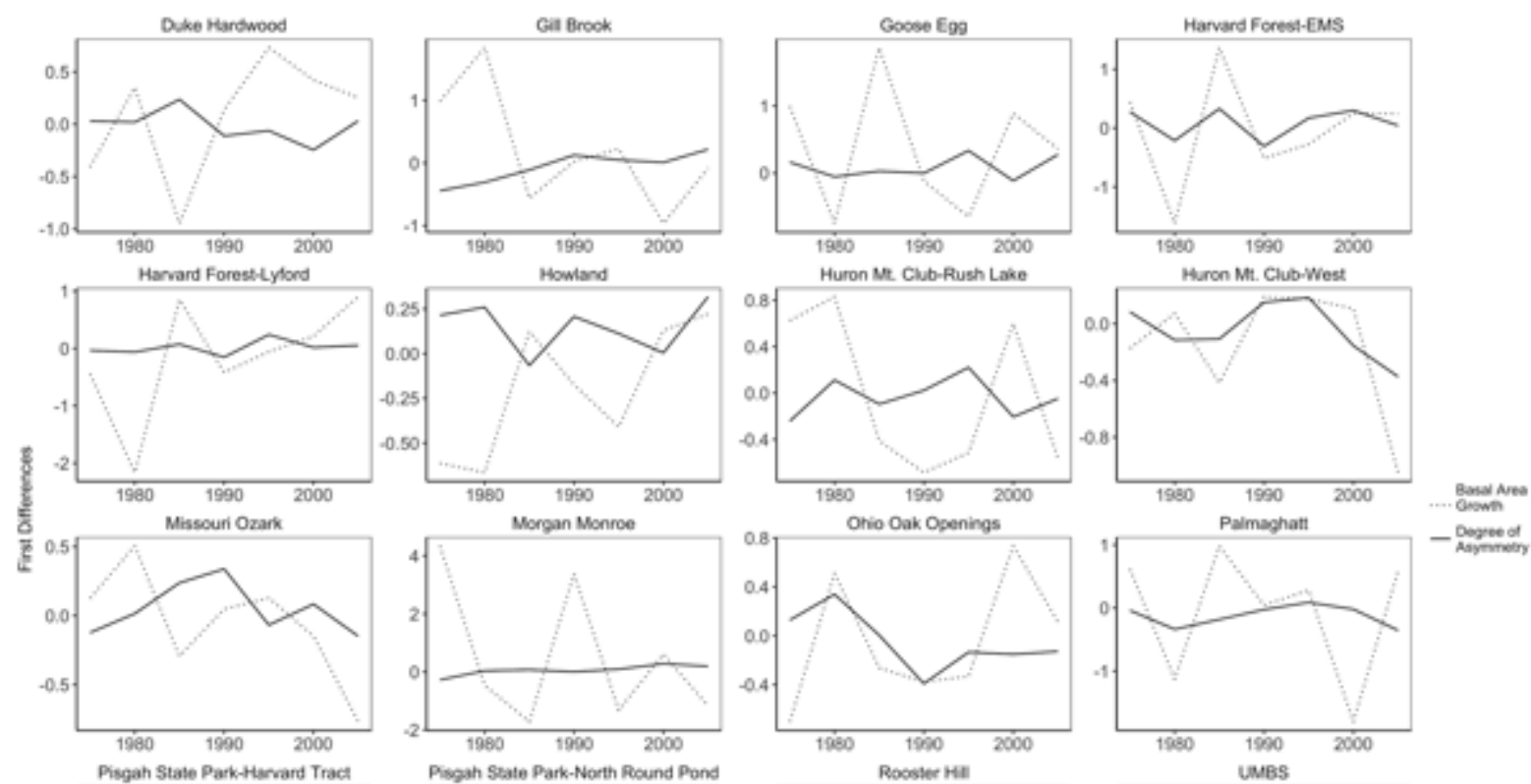

Pisgah State Park-Hervard Tract
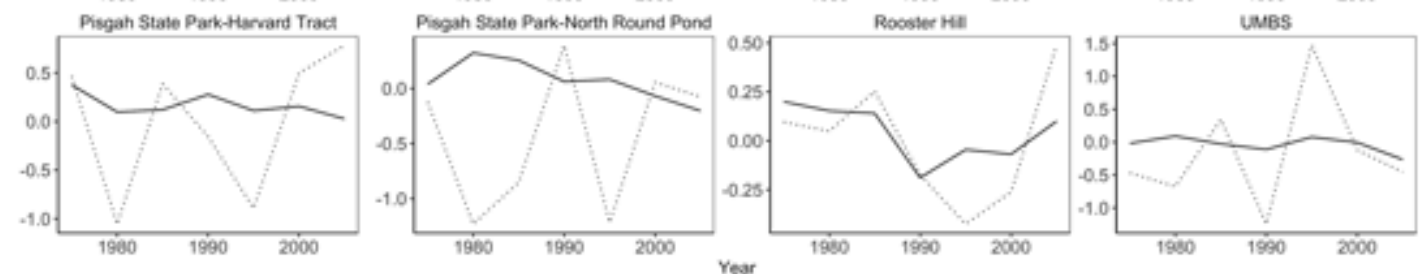

Figure C2. First-differenced basal area growth (dotted) plotted against firstdifferenced degree of asymmetry for 5-year remeasurement intervals, 1970-2011. To enable visualization, degree of asymmetry values are multiplied by a factor of 10 in the graph. 


\section{Summary and Future Directions}

Rising global temperatures resulting from high concentrations of greenhouse gases in the atmosphere is one of the most contentious and pressing issues of the modern era. Now more than ever, ecological science designed at understanding, predicting, and mitigating the negative effects of climate change is of utmost importance. One way to approach the issue is by investigating how components of the environment naturally assimilate, sequester, and release atmospheric carbon. In this dissertation, I have focused on one such component, the aboveground woody biomass of trees in forests. Through this work I hope to further define the role forests have in the global carbon cycle and as potential mitigators of the currently skyrocketing atmospheric carbon levels.

To contribute to this goal, I first devoted significant effort to refining the use of dendrochronology as a method of reconstructing aboveground woody carbon sequestration rates. Unlike other methods, dendrochronology produces annually resolved, spatially explicit, long-term records of aboveground biomass growth that can be obtained from a single sampling and analysis campaign. However, until recently, tree rings have rarely been used in studies of the carbon cycle.

Next, I used my dendrochronological records of biomass growth to produce highly detailed descriptions of the structural (Chapters 2 and 3) and species (Chapter 1, Appendix C) distributions of biomass growth. This was inspired by a need to answer the question: "Where is carbon going in in forests?" Knowing where biomass growth occurs can provide information invaluable to developing forest management strategies for carbon gain, improving predictive models of the carbon cycle, and understanding the ecological drivers behind the distribution of biomass growth in forests.

While setting a solid foundation for using tree rings to understand biomass dynamics in eastern temperate forests, this dissertation also elucidated a number of questions worthy of additional investigation. For example, my work suggests that both the structural distribution of biomass growth and degree of asymmetry may be partially influenced by the specific disturbance history and stand dynamics of a site. Discovering exactly how disturbance influences structural biomass growth would be a major leap forward in forest ecology and help to truly clarify many of the concepts I present in this dissertation. Additonally, the high level of spatial and ecological detail of each of these datasets warrant application of a variety of research questions that are difficult to ask with traditional dendrochronological records: the spatially explicit mapped-plot sampling design can allow for investigation into the spatial distribution of biomass growth; the detailed species and canopy position information can help researchers further pull apart structural and species-related drivers of growth; and the juxtaposition of many sites with other long-term forest monitoring studies (e.g. the AmeriFlux network, Harvard Forest and Huron Mt. Club permanent remeasurement plots) facilitates assimilation of these dendroecological records with additional data, leading to a more complete description of forest carbon dynamics. 